\section{Pacific Northwest} National Laboratory

Operated by Battelle for the

U. S; Department of Enerny

\title{
Enhanced Site Characterization of the 618-4 Burial Ground
}

\author{
C. J. Murray \\ G. V. Last \\ Y. Chien
}

September 2001

Prepared for Bechtel Hanford, Inc. and the U.S. D epartment of Energy under Contract DE-AC06-76RL01830 


\title{
DISCLAIMER
}

This report was prepared as an account of work sponsored by an agency of the United States Government. Neither the United States Government nor any agency thereof, nor Battelle Memorial Institute, nor any of their employees, makes any warranty, express or implied, or assumes any legal liability or responsibility for the accuracy, completeness, or usefulness of any information, apparatus, product, or process disclosed, or represents that its use would not infringe privately owned rights. Reference herein to any specific commercial product, process, or service by trade name, trademark, manufacturer, or otherwise does not necessarily constitute or imply its endorsement, recommendation, or favoring by the United States Government or any agency thereof, or Battelle Memorial Institute. The views and opinions of authors expressed herein do not necessarily state or reflect those of the United States Government or any agency thereof.

\author{
PACIFIC NORTHWEST NATIONAL LABORATORY \\ operated by \\ BATTELLE \\ for the \\ UNITED STATES DEPARTMENT OF ENERGY \\ under Contract DE-AC06-76RL01830
}

Printed in the United States of America

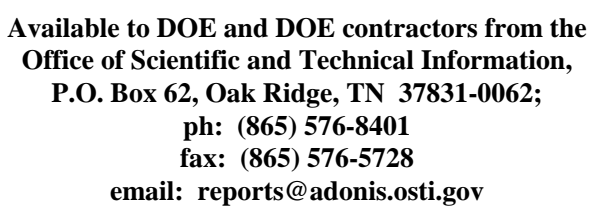

Available to the public from the National Technical Information Service, U.S. Department of Commerce, 5285 Port Royal Rd., Springfield, VA 22161 ph: (800) 553-6847 fax: $(703) 605-6900$

email: orders@ntis.fedworld.gov online ordering: http://www.ntis.gov/ordering.htm 


\title{
Enhanced Site Characterization of the 618-4 Burial Ground
}

\author{
C. J. Murray \\ G. V. Last \\ Y. Chien
}

September 2001

Prepared for Bechtel Hanford, Inc. and the U.S. Department of Energy, Richland Operations Office under Contract DE-AC06-76RL01830

Pacific Northwest National Laboratory Richland, Washington 99352 


\section{Acknowledgments}

This work was conducted as part of the U.S. Department of Energy's Accelerated Site Technology Deployment Program through the Subsurface Contaminant Focus Area. It was jointly funded by the Office of Environmental Management's Office of Science and Technology (EM-50) and Office of Project Completion (EM-40). The authors wish to thank James P. Hanson, Robert G. (Bob) McLeod, Linda K. Bauer, Grover (Skip) Chamberlain, and James A. Wright with the U.S. Department of Energy, for their support of this work. We would also like to express our gratitude to John G. April, Rich A. Carlson, Scott W. Petersen, Jeff R. James, Tammy L. Ingraham, and the radiologic control technicians of Bechtel Hanford, Inc. for their interest in this project and for providing the technical and administrative support necessary to access the site

We would like to thank Wayne J. Martin, William F. Bonner, and Charlotte L. Blair with PNNL for doggedly promoting this work and for providing the programmatic support needed to administer the project.

We would especially like to thank Kevin A. Bergstrom and Tom H. Mitchell with CH2M HILL Hanford, Inc. for providing the recent geophysical support; John Sielinski, Ron Bell, and Charles Spaulding with WMI International, Inc. for testing the Electrical Offset Logging technology; and Yulong Xie, Tyler J Gilmore, and Gerald A. Sandness for providing technical guidance and support throughout the conduct of this study. 


\section{Executive Summary}

This report describes the results obtained from deployment of the Enhanced Site Characterization System (ESCS). The intent of this deployment was to map the distribution of buried waste at the 618-4 Burial Ground. This low-level radioactive waste burial ground is located on the Hanford Site about 1.6 kilometer ( 1 mile) north of the Richland City limits and 340 meters (1,115 feet) west of the Columbia River. The 618-4 Burial Ground was partially excavated during 1997 and 1998. Excavation was halted after 338 drums containing depleted uranium metal shavings and uranium-oxide powder were excavated from the site. These unexpected findings caused major delays in the remedial action and led Hanford Site environmental restoration contractors to the conclusion that accurate delineation of waste boundaries and precise identification of high risk waste prior to excavation, is necessary to avoid unplanned delays, decrease health and safety costs, decrease the need for contract change orders, and reduce costs significantly.

Pacific Northwest National Laboratory performed this study, which was jointly funded by the U.S. Department of Energy's (DOE's) Office of Science and Technology's Accelerated Site Technology Deployment (ASTD) Program (EM-50) through the Subsurface Contaminant Focus Area, and Bechtel Hanford, Inc.'s (BHI) 300-FF-1 Environmental Restoration Project (EM-40). The objective of this study was to map the physical types of waste materials present in the 618-4 Burial Ground using geostatistical methods to integrate and interpret geophysical and ground truth data. The 300-FF-1 Project was particularly interested in the thickness of the remaining deposit of metal drums and the estimated number of drums still requiring removal.

We first deployed a promising geophysical technique, electromagnetic offset logging (EOL), in an attempt to provide a three-dimensional map of the waste site and determine the vertical thickness of stacked drums at the site. This technology was identified in the TechCon database as a mature technology (Gate 6) with a good performance history and the capability of detecting large waste containers. However, the EOL data did not provide useful information, possibly due to the presence of extraneous cultural features (e.g., metal waste piles) and uneven terrain.

While examining the EOL data we also performed an analysis of the existing geophysical data at the site. The multivariate statistical analysis of that data suggested the presence of another anomalous area similar to the area where the drums were known to exist. We recommended the acquisition of new highresolution geophysical data to confirm or refute that anomaly. The new geophysical data was recorded in 2001 by geophysicists at CH2M HILL Hanford, Inc. under contract for this project.

We used a commercial mapping package to calculate the area within the outline of the drum anomaly interpreted from the new data by CH2M HILL Hanford, Inc. The estimated area was the basis for an estimate of the number of remaining drums at the site. For different stacking scenarios, the number of remaining drums ranged from about 770 drums to 850 drums. The estimate was provided to the Environmental Restoration Contractor (ERC) for use in budgeting and planning. 
A combination of box plots and discriminant function analysis (DFA): indicate that the drum area is different from the rest of the study area. The major difference is the presence of higher measurements of magnetic field strength, suggesting the presence of ferric metals, and a greater thickness of overlying fill. Although the magnetic field strength is higher, the electromagnetic signal recorded by the EM-61 instrument is not higher in the drum area. The increased thickness of fill may be responsible for the attenuation of the expected electromagnetic (EM-61) signal, which should respond to the presence of conductive metal. Multiple linear regression within the area of the drum anomaly indicated that the thickness of the fill has a strong negative correlation with the strength of the EM-61 signal.

Fuzzy adaptive resonance theory (ART), a neural network classification method successfully clustered the study area into three classes. The classes identified by neural network analysis appear reasonable for several different reasons: 1) the partitioning was stable for a wide choice of the input parameters to the fuzzy ART program; 2) the partitioning roughly paralleled the results of a third unsupervised classification method (k-means clustering); 3) the partitions form relatively compact spatial classes that coincide with known and/or previously identified areas; and 4) there are significant differences between the geophysical properties that can be related to the spatial location of the classes. The drum anomaly and the SW anomaly have similar geophysical signatures, and are dominantly composed of Class 1 . The area between the drum anomaly and the SW anomaly, dominated by Class 2, also appears to contain waste with a high metallic content, but the character of that anomaly is quite different, with a very high EM-61 signature and a greater GPR reflection amplitude. The difference between Class 1 and Class 2 may indicate a higher proportion of conductive but non-ferric waste in the area dominated by Class 2 and/or the difference may be due mostly to the shallow burial of that waste. Areas dominated by Class 3 appear to contain much less metallic waste than the rest of the study area.

Deployment of the ESCS technology was successful in integrating multiple geophysical variables and class observations into clusters that are relevant for planning the excavation of the buried waste. The method allows us to provide input to site personnel on areas that need special caution and planning during excavation.

However, the success of the technology can't be fully evaluated at this time because reliable ground truth data are not available to calibrate to the geophysical signatures. The initial plan for this study was to apply statistical classification techniques and geostatistics to both new and existing geophysical data and available discrete samples of excavated materials (ground truth data) to develop a discrete threedimensional map of specific waste types. Each defined section of the burial ground would be defined as a specific waste category within a defined probability. The resulting map was to be validated by comparing the materials actually excavated (when excavation resumed) to the predicted waste types. However, accurate spatial locations of available ground truth data, which were expected to be available from the partial excavation of the 618-4 burial ground, were not available. This made it impossible to attempt an initial calibration of the geophysical data to the excavated waste. In addition, the delay in excavating the remainder of the buried waste site has prevented us from performing a post-excavation calibration of the waste types against the Classes identified in the geophysical data by neural network analysis.

The ESCS deployment allowed us to build a conceptual model of the buried waste at the 618-4 burial ground. This conceptual model includes updated estimates of the number of drums remaining in the area 
of the burial ground where uranium-filled drums were partially excavated. The conceptual model also includes confirmation of a previously identified area that has a similar geophysical signature to the area where the drums were found, and the identification of a third area that appears to contain large quantities of metallic waste, but that has a different geophysical signature than the area containing the drums.

Several recommendations were developed as a result of this deployment:

- We advise the ERC to proceed with caution during excavation of the southwest area of the 618-4 burial ground because of similarities between the geophysical signature in that area and the geophysical signature found in the drum anomaly. In addition, though the geophysical signature of the central portion of the burial ground differs from that found in the drum anomaly, it still appears to be highly conductive, suggesting the presence of large amounts of shallowly-buried metal. We also advise caution during excavation of that area.

- An effort should be made to provide detailed and accurate locations during excavation of the remaining waste in the 618-4 Burial Ground, which can be used to establish a calibration with geophysical data from the site. This should be performed using a high-resolution global positioning system (GPS), able to located objects within 1 to 2 meters (3.2 to 6.4 feet) of their true location.

- Before excavating the nearby 618-5 Burial Ground, we recommend calibration of the high-resolution geophysical data from the 618-4 Burial Ground with the waste types identified during excavation of the site. If that calibration is successful, we recommend re-analysis of the existing 618-5 geophysical data (WHC 1992), and, pending said re-analysis, consideration of gathering new geophysical data at that burial ground. 


\section{Acronyms}

$\begin{array}{ll}\text { ART } & \text { adaptive resonance theory } \\ \text { ASTD } & \text { Accelerated Site Technology Deployment } \\ \text { BHI } & \text { Bechtel Hanford, Inc. } \\ \text { DFA } & \text { discriminant function analysis } \\ \text { DOE } & \text { U.S. Department of Energy } \\ \text { EM } & \text { environmental management } \\ \text { EM-40 } & \text { 300-FF-1 Environmental Restoration Project } \\ \text { EM-50 } & \text { Office of Science and Technology's Accelerated Site Technology Deployment Program } \\ \text { EM-61 } & \text { Model number of the Geonics Ltd. instrument used for the time-domain electromagnetic } \\ & \text { surveys } \\ \text { EOL } & \text { electromagnetic offset logging } \\ \text { ERC } & \text { Environmental Restoration Contractor } \\ \text { ERDF } & \text { Environmental Restoration Disposal Facility } \\ \text { ESCS } & \text { Enhanced Site Characterization System } \\ \text { FY } & \text { fiscal year } \\ \text { GPH } & \text { ground penetrating holography } \\ \text { GPR } & \text { ground penetrating radar } \\ \text { GPS } & \text { global positioning system } \\ \text { LEMA } & \text { low frequency electromagnetic array } \\ \text { OST } & \text { Office of Science and Technology } \\ \text { PNNL } & \text { Pacific Northwest National Laboratory } \\ \text { PVC } & \text { polyvinyl chloride } \\ \text { RTP } & \text { reduction to the pole } \\ \text { STOLS } & \text { arrayed full-field magnetometer } \\ \text { TDEM } & \text { time domain electromagnetic } \\ \text { WMI } & \text { WMI International, Inc. } \\ & \end{array}$




\section{Contents}

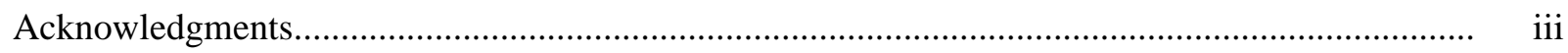

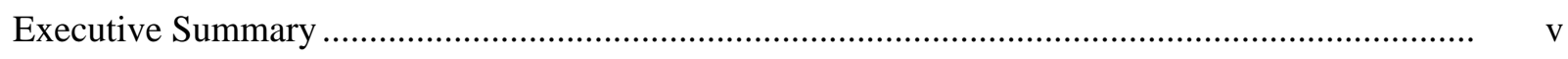

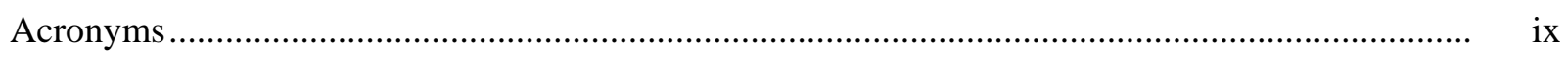

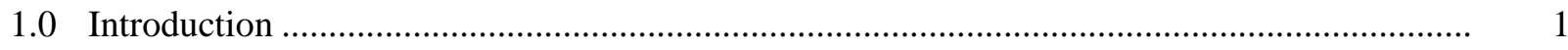

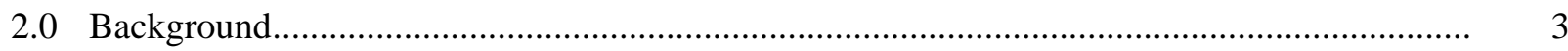

2.1 ESCS Technology/Deployment Plan ................................................................... 3

2.2 618-4 Burial Ground Site History and Layout .......................................................... 5

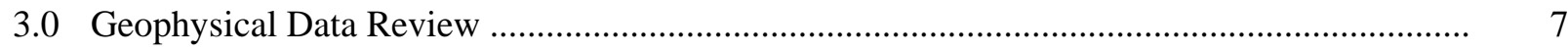

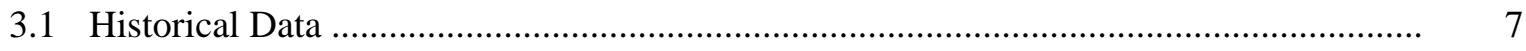

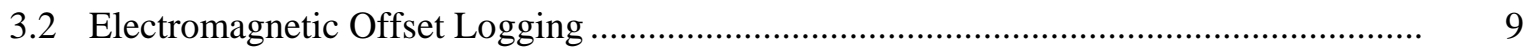

3.3 FY 2001 High Resolution Geophysical Data ............................................................. 10

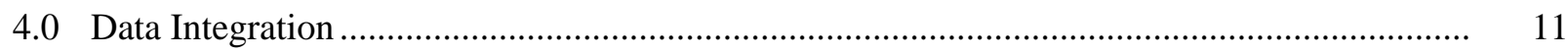

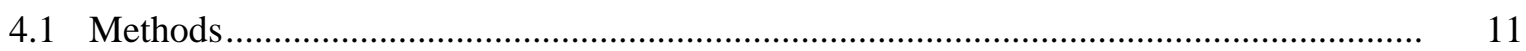

4.1.1 Data Included in the Analysis and Integration ............................................ 11

4.1.2 Statistical Methods ........................................................................................... 13

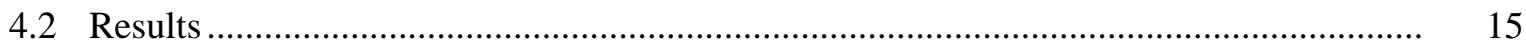

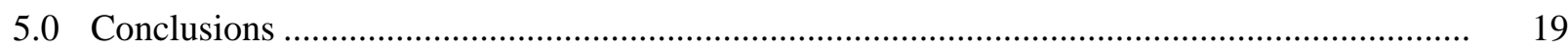

5.1 Conceptual Model of Buried Waste in the 618-4 Burial Ground.................................... 19

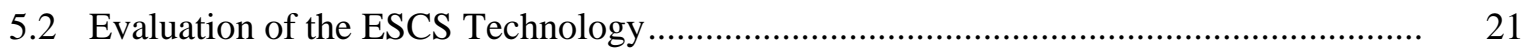

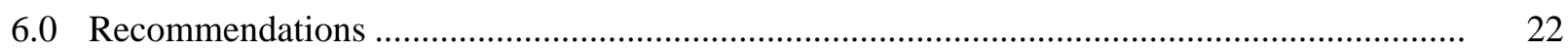

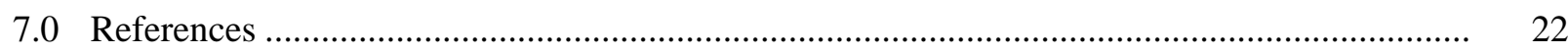

Appendix A - Preliminary Conceptual Model of Buried Waste in the 618-4 Burial Ground ........... A.1

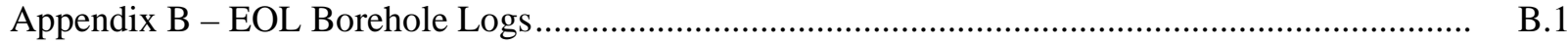

Appendix C - EOL Data Report ............................................................................................ C

Appendix D - High Resolution Geophysical Survey ................................................................. D.1 


\section{Figures}

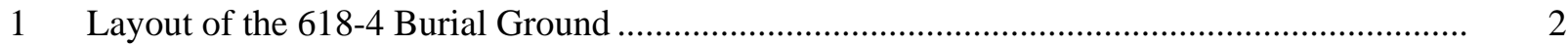

2 Schematic of the Enhanced Site Characterization System Technology …................................ 4

3 Aerial Photograph of the 618-4 Burial Ground Looking South, June 1998 …........................ 6

4 Map of the 618-4 Burial Ground Showing Extent of Partial Excavation

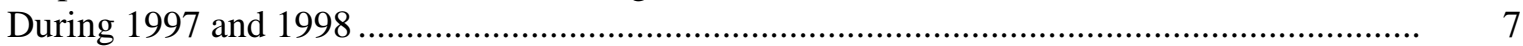

5 GPR Reflection Amplitude at the 618-4 Burial Ground..................................................... 11

6 Time Domain Electromagnetic Calculated Differences at the 618-4 Burial Ground ............... 12

7 Hanford Magnetic Survey Reduced-to-Pole Data at the 618-4 Burial Ground ........................ 13

8 Thickness of Fill Overlying Buried Debris at the 618-4 Burial Ground ................................. 13

9 Terrain Slope of Elevation of Top of Buried Debris at the 618-4 Burial Ground ................... 14

10 Box Plots of Five Variables Within and Outside the Identified Drum Area ......................... 17

11 Classes Defined by Neural Network Fuzzy ART Approach Using Five Variables ................. 18

12 Box Plots of Five Variables in Three Classes Identified by Neural Network Fuzzy ART

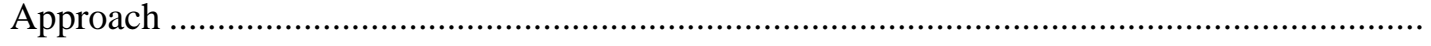

\section{Table}

1 Estimates of Remaining Drums in 618-4 Burial Ground 


\subsection{Introduction}

This report describes the results obtained from deployment of the Enhanced Site Characterization System (ESCS). The intent of this deployment was to map the distribution of buried waste at the 618-4 burial ground. This low-level radioactive waste burial ground is located on the Hanford Site about 1.6 kilometers ( 1 mile) north of the Richland City limits and 340 meters $(1,115$ feet) west of the Columbia River. The 618-4 burial ground, located in the 300-FF-1 Operable Unit, was partially excavated during 1997 and 1998. Excavation was halted in April 1998 after 338 drums containing depleted uranium metal shavings and uranium-oxide powder were excavated from the site (see Figure 1 for location where these drums were removed).

This study was jointly funded by the U.S. Department of Energy's (DOE) Office of Science and Technology's (OST) Accelerated Site Technology Deployment (ASTD) Program (EM-50) through the Subsurface Contaminant Focus Area, and Bechtel Hanford, Inc.'s (BHI) 300-FF-1 Environmental Restoration Project (EM-40). The objective of this study was to map the physical types of waste materials present in the 618-4 burial ground using geostatistical methods to integrate and interpret geophysical and ground truth data. The 300-FF-1 Project particularly wanted to determine the thickness of the remaining deposit of metal drums and the estimated number of drums still requiring removal.

This study began in fiscal year (FY) 1999. The study was placed on hold throughout FY 2000 to allow BHI to complete plans for resuming excavation of the burial ground and treatment of the drummed waste. However, the study was resumed again in FY 2001 to complete a redirected study because excavation of the burial ground would not resume for at least another year.

Initially, this study was to apply statistical classification techniques and geostatistics to new and existing geophysical data and available discrete samples of excavated materials (ground truth data) to develop a discrete three-dimensional map of specific waste types. Each defined section of the burial ground would be defined as a specific waste category within a defined probability. The resulting map was to be validated by comparing the materials actually excavated (when excavation resumed) to the predicted waste types. However, significant differences between the site geometry of old and new geophysical data, limitations placed on the collection of new geophysical data, the inadequacy of a stateof-the-art three-dimensional geophysical method used by the study, the delay in excavating the remainder of the 618-4 burial ground and the severe lack of good discrete (ground truth) samples hampered the deployment of this plan. These changes meant this study used two-dimensional data sets to produce a two-dimensional map of the waste site, rather than a three-dimensional map, as originally planned. In addition, excavation of the burial ground remains on hold; therefore, validation of the waste types predicted using the ESCS technology, could not be performed. 


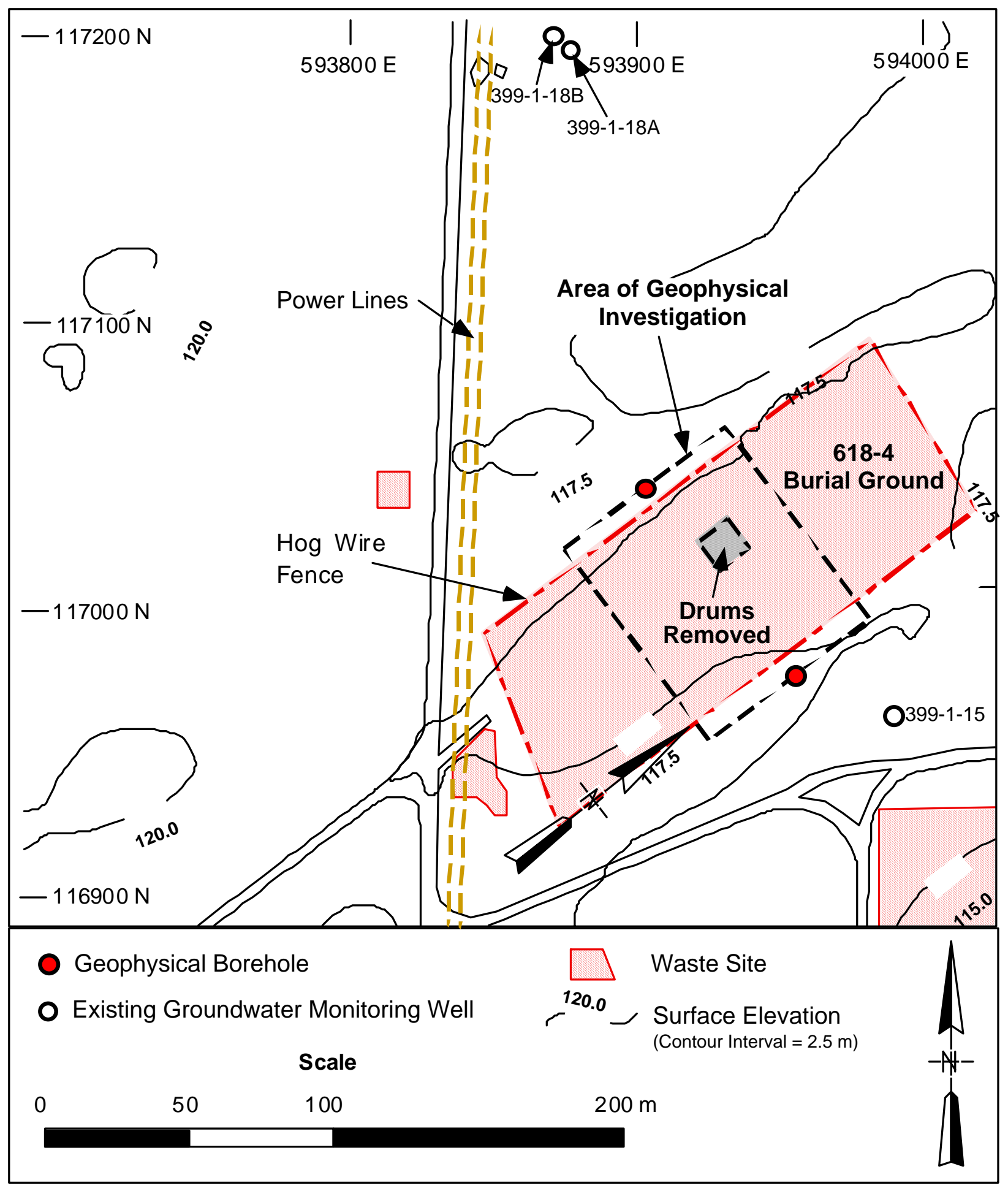

Figure 1. Layout of the 618-4 Burial Ground 


\subsection{Background}

Environmental restoration of buried waste sites is a major problem facing all DOE facilities. At the Hanford Site alone, there are more than 100 burial grounds, with 45 currently scheduled for remediation at an estimated cost of $\$ 500 \mathrm{M}$. Previously, detailed characterization of these sites has not been recommended due to their high degree of heterogeneity and the large uncertainties and costs inherent with their characterization. Thus, the baseline approach has been to use limited pre-excavation characterization and an observational approach, where waste is characterized as it is unearthed. Typically, limited geophysical surveys (e.g., ground penetrating radar, electromagnetics, and/or magnetics) are applied individually to determine the presence or absence of subsurface debris - minimal information is determined on the characteristics of these materials. However, unexpected findings during recent remedial actions (e.g., Hanford burial grounds 118-B-1, 618-4, and landfill 1-D, as well as Idaho National Engineering Environmental Laboratory Pit 9) have led Hanford Site environmental restoration contractors (ERCs) to the conclusion that accurate delineation of waste boundaries and precise identification of high risk waste prior to excavation, is necessary to avoid unplanned delays, decrease health and safety costs, decrease the need for contract change orders, and reduce costs significantly. ${ }^{1}$ Specifically, the large cache of buried drums containing uranium shavings discovered during excavation of the 618-4 burial ground caused major delays in the remedial action and increased costs by nearly $\$ 1 \mathrm{M}$ for the site. Without a new approach, the previously estimated cost of remediation for the 45 buried waste sites could easily double.

\subsection{ESCS Technology/Deployment Plan}

The ESCS combines advanced geophysical data and interpretation techniques with existing information and traditional characterization and ground truth data to type match the geophysical and chemical signatures of various waste types. Geostatistical techniques and multivariate statistics are used to integrate the multiple environmental data sets to model the spatially distributed data and provide the classification of different waste types. If ground truth data are available, then we can estimate the probability that the different waste type classes contain a particular type of waste (Figure 2).

ESCS is intended for use with a suite of state-of-the-art geophysical technologies (e.g., electromagnetic offset logging [EOL], multi-frequency ground penetrating radar [GPR], arrayed full-field magnetometer [STOLS]) in combination with ground truth sampling of selected target areas. New data sets are designed to complement existing data sets (historical records and photographs, past geophysical surveys, soil gas surveys, radiation surveys, trench sampling). Individual geophysical technologies generally measure only one physical property of the subsurface. For example, EOL uses an electromagnetic source coil at the surface and a receiver coil in an adjacent borehole to measure changes in the ground's resistance to transmitted electrical signals. GPR derives images of the subsurface by obtaining reflections of

\footnotetext{
${ }^{1}$ DOE. June 18, 1998. Proposal for Accelerated Site Technology Deployment, Enhanced Site Characterization System. U.S. Department of Energy, Richland Operations Office, Richland, Washington.
} 


\section{Existing Data}

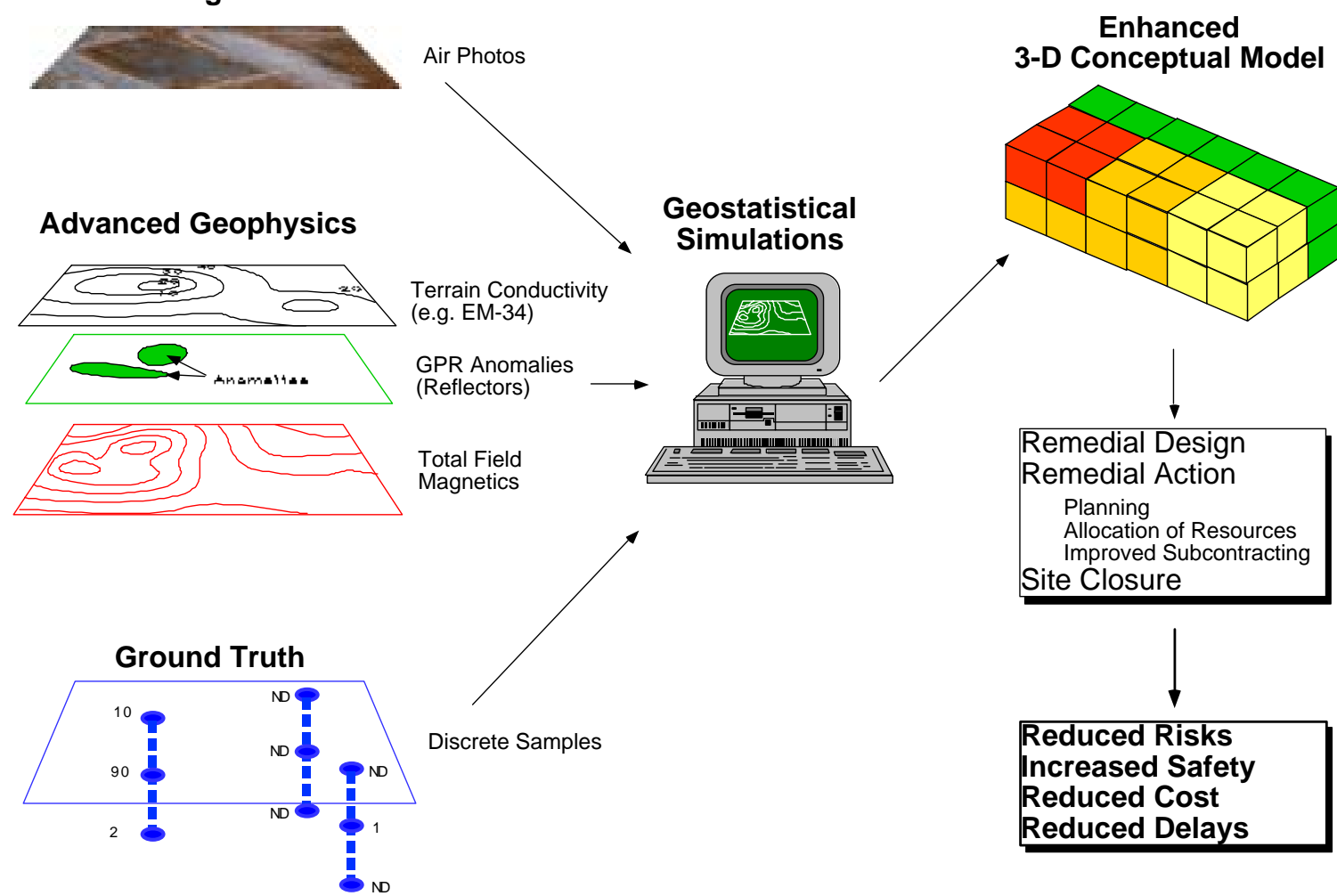

Figure 2. Schematic of the Enhanced Site Characterization System Technology

radar waves from reflective surfaces (i.e., contrasts in conductivity and permittivity), and is generally used for mapping soil stratigraphy, determining the depth to a shallow water table or bedrock, and locating buried metallic and non-metallic targets such as drums or building foundation materials. Magnetometers are used to locate ferrous metal objects in the subsurface by measuring the magnetic field produced by these objects. STOLS consists of seven magnetometers in an array that is towed on a sled, and can locate metallic objects less than 1 foot across and provide an estimate of the depth of burial. Together, these geophysical technologies measure several different properties of the subsurface materials (producing many different types of geophysical anomalies).

An advanced geophysical technique deployed by this project at the 618-4 burial ground was EOL. Two boreholes were drilled on the edges of the burial ground, then EOL was conducted to provide a three-dimensional resistivity survey of the site. The objective of this survey was to define the horizontal and vertical extent of the uranium-filled drums present at the site. (NOTE: At this point, the number of layers of drums is unknown, therefore, the total number of drums that will need to be excavated and stabilized is also unknown.) The EOL data was to be integrated with previously recorded geophysical data (GPR, electromagnetic, and a magnetometer survey), as well as other information from historical photographs, soil gas results, radiation surveys, etc.

A detailed conceptual model of the waste site was to be generated based on all the characterization data. Direct sampling via trenching, soil borings, test pits, and the aborted excavation of the site have 
already been conducted. That sampling data was to be used as ground truth data to provide calibration of the various types of geophysical properties against the type of waste present and the degrees and types of contamination. Statistical classification techniques, such as discriminant function analysis (DFA), were then to be used to estimate the probability that a subsurface block within the burial ground is of a specified waste type (e.g., exceeds cleanup criteria, contains high risk or problem wastes) given the suite of geophysical measurements recorded for that location. The calibration to be performed using the ground truth data from the direct sampling areas could then be extrapolated to other locations where only geophysical data is present. This calibration process would use the relatively cheap and plentiful geophysical data as a proxy for more expensive direct sampling data.

The probability that subsurface blocks within the burial ground contain specific waste types would then be modeled in three dimensions using geostatistical techniques including variogram analysis and conditional simulation. Variogram analysis would be used to provide quantitative models describing the spatial heterogeneity of the probability estimates determined from the DFA (i.e., the probability that a subsurface block belongs to a particular waste type). The modeling technique to be used would be the generation of multiple stochastic simulations of the waste type status of each block, using the probabilities determined from the DFA and the variogram models of the probability measure. Multiple stochastic simulations would be used for Monte Carlo analysis of the uncertainty of waste classification of each subsurface block. The resulting three-dimensional conceptual model of buried waste within the burial ground would provide ERCs with the identification and location of high risk and/or problem wastes, improve excavation volumes estimates, and delineate various waste categories within the burial ground to support excavation and waste handling decisions both prior to and during soil/debris excavation (e.g., acceptable for Environmental Restoration Disposal Facility (ERDF) disposal, requires pretreatment, does not require excavation).

\subsection{8-4 Burial Ground Site History and Layout}

The 618-4 burial ground is located north of the 300 Area on the Hanford Site about 1.6 kilometers ( 1 mile) north of the Richland City limits and 340 meters (1,115 feet) west of the Columbia River. The site is in the northwestern corner of the 300-FF-1 Operable Unit and is enclosed by a hog wire fence encompassing an area of approximately $5,845 \mathrm{~m}^{2}\left(62,890 \mathrm{ft}^{2}\right.$ [1.4 acres]) (see Figure 1). The burial ground is oriented in a southwest-northeast direction (trending approximately $35^{\circ}$ east of north).

The burial ground consists of a single pit measuring 32 meters (105 feet) by 160 meters (525 feet) with the main part of the disposal pit estimated to be at least 6 meters (19 feet) deep. Little information is available regarding the waste disposed to this facility, however, it reportedly operated between 1955 to 1961 and received uranium contaminated trash and debris from nuclear fuel manufacturing processes located in the 300 Area (DOE 1990).

Ground-penetrating radar, magnetometer, and metal detector surveys were conducted over the burial ground in 1991 (WHC 1992). This burial ground was partially excavated during 1997 and 1998 as part of environmental restoration at the 300-FF-1 Operable Unit (Lerch 1998). Excavated material consisted mostly of metallic debris and soil contaminated with uranium, but asbestos, wood, glass, and lead debris were also unearthed. Excavation halted in April 1998 after 338 drums (132 liters [35 gallons]) containing 
depleted uranium metal shavings and uranium-oxide powder were excavated at the site of a strong magnetic anomaly near the center of the burial ground (see Figure 1 for location where these drums were removed).

When excavation halted in April 1998, the burial ground was left with an uneven topographical surface (Figures 3 and 4). A coarse wire (hog wire) fence with wooden posts marks the perimeter of the burial ground, and two power lines are located approximately 30 meters (100 feet) west of the study area. Two boreholes cased with polyvinyl chloride (PVC) were installed on the northwest and southeast sides of the study area to a depth of about 9.7 meters (32 feet), the depth to groundwater. The native geologic materials of the site consist of a thin veneer ( 1.5 meters [ 5 feet] thick) of poorly graded sand overlying well-graded sandy gravel. The moisture content of these soils is very low, on the order of 5 to $10 \%$ by weight.

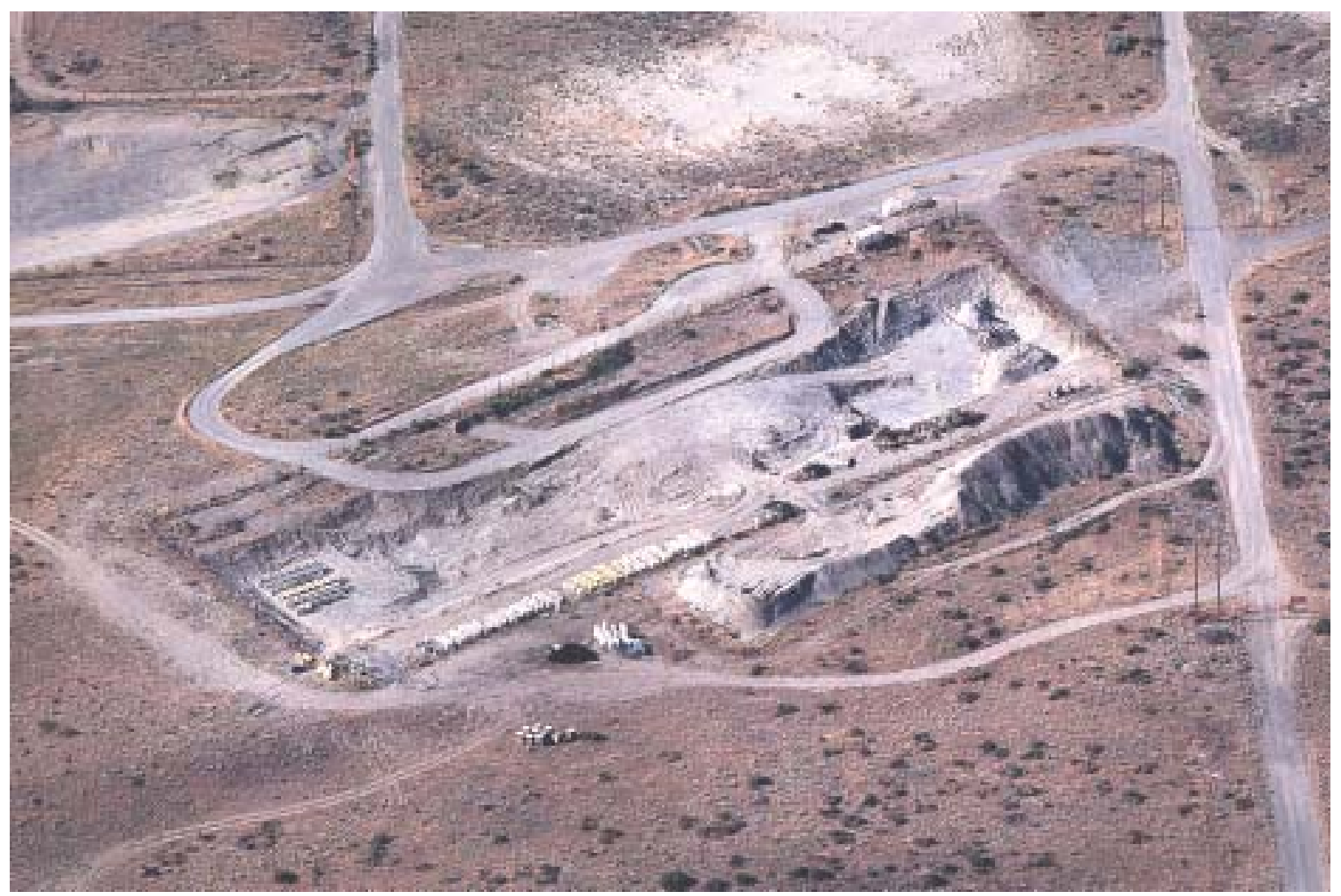

Figure 3. Aerial Photograph of the 618-4 Burial Ground Looking South, June 1998 


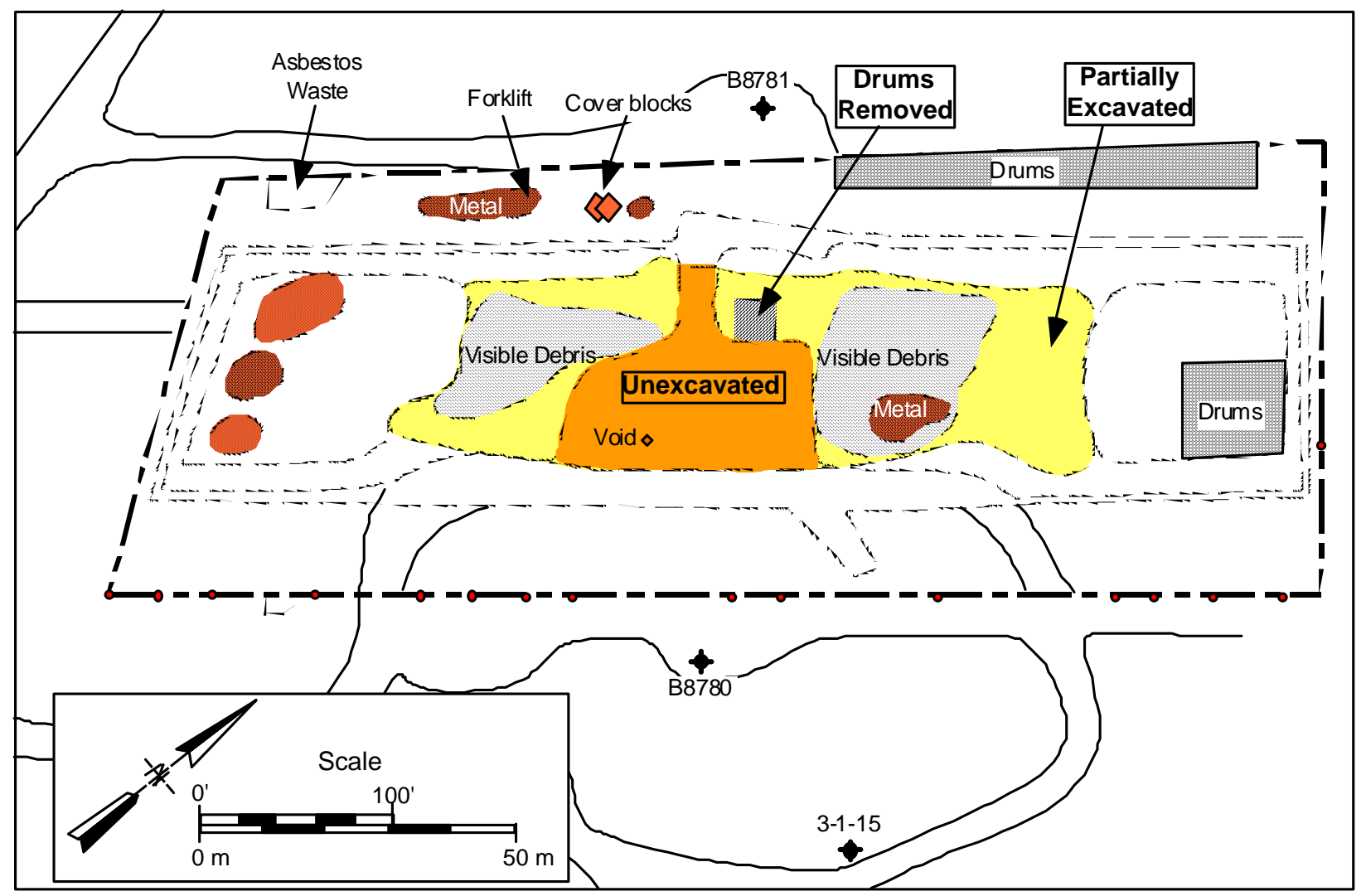

Figure 4. Map of 618-4 Burial Ground Showing Extent of Partial Excavation During 1997 and 1998

\subsection{Geophysical Data Review}

Site characterization data was generated during previous remedial investigation activities and more recent technology demonstrations. Brief summaries of the historic data as well as geophysical data collected specifically for this study are presented in the following sections.

\subsection{Historical Data}

Geophysical surveys of the 618-4 burial ground were conducted as part of remedial investigation at the 300-FF-1 Operable Unit (WHC 1992). The objectives of these surveys were to identify and/or confirm the boundary of the disposal pit, estimate the depth of fill material, and locate waste materials or other significant features. Magnetometer, GPR, and metal detector surveys were conducted in June and August 1991. The GPR surveys were conducted using a grid 2 meters by 2 meters, while the magnetometer and metal detector surveys were conducted using a 2-meter line spacing, with the lines running perpendicular to the length of the burial ground. Results of these surveys suggested that a majority of the waste was metallic in composition. Strong magnetic anomalies at the southwest end of the burial ground 
indicated the presence of a significant amount of ferrous metallic waste materials. The GPR data indicated that waste material and debris in the main part of the pit extended to a depth of at least 6 meters (19 feet). The results also suggested that the waste materials were covered with a layer of relatively clean sand and gravel that varied between 1 to 4 meters (3.28 to 13 feet).

In 1999, the GPR lines were re-interpreted to identify the locations of anomalies that might be caused by buried drums (Appendix A). A distinctive anomaly was detected over the area where drums containing depleted uranium were later removed from the 618-4 burial ground. That anomaly consists of areas on the GPR profiles where the uppermost reflection is flat, unlike most areas where that reflection is highly irregular. In addition, the reflections below the uppermost flat reflection are also more regular and lower in amplitude than the reflections from other parts of the burial ground. Thus, the character of the GPR signals in the area of this anomaly is visually quite distinct from the character of the signals in other areas.

The GPR data were examined on a line-by-line basis to attempt to delineate the boundaries of the drum deposit. This re-interpretation was done separately for both the north-south and the east-west lines. The apparent boundaries derived from the north-south and east-west sets of GPR data are centered around the location $\mathrm{X}=104$ meters ( 341 feet), Y = 38 meters (124.6 feet) and are outlined in Figure 5 by irregularly shaped white and black solid lines. Where the anomaly is outlined by a solid gray line, the anomaly appeared to be present in both sets of lines; therefore, that area may have the greatest probability of containing drums.

The GPR profiles were scanned to determine if similar anomalies existed in other areas. Another anomaly, considered to be potentially associated with a deposit of drums was identified southwest of the first anomaly, with the center located at about $X=75$ meters ( 246 feet), $Y=30$ meters ( 98 feet). The GPR reflections within this anomaly have characteristics similar to that produced by the known drums, but the surface defined by the uppermost reflections is not as flat as it is where drums are known to be present. However, based on the overall similarity of the GPR anomalies, and the fact that the GPR anomaly at the second site occurs over an area with a strong magnetic anomaly, the possibility that a second cache of drums exists at the second site was suggested in the earlier report (Appendix A).

In addition to the geophysical investigations described above, remedial investigation activities also included a soil gas survey and test pit excavations. The soil gas survey was performed in August 1991 to determine the nature and extent of volatile organics. Soil gas probes were installed at depths of 0.6 to 1.2 meters (1.96 to 3.9 feet) at 60 locations. Detectable concentrations up to 15.6 parts per million were found at eight locations primarily located in the southwestern end of the burial ground. In February 1992, two test pits were excavated in the burial ground. These test pits unearthed contaminated pipe, scrap metal, salt-bath precipitate, rubber, pipe insulation, burnt wood, melted glass, asbestos, lead bricks, an a empty drum, and miscellaneous debris mixed with sand and gravel (Lerch 1998).

In June and July 1997, a technology demonstration was conducted using the low frequency electromagnetic array (LEMA) ground penetrating holography (GPH) technology at three small test sites within 
the southwestern portion of the burial ground. ${ }^{2}$ LEMA GPH radar data were collected on intervals of 10 centimeters (3.94 inches) in discrete point acquisition mode. Images of actual buried waste objects at these three sites were generated, demonstrating the capability of GPH technology to locate, size, and show orientation of buried waste. ${ }^{3}$

\subsection{Electromagnetic Offset Logging}

The EOL method has been previously used by WMI International, Inc. and its geophysical subcontractor ENW Services (referred to together as WMI) to identify and map three-dimensional deposits of low-conductivity soil contaminated by organic compounds. This technology was identified in the TechCon database as a mature technology (Gate 6, where Gate 6 is the last of six gates or decision points in the OST Technology Decision Process) with a good performance history and the capability of detecting large waste containers. The deployment of this technology for this study was very different because it involved the three-dimensional mapping of a deposit of metallic drums expected to be highly conductive. However, WMI indicated they did not expect a problem with application of the EOL technology to the mapping of a conductive deposit, and their proposal for geophysical services was accepted based on their low bid and the unique potential of their technology.

During June 1999, two boreholes were drilled on the northern and southern sides of the 618-4 burial ground (Appendix B), each of which was cased with PVC to an approximate total depth of 9.7 meters (32 feet). These boreholes were used by WMI to perform an EOL survey of the central part of the burial ground (Appendix C). EOL data were collected for 184 stations during June 1999. A rectangular source loop 1.8 by 1.8 meters ( 6 by 6 feet) was placed at each station and energized with alternating current. The total electromagnetic field induced by the source loop was then measured at $\sim 3$-centimeter ( 0.1 -foot) intervals in the closest borehole, from depths of 1.2 to 9.7 meters (4 to 32 feet). The data were then processed by WMI to remove the primary field response due to the source coil, thereby permitting measurement of the secondary field response caused by the presence of conductive materials in the subsurface below the source coil. The output data, after processing of the EOL data, were provided as relative conductivity measurements. Because no phase information was recorded by the EOL instruments, it was not possible to calibrate the relative conductivity data to a measurement of true terrain conductivity.

The EOL data were processed twice. The first time, the processing was rushed in order to meet a contract deadline, but the resulting output was unsatisfactory, and the data appeared to bear no relationship to the site. The data were then reprocessed by WMI.

\footnotetext{
${ }^{2}$ Collins, H. Dale. 1997. Portable Selective Hot Spot Removal System Demonstration, RL 37SS41, Technology Evaluation Report. Draft Report, Pacific Northwest National Laboratory, Richland, Washington.

${ }^{3}$ Ibid.
} 
Examination of the final EOL data has proved to be inconclusive. Two high conductivity zones were interpreted by WMI. However, after examining the relative conductivity maps and the vertical crosssections provided by WMI, we concluded that the EOL data cannot be used to identify, even coarsely, the lower boundary of the partially excavated deposit of buried drums, or of the buried waste present in other locations within the trench. Because the EOL data are not suitable for three-dimensional analysis, we elected to pursue other methods using the existing geophysical data to better resolve the location of the edges of the deposit and the number of drums that remain to be excavated.

The performance of the EOL method may have been adversely affected by extraneous cultural features (e.g., metal waste piles) and uneven terrain. When Sandness (WHC 1992) conducted geophysical surveys over the burial ground, it was prior to remediation, hence, the burial ground surface was essentially undisturbed. The ground was fairly flat and was surrounded by a single hog-wire fence. The intended purpose of the 1991 geophysical surveys was to delineate the waste trench boundaries, not to determine what types of waste might be buried within the trench. Thus, the geophysical data were collected on a rather coarse grid. By contrast, the EOL survey was conducted after the overburden had been removed from the entire waste trench area and portions of the site completely or partially excavated. This includes partial removal of the drum deposit. The terrain was very uneven. Debris was visible at the ground surface over several portions of the partially excavated waste trench. In addition, several large metallic objects (including a forklift and a dumpster containing uranium-oxide powder) were located on or near the waste trench. These objects represent strongly conductive cultural features that can generate secondary electromagnetic fields that greatly complicate interpretation of the EOL data. Removal of the overburden and portions of the buried waste also complicated the correlation of the EOL data with the older geophysical data.

\subsection{FY 2001 High Resolution Geophysical Data}

A detailed geophysical investigation was conducted over the central (unexcavated) portion of the burial ground in March 2001. The objective of this investigation was to better define the boundaries of two main target areas (the location of known drums and a second location preliminarily identified as having a similar character) within the 618-4 burial ground and to provide data on their geophysical signatures. This investigation included ground penetrating radar, magnetics, and time domain electromagnetic (TDEM) surveys. Data were collected along profiles spaced 1 meter (3.2 feet) apart. A summary map identified the locations of highly concentrated buried debris, debris that is buried relatively deep with significantly less ferrous material in it, and the area containing a high concentration of drums. While the investigation did provide good definition of the main target area (known to contain drums), the investigation did not distinguish the second target area from the area of highly concentrated debris. Appendix D presents the details of this investigation and its results. 


\subsection{Data Integration}

This section describes the methods and results of the ESCS deployment at the 618-4 burial ground.

\subsection{Methods}

An analysis of historical geophysical data (the WHC 1992 data set) was performed for this project in 1999 (Appendix A). That study suggested that an additional anomalous area existed southwest of the known deposit of steel drums containing depleted uranium. The previous study recommended that updated geophysical data be gathered to examine the anomalous area, and new geophysical data were collected in the spring of 2001. This section describes the application of the ESCS approach to the analysis and integration of that data.

\subsubsection{Data Included in the Analysis and Integration}

Five variables were incorporated in the data analysis and integration. Four of them were based on geophysical data collected in 2001. These include the TDEM data recorded by the Geonics Ltd. EM-61 electromagnetic metal detector instrument, the magnetic field strength, the thickness of the fill overlying the buried waste, and the slope of the top of the buried waste. The fifth variable used in the analysis was the amplitude of the GPR reflection, which was available for the GPR data set collected in 1990 (Figure 5). The EM-61 data used in the analysis was the difference between the top and bottom coils for the 660 microsecond time gate (Figure 6).

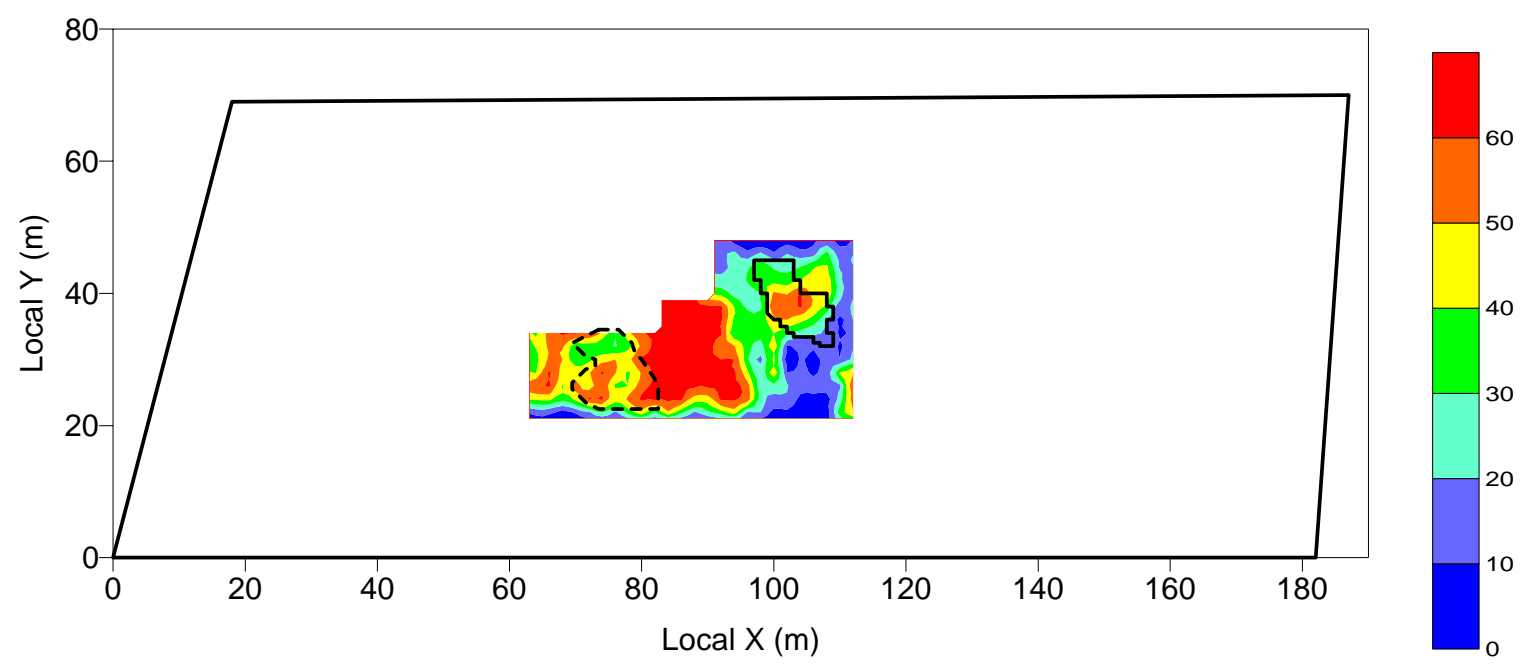

Figure 5. GPR Reflection Amplitude at the 618-4 Burial Ground. (Heavy black outline near $X=100$ is the drum anomaly; dashed outline near $X=70$ represents the southwest anomaly.) 


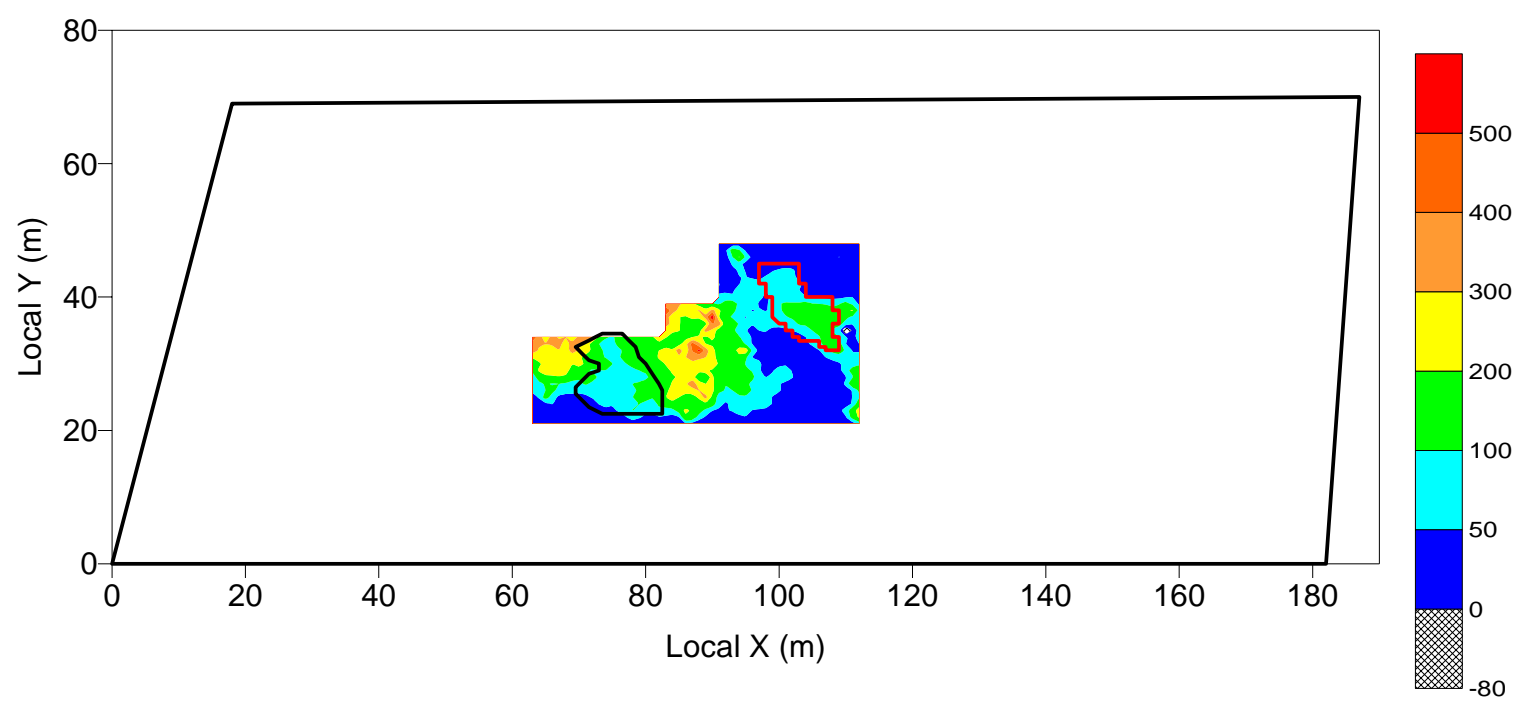

Figure 6. Time Domain Electromagnetic Calculated Differences (top coil - bottom coil 660 value) at the 618-4 Burial Ground

The magnetic field strength data were processed before being included in the analysis. One difficulty that exists with the interpretation of magnetic data is that the position of an anomaly is normally shifted in space from the actual location of the metallic object causing the anomaly. This shift is caused by the interaction of a magnetic dipole with the inclined axis of the earth's magnetic field. A modeling procedure known as reduction to the pole (RTP) can be used to model the magnetic response expected if the magnetic pole were vertical. This shifts the position of magnetic anomalies so that they are directly over the objects that cause them. The RTP transformation of the 2001 magnetic data was performed for Pacific Northwest National Laboratory (PNNL) by Dr. William Clement of the Center for the Geophysical Investigation of the Shallow Subsurface at Boise State University, Boise, Idaho. Dr. Clement used published algorithms and software (Blakely 1995) to perform the reduction to the pole. Figure 7 displays the RTP magnetic field strength data.

The thickness of the fill overlying the buried waste is a numerical 1 by 1 meter ( 3.2 foot) grid created by ordinary kriging of the point measurements of thickness data provided by CH2M HILL Hanford, Inc. (Figure 8 and see Appendix D). The slope of the top of the buried waste was produced in several steps. The basic input data used were the grid of the thickness of the fill just described and point measurements of the topographic relief provided by CH2M HILL Hanford, Inc. (Appendix D). The topographic elevation data were interpolated onto a regular 1 by 1 meter (3.2 foot) grid by ordinary kriging. The top of the buried waste was calculated by subtracting the thickness of the fill and the topography grids from an arbitrary horizontal datum. The slope of the top of the buried waste was calculated using the terrain slope function within SURFER ${ }^{\mathrm{TM}^{4}}$ which determines the local gradient at each grid node. The map of this variable (Figure 9) will be zero in areas where the top of the buried waste is flat, e.g., where drums are neatly stacked. Areas with greater slope on the top of the buried waste are found where the waste was deposited haphazardly.

\footnotetext{
${ }^{4}$ SURFER is a trademark of Golden Software, Inc.
} 

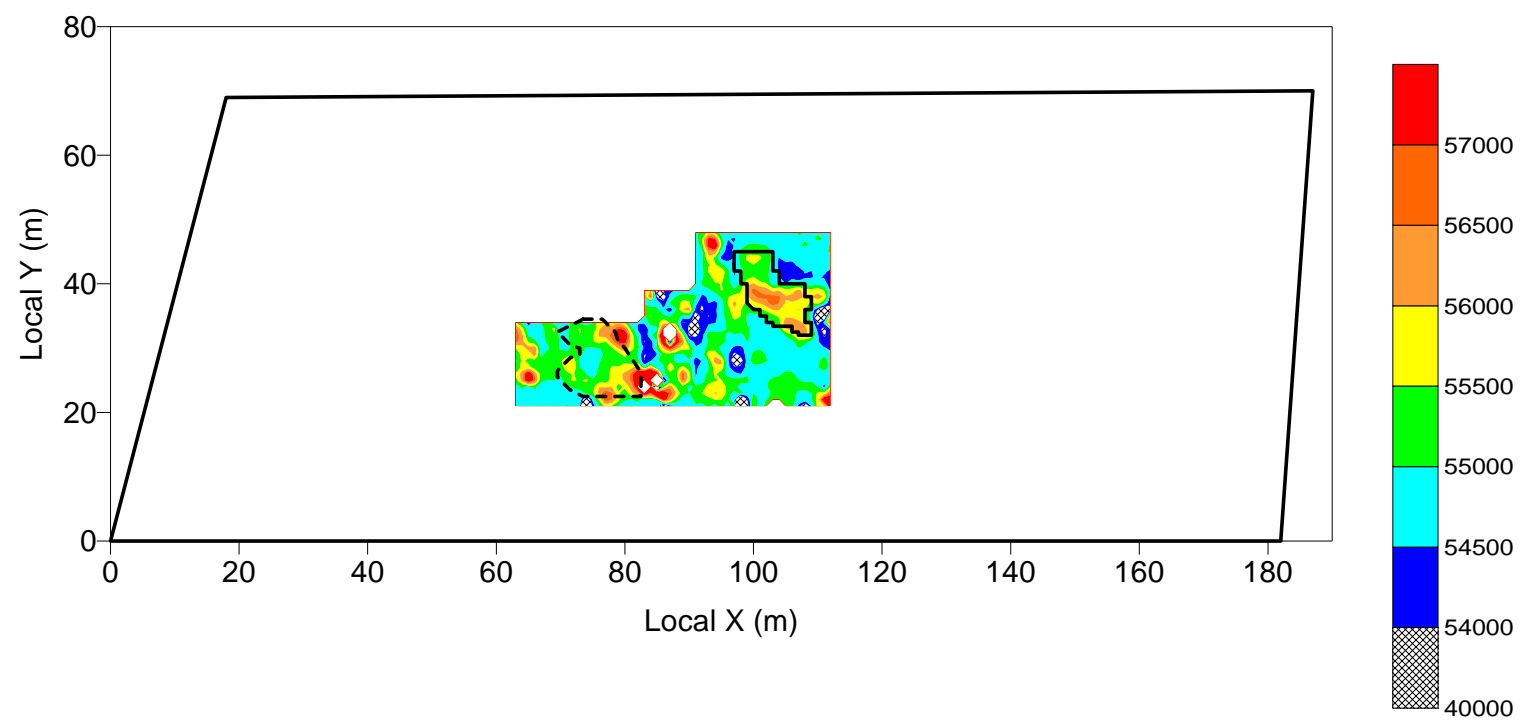

Figure 7. Hanford Magnetic Survey Reduced-to-Pole Data (ambient field strength $=55100$ ) at the 618-4 Burial Ground
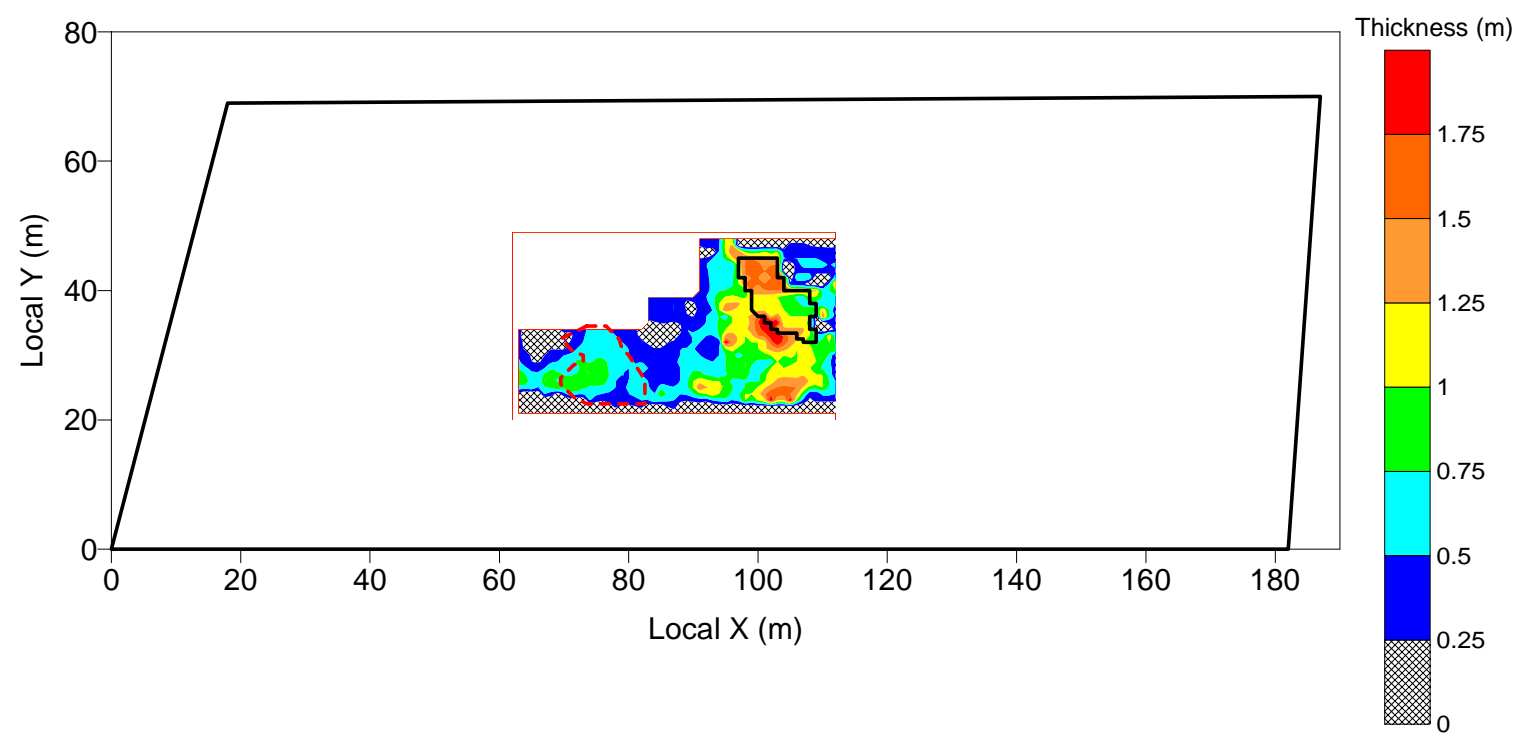

Figure 8. Thickness of Fill Overlying Buried Debris at the 618-4 Burial Ground

\subsubsection{Statistical Methods}

Several statistical methods were employed in the data analysis, including DFA, multiple linear regression, hierarchical cluster analysis, and fuzzy adaptive resonance theory (fuzzy ART). DFA, multiple linear regression, and hierarchical cluster analysis were performed using the SYSTAT ${ }^{5}{ }^{5}$

${ }^{5}$ SYSTAT is a trademark of SPSS, Inc. 


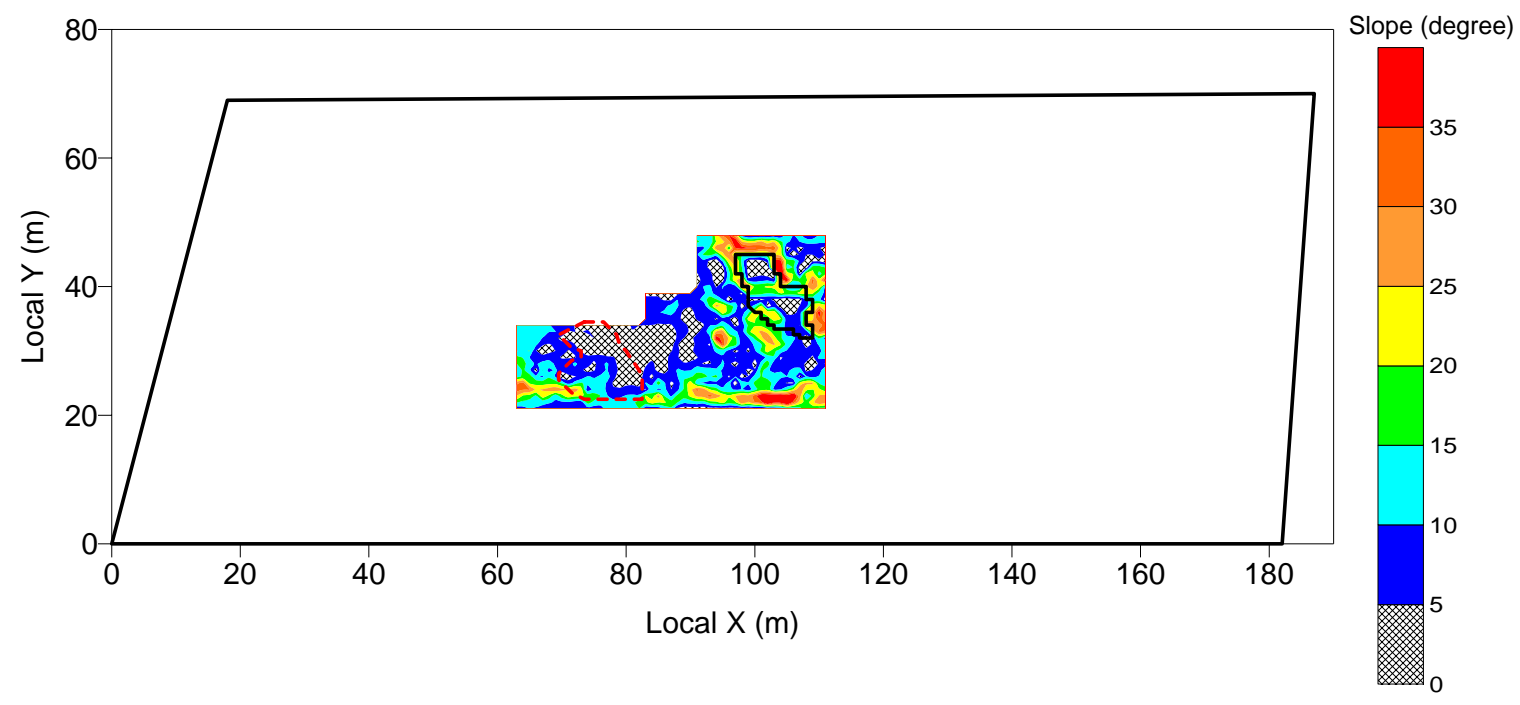

Figure 9. Terrain Slope of Elevation of Top of Buried Debris at the 618-4 Burial Ground

commercial statistical software package (version 10). The fuzzy ART analysis was employed using software developed by YuLong Xie (PNNL) from published algorithms (Carpenter et al. 1991, 1992).

DFA calculates the linear combination of a set of variables that best separates two or more groups of observations (Ripley 1996). Jackknife techniques were employed to estimate the ability of the technique to correctly classify the observations when they are left out of the model one at a time. The group identifications of the observations must be known in advance. In this study, DFA was used to examine the difference between the area designated by the geophysicists as containing drummed waste with the rest of the study area.

We used multiple linear regression to explore the relationship between the EM-61 data, the magnetic field strength, and the thickness of the fill. Multiple linear regression is a technique for modeling the relationship between a dependent (response) variable and two or more independent (predictor) variables (Johnson and Wichern 1988).

We employed traditional and neural network classification methods to classify waste types based on the differences between the geophysical signatures of the classes. The methods that we employed, hierarchical cluster analysis and fuzzy ART, are both unsupervised classification methods (Ripley 1996). This means that they are used to classify observations into "natural" groups where predetermined group identifications are not available (Johnson and Wichern 1988). In essence, they each attempt to identify groups within the samples based on similarities between the members of the groups and the differences between groups. 
Hierarchical cluster analysis uses a measure of the distance between samples and/or groups of samples to successively join each sample to the sample or samples to which it is most similar. In this study, we used the Euclidean distance to measure the distance between samples:

$$
d(x, y)=\sqrt{\left.\left(x_{1}-y_{1}\right)^{2}+\left(x_{2}-y_{2}\right)^{2}+L+\left(x_{p}-y_{p}\right)^{2}\right)}
$$

where $x$ and $y$ are two different samples on which we have made $p$ measurements.

The hierarchical clustering algorithm employed in this study was the average linkage method. This method uses the average of the distances between a sample and a group of samples or between two groups of samples to determine the distance between groups. Average linkage cluster analysis was employed in the previous analysis performed for this study (Appendix A), so we wanted to be able to compare the results from the same technique for the new data set.

Fuzzy ART is a neural network method developed for unsupervised classification (Ripley 1996). Like most neural network methods, fuzzy ART is based on multiple layers, in this case an input and output layer, that are connected by sets of weights. The measurement data for each sample in the input layer are compared to the weighted existing clusters in the output layer to determine which cluster that each sample is most similar to. If the sample being considered is sufficiently similar to one of the existing clusters, then the sample is joined to the cluster and the weights for that cluster are then recalculated. If the sample is still sufficiently similar to the recalculated weights of the cluster, passing what is known as a vigilance check, then the sample is said to resonate with that cluster. If a sample doesn't pass the vigilance check with any existing cluster, then a new cluster is formed, with weights patterned after the sample. This facility to form new clusters when a sample doesn't match the pattern of existing clusters is what leads to the method being termed adaptive. The ART classification method was originally developed for binary data (Ripley 1996). Modifications to the logic that made it possible to apply the algorithm to continuous data, like the geophysical data employed in this study, led to the "fuzzy" modifier for the name of the algorithm.

\subsection{Results}

The interpretation of the high-resolution geophysical data by CH2M HILL Hanford, Inc. provided an outline for the area that they interpreted as the remainder of the cache of uranium filled drums that was partially excavated in 1998 (hereafter referred to as the drum anomaly). We prepared an estimate of the number of drums that might be present at the site, using the outline of the area they provided. We digitized the outline of the drum anomaly, and calculated its area using SURFER ${ }^{\mathrm{TM}}$. We looked at several scenarios and determined there could be $\sim 770$ to 850 drums remaining at the site. In Table 1, all areas are in square meters. The two scenarios are based on our digitized estimate of the area interpreted as probably containing drums by geophysicists at CH2M HILL Hanford, Inc. using the data they recently collected at the site. The first scenario assumes that we have three layers of 208-liter (55-gallon) drums with an average diameter of 58.4 centimeters ( 23 inches), while the second scenario assumes that the drums were all loaded on standard pallets 122 by 102 centimeters ( 48 by 40 inches), four drums to a 
Table 1. Estimates of Remaining Drums in 618-4 Burial Ground

\begin{tabular}{||c|c|c|c||}
\hline $\begin{array}{c}\text { Remaining Area } \\
\left(\mathrm{m}^{2}\right)\end{array}$ & $\begin{array}{c}\text { Drum Area } \\
\left(\mathrm{m}^{2}\right)\end{array}$ & $\begin{array}{c}\text { Pallet Area } \\
\left(\mathrm{m}^{2}\right)\end{array}$ & $\begin{array}{c}\text { Remaining } \\
\text { Drums }\end{array}$ \\
\hline 88 & 0.34 & & 776 \\
\hline 88 & & 1.24 & 852 \\
\hline
\end{tabular}

pallet, stacked three layers high. Of course if the average drum diameter is smaller (large number of 113.5-liter (30-gallon) drums without 208-liter (55-gallon) overpacks), or if they stacked more than four drums to a pallet, these estimates would be low.

We used box plots and DFA to examine the difference in the geophysical properties between the area within the drum anomaly outline and the remainder of the study area. The box plots (Figure 10) indicate that two variables are significantly different within the outline. The median RTP magnetic data is higher within the mapped outline and the thickness of the fill overlying the buried waste is greater within the outline. DFA indicated that in 83 to $85 \%$ of the cases within the study area it is possible to correctly predict whether a given location is inside the mapped outline just based on the geophysical data (i.e., without considering the spatial location). The two lines of evidence strongly suggest that the area interpreted as containing drums is geophysically different from the rest of the study area.

However, it is important to note that the EM-61 data did not appear to be different on either side of the boundary (e.g., see the box plot for the EM-61 data in Figure 10). This is surprising because the uranium filled drums are made out of steel (Lerch 1998), and it might be expected that the EM-61 instrument, which is primarily used for metal detection, would exhibit a high conductivity response over the area containing drums. One possible reason for the low EM-61 response in the area where the drums are buried is the greater depth of fill overlying that area (see Figure 10). To examine that idea, we examined the correlation of the EM-61 data with the thickness of the fill. The correlation for the entire study area is -0.542 , which is the strongest correlation found for the dataset as a whole. The correlation between the two variables is even stronger within the area identified as probably containing metallic drums, where it is -0.764 . The increase in correlation may be due to the fact that the area within the outline is more homogenous than the site as a whole. The correlation between the EM-61 data and the thickness of the fill suggests that the EM-61 signal is being attenuated by the increased distance and material between the instrument and the metallic objects in the buried waste.

We also used multiple linear regression to estimate the relationship between the EM-61 data, the thickness of the fill, and the RTP magnetic field strength data. The linear correlation coefficient between EM-61 data and the RTP data was 0.757 within the drum outline. The positive correlation is expected because both instruments are influenced by the presence of metallic objects, although the magnetometer primarily responds to ferric metal while the EM-61 instrument detects any conductive material. The multiple correlation coefficient for the regression model was 0.866; the squared correlation coefficient of 0.75 indicates that about $75 \%$ of the variance of the EM-61 data within the drum outline can be explained by a combination of the RTP magnetic data and the thickness of the fill. 


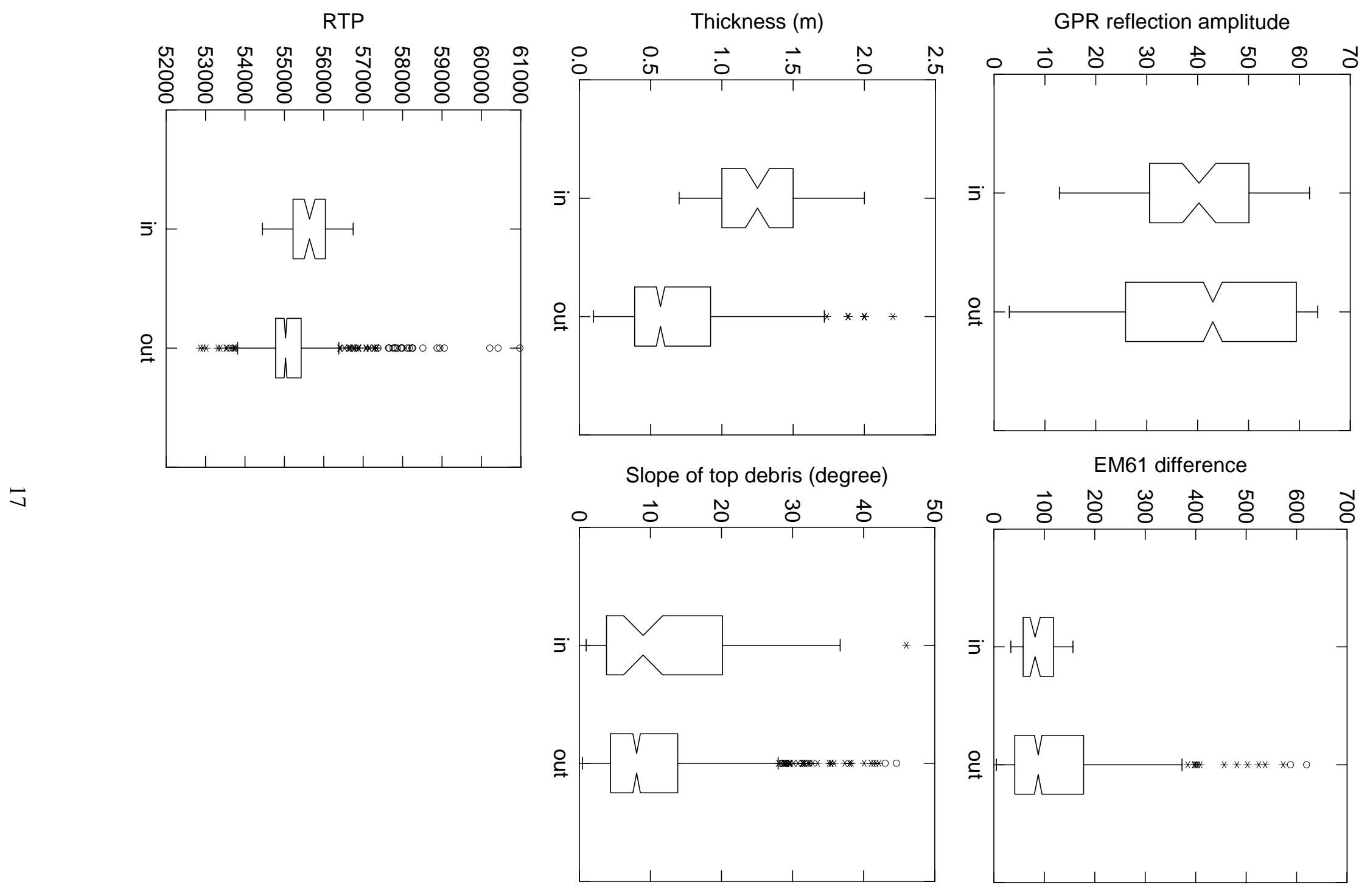

Figure 10. Box Plots of Five Variables Within and Outside the Identified Drum Area 
The box plots shown in Figure 10 and the DFA results discussed earlier indicate that there are significant differences between the drum outline area and the study area as a whole. However, previous work (see Appendix A) suggested that there was at least one area outside of the area known to contain drums that had a similar geophysical signature. We used several unsupervised classification methods to determine if there were other areas outside of the known drum area that had a similar geophysical signature using the high-resolution geophysical data set gathered in 2001. We first tried hierarchical cluster analysis using the average linkage algorithm that had been employed in the earlier phase of the study. However, that effort was unsuccessful, as the vast majority of the observations were all classified within a single class. For example, with three classes selected, $98.8 \%$ of the observations were classified within a single class, while with four classes, $95.5 \%$ of the observations were placed in the same class.

Given the inability of hierarchical clustering to satisfactorily partition the geophysical data, we applied an alternative method of unsupervised classification, fuzzy ART, that is based on neural network methods. This method classified the data more successfully, partitioning the area into three different classes (Figure 11). The partitioning appears reasonable for several different reasons:

- the partitioning was stable for a wide choice of the input parameters to the fuzzy ART program

- the partitioning roughly paralleled the results of a third unsupervised classification method (k-means clustering, results not shown)

- the partitions form relatively compact spatial classes that coincide with known and/or previously identified areas

- there are significant differences between the geophysical properties that can be related to the spatial location of the classes.

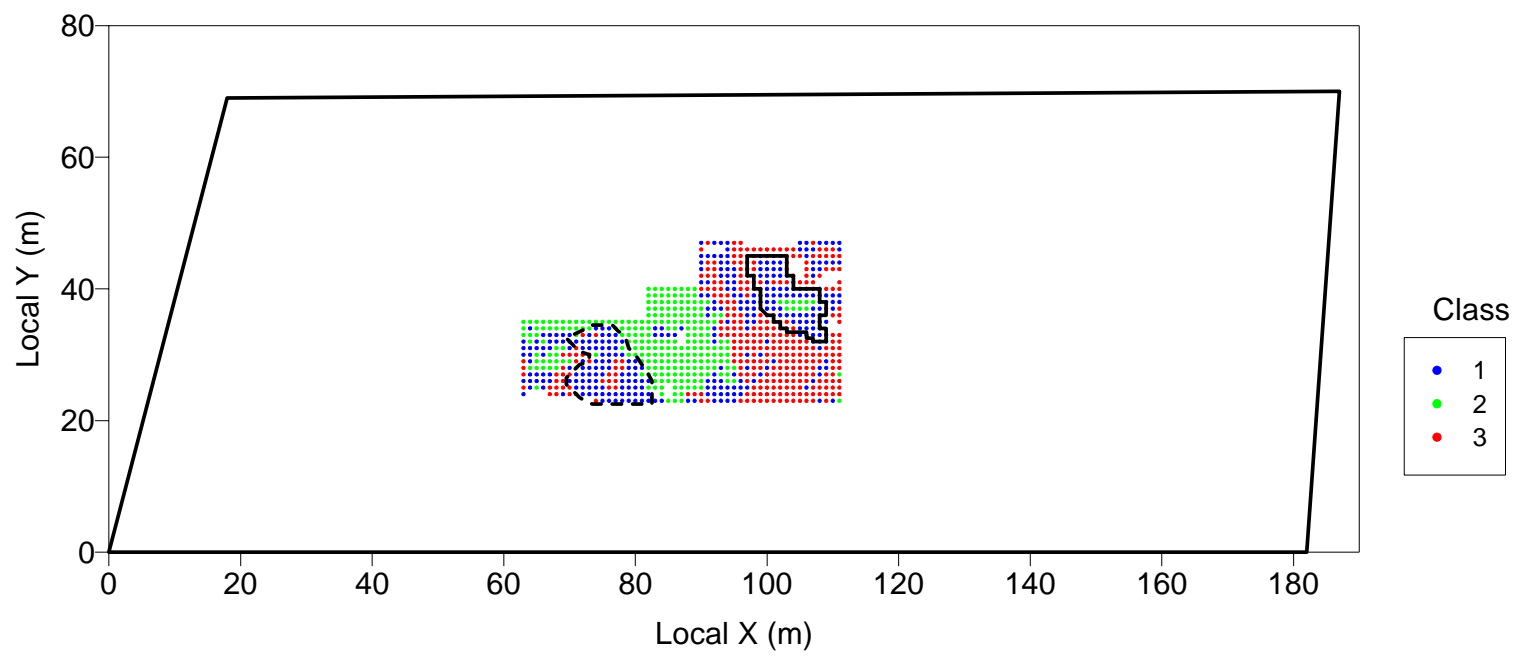

Figure 11. Classes Defined by Neural Network Fuzzy ART Approach Using Five Variables 
Class 1 is the class that coincides most directly with the location of the drum anomaly, as identified by the geophysicists, and the anomaly that had been previously identified to the southwest of it (see Figure 11). Class 1 has high RTP magnetic field strength, intermediate values for EM-61 difference, GPR reflection amplitude, and the thickness of the overlying fill, and low values for the slope on top of the buried waste (Figure 12). Class 1 is concentrated in the drum anomaly and the area of the southwest anomaly, with another small patch located in the eastern southcentral portion of the map. Although it is not conclusive without the ability to calibrate the group identifications with specific waste types that have been excavated, the similarity between the drum anomaly and the southwestern anomaly suggest caution in excavating the southwestern and southcentral anomalies. Class 3, on the other hand, appears to identify areas with much less metallic waste present, as indicated by the fact that this class is marked by the lowest RTP magnetic field strength, EM-61 values, and GPR reflection amplitudes (see Figure 12). Class 3 occurs mostly in the "eastern" portion of the map area, with the greatest concentration in the southeast corner of the map. It is worth noting that there are small patches of Class 3 observations within the drum anomaly and the southwest anomaly (see Figure 11). Like Class 1, Class 2 has properties consistent with the presence of metallic waste. Class 2 has RTP magnetic field strength values that are about the same as those found in Class 1, but the EM-61 data values and the GPR reflection magnitude for Class 2 are far higher than those of Class 1 (see Figure 12). One factor that might explain the high EM-61 values are that Class 2 is also the class with the thinnest fill overlying the buried waste. As shown previously, the EM-61 instrument appears to be very sensitive to the thickness of the fill overlying the buried waste.

\subsection{Conclusions}

The ESCS deployment allowed us to test the ESCS approach and employ multivariate geostatistical methods to build a conceptual model of the buried waste distribution at the 618-4 burial ground, which was the objective of the study. The conceptual model, which provides information that can be used to increase the efficiency of remediating the 618-4 burial ground, is discussed below, along with an evaluation of the ESCS deployment itself.

\subsection{Conceptual Model of Buried Waste in the 618-4 Burial Ground}

We used a commercial mapping package to calculate the area within the outline of the drum anomaly interpreted by geophysicists at CH2M HILL Hanford, Inc. from the new geophysical data, which they recorded under contract for this project. The estimated area was the basis for an estimate of the number of remaining drums at the site. For different stacking scenarios, the number of remaining drums ranged from about 770 drums to 850 drums. The estimate was provided to the ERC for use in budgeting and planning. 

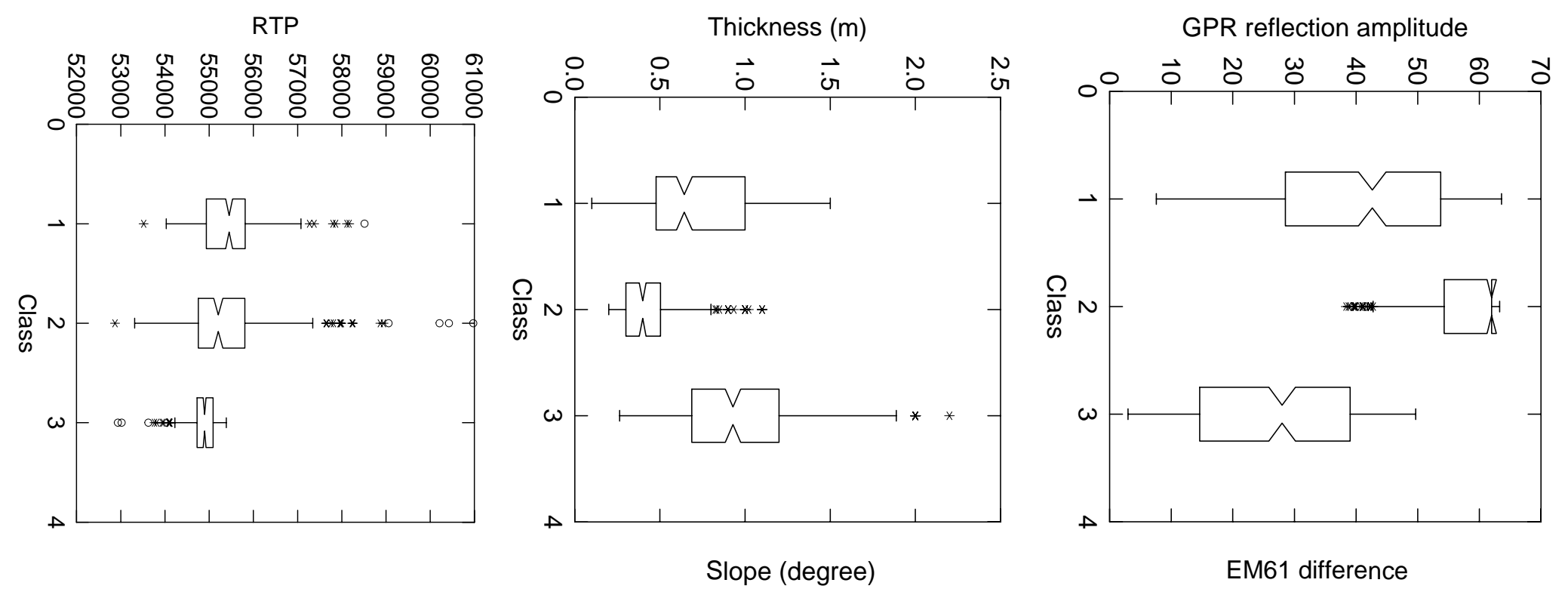

N

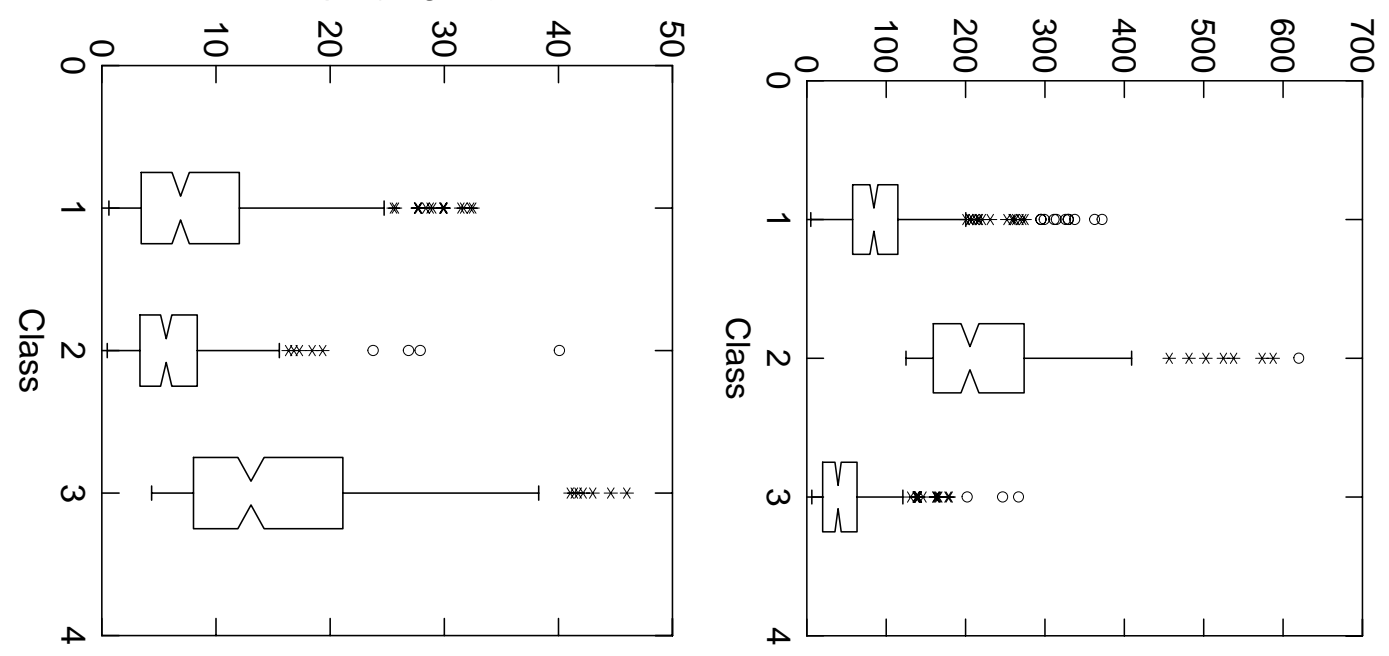

Figure 12. Box Plots of Five Variables in Three Classes Identified by Neural Network Fuzzy ART Approach 
A combination of box plots and DFA indicate that the drum area and the southwest anomaly are similar to one another, but different from the rest of the study area. The major difference between the two anomalies and the rest of study area is the presence of higher measurements of magnetic field strength, suggesting the presence of ferric metals, and a greater thickness of overlying fill. The increased thickness of fill may be responsible for the attenuated EM-61 signal, which should respond to the presence of conductive metal. Multiple linear regression within the area of the drum anomaly indicated that the thickness of the fill has a strong negative correlation with the strength of the EM-61 signal.

Fuzzy ART, a neural network classification method, successfully clustered the area into 3 classes. The classes identified by neural network analysis appear reasonable for several different reasons:

- the partitioning was stable for a wide choice of the input parameters to the fuzzy ART program

- the partitioning roughly paralleled the results of a third unsupervised classification method (k-means clustering)

- the partitions form relatively compact spatial classes that coincide with known and/or previously identified areas

- there are significant differences between the geophysical properties that can be related to the spatial location of the classes.

The drum anomaly and the southwest anomaly have similar geophysical signatures, and are dominantly composed of Class 1 . The area between the drum anomaly and the southwest anomaly, dominated by Class 2, also appears to contain waste with a high metallic content, but the character of that anomaly is quite different, with a very high EM-61 signature and a greater GPR reflection amplitude. The difference between Class 1 and Class 2 may indicate a higher proportion of conductive but non-ferric waste in the area dominated by Class 2 and/or the difference may be due mostly to the shallow burial of that waste. Areas dominated by Class 3 appear to contain much less metallic waste than the rest of the study area.

\subsection{Evaluation of the ESCS Technology}

Evaluation of the ESCS technology can only be partially concluded at this time. The multivariate techniques employed by the ESCS approach can successfully integrate multiple geophysical variables and group observations into clusters that are relevant for planning the excavation of the buried waste. The method allowed us to provide input to site personnel on areas that need special caution and planning during excavation.

However, the success of the technology cannot be fully evaluated at this time because reliable ground truth data are not available to calibrate to the geophysical signal. The initial plan for this study was to apply statistical classification techniques and geostatistics to both new and existing geophysical data and available discrete samples of excavated materials (ground truth data) to develop a discrete threedimensional map of specific waste types. Each defined section of the burial ground would be defined as a specific waste category within a defined probability. The resulting map was to be validated by comparing 
the materials actually excavated (when excavation resumed) to the predicted waste types. However, accurate spatial locations of available ground truth data, which were expected to be available from the partial excavation of the 618-4 burial ground, were not available. This made it impossible to attempt an initial calibration of the geophysical data to the excavated waste. In addition, the delay in excavating the remainder of the burial ground prevented us from performing a post-excavation calibration of the waste types against the classes identified in the geophysical data by neural network analysis.

\subsection{Recommendations}

Several recommendations were developed as a result of this deployment:

- The ERC should proceed with caution when excavating the southwest anomaly because of similarities between the geophysical signature in that area and the geophysical signature found in the drum anomaly. In addition, although the geophysical signature of Class 2 differs from that found in the drum anomaly, it still appears to be highly conductive, suggesting the presence of large amounts of shallowly-buried metal. We also advise caution during excavation of that area.

- An effort should be made to provide detailed and accurate locations during excavation of the remaining wastes in the 618-4 burial ground, which can be used to establish a calibration with geophysical data from the site. This should be performed using a high-resolution global positioning system (GPS), able to located objects within 1 to 2 meters (3.28 to 6.56 feet) of their true location.

- Before excavating the nearby 618-5 burial ground (which is believed to have received similar waste to that of the 618-4 burial ground), we recommend calibration of the high-resolution geophysical data from the 618-4 burial ground with the waste types identified during excavation of the site. If that calibration is successful, we recommend analysis of the existing 618-5 geophysical data (WHC 1992), and, pending the results of that reanalysis, consideration of gathering new (higher resolution) geophysical data at that burial ground.

\subsection{References}

Blakely, R. J. 1995. Potential Theory in Gravity and Magnetic Applications. Cambridge University Press, Cambridge, England, 441 p.

Carpenter, G. A., S. Grossberg, and D. B. Rosen. 1991. "Fuzzy ART: Fast Stable Learning and Categorization of Analog Patterns by an Adaptive Resonance System." Neural Networks 4:759-771. 
Carpenter, G. A., S. Grossberg, N. Markuzon, J. H. Reyholds, and D. B. Rosen. 1992. "Fuzzy ARTMAP: A neural network architecture for incremental supervised learning of analog multidimensional maps." IEEE Transactions on Neural Networks, 3(5):699.

DOE - U.S. Department of Energy. 1990. Remedial Investigation/Feasibility Study Work Plan for the 300-FF-1 Operable Unit, Hanford Site, Richland, Washington. DOE/RL 88-31, U.S. Department of Energy, Richland, Washington.

Johnson, R. A. and D. W. Wichern. 1988. Applied Multivariate Statistical Analysis, 2nd ed., Prentice Hall, Englewood Cliffs, New Jersey, 607 p.

Lerch, J. A. 1998. 618-4 Burial Ground Excavation Report. BHI-01200, Bechtel Hanford, Inc., Richland, Washington.

Ripley, B. D. 1996. Pattern Recognition and Neural Networks. Cambridge University Press, Cambridge, England, 403 p.

WHC - Westinghouse Hanford Company. 1992. Geophysical Surveys Performed by the Automatic and Measurement Sciences Department of the Pacific Northwest Laboratory at Hanford Burial Grounds 618-4 and 618-5. WHC-SD-EN-TI-061, Rev.0, Westinghouse Hanford Company, Richland, Washington. 


\begin{abstract}
Appendix A
Preliminary Conceptual Model of Buried Waste in the 618-4 Burial Ground
\end{abstract}




\section{5}

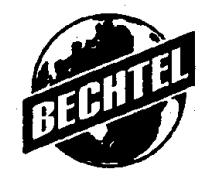

Job No. 22192

Written Response Requirnd: NO

Due Dute: N/A

Aetionee: NVA

Cus: $N$.

TSD: $\mathbf{N} / \mathbf{A}$

ERA: NA

Subject Code: 8700

\section{SEP 171999}

U.S. Department of Energy

Richland Operations Office

D. E. Trader, Director

Science and Technology Programs Division

P.O. Box 550, MSIN K8-50

Richland, Washington 99352

Subject: $\quad$ Contract No. DE-AC06-93RL12367

\section{COMPLETION OF MILESTONE FOR PACIFIC NORTHWEST NATIONAL LABORATORY'S FY 1999 TECHNICAL TASK PLAN RL0-9-SS-21, ENHANCED SITE CHARACTERIZATION}

Dear Ms. Trader:

Milestone D1, "Prepare 3-D Conceptual Model and Report," due September 17, 1999, for the subject Technical Task Plan (TTP) has been completed on time. Three copies of the report, "Preliminary Conceptual Model of Buried Waste in the 618-4 Burial Ground," are provided for your convenience.

If you have any questions, please contact Scott Petersen of my staff on 372-9126.

Sincerely,

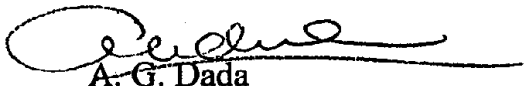

Manager, Technology Applications

SWP:ked

Attachments: (3) Preliminary Conceptual Model of Buried Waste in the 618-4 Burial Ground

cc: w/o

S. N. Balone (RL) H0-12

T. L. Davis (RL) K8-50

F. R. Serier (RL) H0-12

J. P. Hanson (RL) K8-50

G. V. Last (PNNL) K6-81

C. R. Richins (RL) K8-50

S. C. Foelber (BHI) H0-09

cc: $w / a$

J. A. Wright SR (SCFA) 


\title{
WhitePaper \\ Preliminary Conceptual M odel of Buried Waste in the 618-4 Burial G round
}

\author{
C. J. Murray \\ G. V. Last \\ Y. Chien \\ G. A. Sandness \\ Pacific Northwest National Laboratory \\ Richland, Washington
}

September 16, 1999

Prepared for

Bechtel Hanford, Incorporated

Richland, Washington 


\section{Introduction}

This report describes preliminary results obtained from deployment of the Enhanced Site Characterization System (ESCS) to map the distribution of buried waste at the 618-4 Burial Ground. This low-level radioactive waste burial ground is located on the Hanford Site about 1.6 $\mathrm{km}$ (1 mi.) north of the Richland City limits and $340 \mathrm{~m}(1115 \mathrm{ft})$ west of the Columbia River. The 618-4 Burial Ground, located in the 300-FF-1 Operable Unit, was partially excavated during 1997 and 1998. Excavation was halted in April 1998 after 338 drums containing depleted uranium metal shavings and uranium-oxide powder were excavated from the site (see Figure 1 for location where these drums were removed).

This report meets the objective of a Department of Energy Headquarters (DOE-HQ) milestone identified in the ESCS Deployment Plan and Fiscal Year 1999 Technical Task Plan (TTP). This ESCS project was jointly funded by DOE's Office of Science and Technology's Accelerated Site Technology Deployment (ASTD) Project (EM-50) through the Subsurface Contaminant Focus Area, and Bechtel Hanford Incorporated's (BHI) 300-FF-1 Environmental Restoration Project (EM-40). The objective of this deployment was to map the physical types of waste materials present in the 618-4 burial ground, using geophysical and geostatistical methods. Of particular interest to the $300-\mathrm{FF}-1$ Project, was the thickness of the remaining deposit of metal drums and the estimated number of drums still requiring removal.

Geophysical surveys, including ground penetrating radar (GPR) and measurement of the intensity of the total magnetic field, were performed in 1991 (WHC 1991). Mapping of the data for the current study was performed using the local coordinate system developed for the previous geophysical surveys. That coordinate system parallels the fenceline surrounding the 618-4 Burial Ground. For convenience, areas of the maps produced using the local coordinate system will be identified using compass directions; e.g., the "southwest" corner of the map, even though true north is approximately 52 degrees east of north on the maps.

\section{Electromagnetic Offset Logging (EOL)}

Two boreholes were drilled on the northern and southern sides of the 618-4 Burial

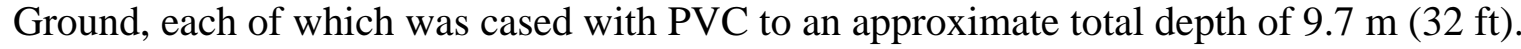
These boreholes were utilized by WMI International and its geophysical subcontractor ENW Services (referred to together as WMI) to perform an EOL survey of the central part of the burial ground. The EOL method has been previously used by WMI to identify and map 3-D deposits of low-conductivity soil contaminated by organic compounds. This technology was identified in the TechCon database as a mature technology (Gate 6) with a good performance history and the capability of detecting large waste containers ${ }^{1}$. The current application of the technology was very different, because it involved the 3-D mapping of a deposit of metallic drums expected to be highly conductive. However, WMI indicated that they did not expect a problem with application of the EOL technology to the mapping of a conductive deposit, and their proposal for geophysical services was accepted based on their low bid and the unique potential of their technology.

\footnotetext{
${ }^{1}$ Last, G. V., T. L. Walton, L. M Bagaasen, H. D. Freeman, T. J Gilmore, T. L. Liikala, P. M. Molton, and S. S. Teel. August 1996. "A Survey of Commercially Available Technologies For Characterization, Excavation, and Handling of Buried Waste at the Hanford Site". A Report for Bechtel Hanford, Incorporated. Prepared by Pacific Northwest National Laboratory, Richland, Washington.
} 


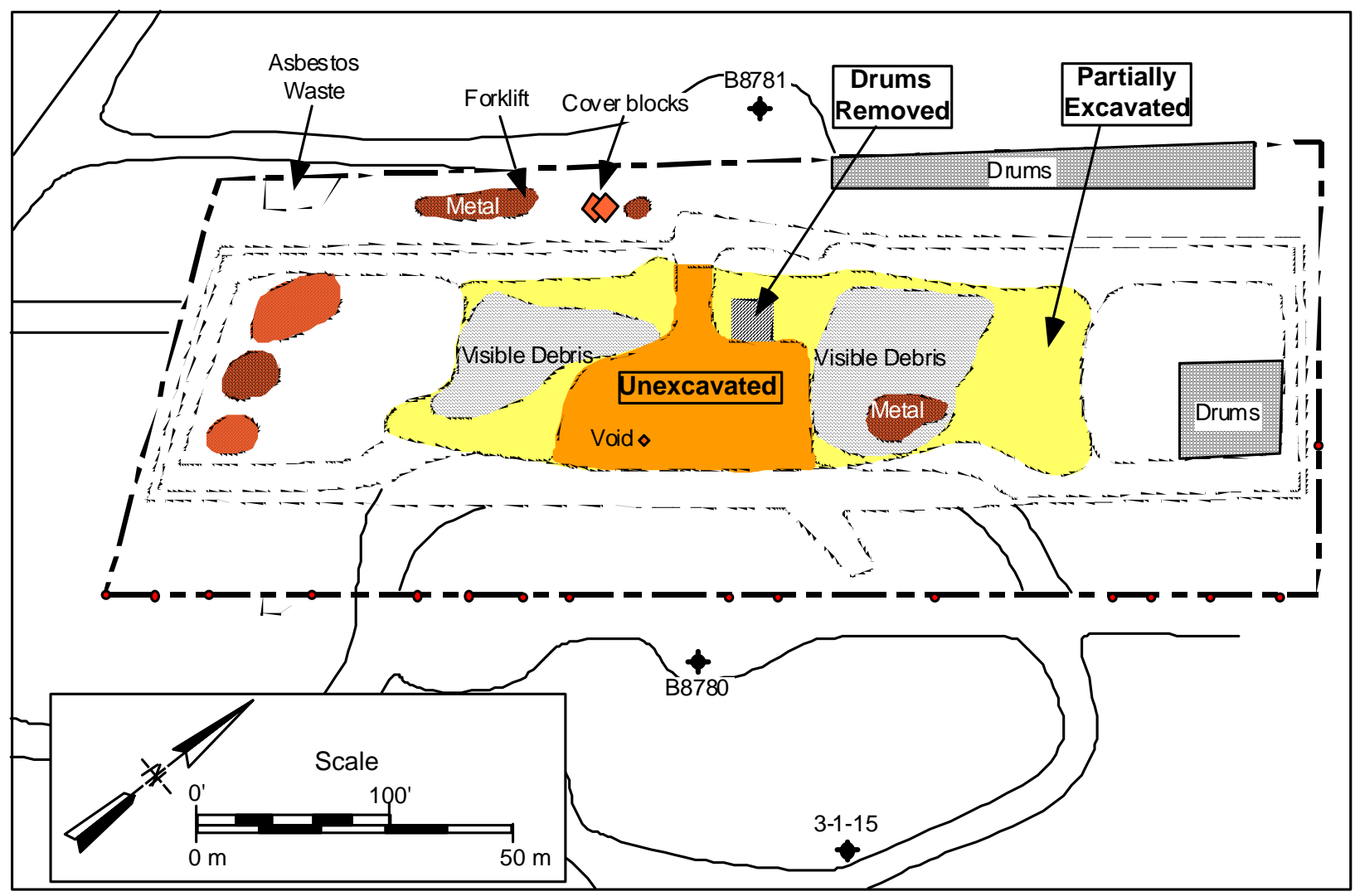

Figure 1. Map of 618-4 Burial Ground, showing extent of partial excavation.

EOL data were collected for 184 stations during June of 1999. A 6-ft by 6-ft (1.8-m by $1.8-\mathrm{m})$ rectangular source loop was placed at each station and energized with alternating current. The total electromagnetic field induced by the source loop was then measured at $0.1-\mathrm{ft}(\sim 3 \mathrm{~cm})$ intervals in the closest borehole, from depths of $32 \mathrm{ft}(9.7 \mathrm{~m})$ to $4 \mathrm{ft}(1.2 \mathrm{~m})$. The data were then processed by WMI to remove the primary field response due to the source coil, thereby permitting measurement of the secondary field response caused by the presence of conductive materials in the subsurface below the source coil. The output data, after processing of the EOL data, were provided as relative conductivity measurements. Because no phase information was recorded by the EOL instruments, it was not possible to calibrate the relative conductivity data to a measurement of true terrain conductivity.

The EOL data were processed twice. The first time, the processing was rushed in order to meet a contract deadline, but the resulting output was unsatisfactory, and the data appeared to bear no relationship to the site. The data were then reprocessed by WMI.

Examination of the final EOL data ${ }^{2}$ has proved to be inconclusive. Two high conductivity zones were interpreted by WMI (Figure 2). The upper zone, which is centered at a

\footnotetext{
${ }^{2}$ WMI International, Inc. “618-4 Burial Ground” Report No. BAT-(PNNL) 269421-618-4-EOL-1. Prepared by WMI International, Inc., Houston, TX
} 


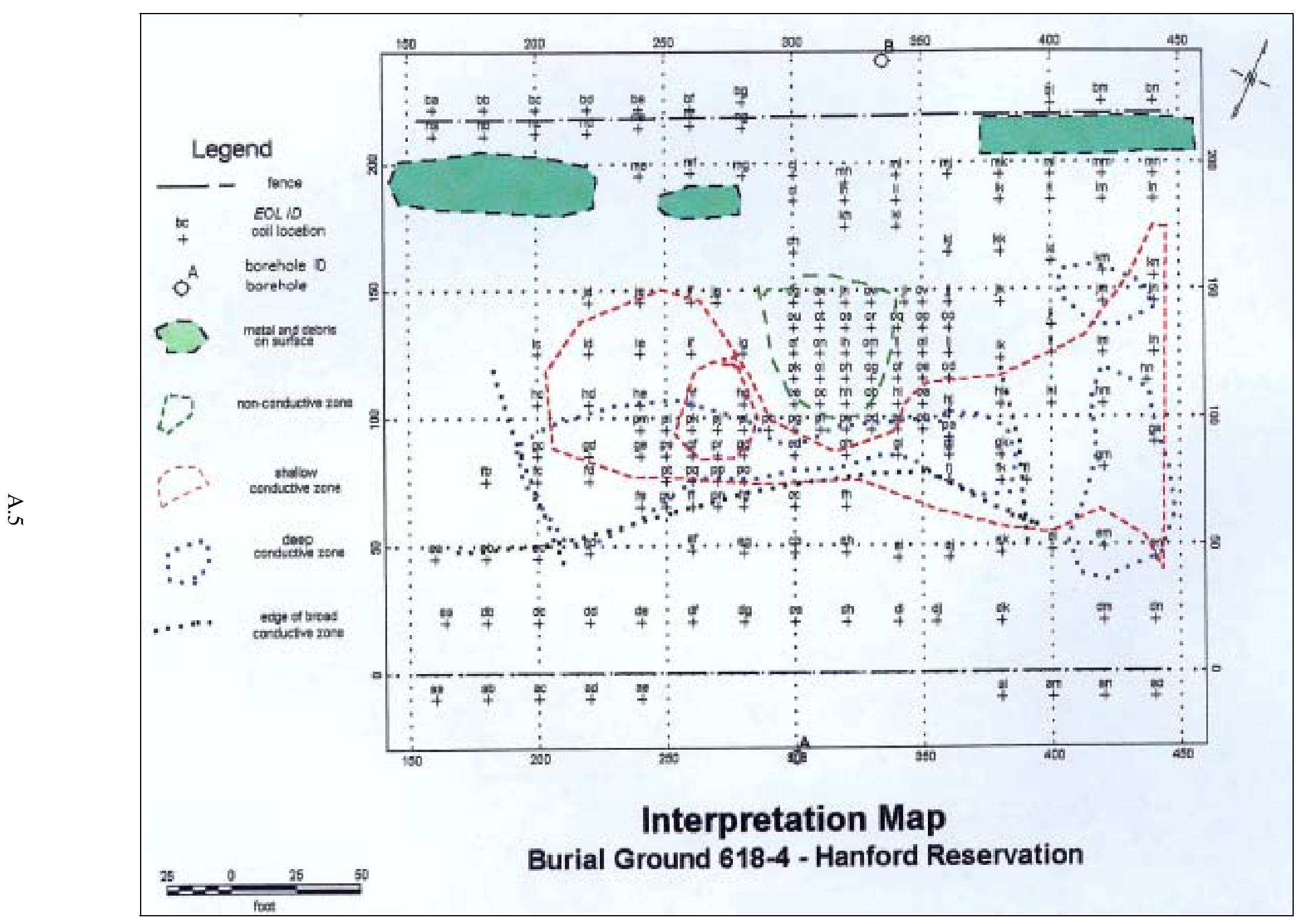

Figure 2. EOL anomalies interpreted in the 618-4 Burial Ground by WMI 
depth of approximately 15 feet $(4.6 \mathrm{~m})$, does appear to generally follow the outline of the burial trench on its southern edge (as identified by previous geophysical surveys). However, the northern edge of the anomaly is poorly defined, and it is very difficult to reconcile the EOL data with other data from the site. In particular, there is no conductive anomaly in the northern area of the trench where the drums of uranium were located. WMI indicated that they considered that area (shown as a non-conductive zone in Figure 2) to be anomalous because no conductive anomaly was found in the drum area where a strong magnetic anomaly was previous found and where one would normally be expected. Another troubling aspect to the EOL data is the presence of high-conductivity anomalies in areas where they are completely unexpected. An example can be seen in Figure 3, where a high-conductivity anomaly is present in the southwest corner of the map. This anomaly is defined by a large number of data points (about as many as define the shallow high-conductivity anomaly identified by WMI), and is visible in several layers of the data in that location, yet no wastes have been identified near that location by any other method. A deeper anomaly was also identified by WMI (Figure 2) in the general area of the trench, at a depth of 23-27 feet (7-8.2 m), but most of that anomaly appears to be south of the trench as identified by other methods, and WMI suggested that the deep anomaly is suspect.

After examining the relative conductivity maps and the vertical cross-sections provided by WMI, we concluded that the EOL data cannot be used to identify, even coarsely, the lower boundary of the partially excavated deposit of buried drums, or of the buried waste present in other locations within the trench. Because the EOL data are not suitable for 3-D analysis, we elected to pursue other methods using the existing geophysical data to better resolve the location of the edges of the deposit and the number of drums that remain to be excavated.

The performance of the EOL method may have been adversely affected by extraneous cultural features (e.g., metal waste piles) and uneven terrain. When Sandness (WHC 1992) conducted geophysical surveys over the burial ground, it was prior to remediation, hence, the burial ground surface was essentially undisturbed. The ground was fairly flat, and was surrounded by a single hog-wire fence. The intended purpose of the 1991 geophysical surveys was to delineate the waste trench boundaries, not to determine what types of waste might be buried within the trench. Thus, the geophysical data were collected on a rather coarse grid. By contrast, the EOL survey was conducted after the overburden had been removed from the entire waste trench area and portions of the site completely or partially excavated. This includes partial removal of the drum deposit. The terrain was very uneven. Debris was visible at the ground surface over several portions of the partially excavated waste trench. In addition, several large metallic objects (including a forklift, and a dumpster containing uranium-oxide powder) were located on or near the waste trench. These objects represent strongly conductive cultural features that can generate secondary electromagnetic fields that greatly complicate interpretation of the EOL data. Removal of the overburden and portions of the buried waste also complicated the correlation of the EOL data with the older geophysical data.

\section{Reinterpretation of GPR Data}

GPR data were originally recorded in 1991 (WHC 1992). The data were collected along parallel sets of lines paced $2 \mathrm{~m}$ apart and oriented in both the north-south and east-west directions. The lines were reinterpreted to identify the locations of anomalies that might be attributable to buried drum deposits. A distinctive anomaly was observed over the area where drums containing depleted uranium were extracted from the 618-4 Burial Ground. That anomaly consists of areas on the GPR profiles where the uppermost reflection is flat, unlike most 


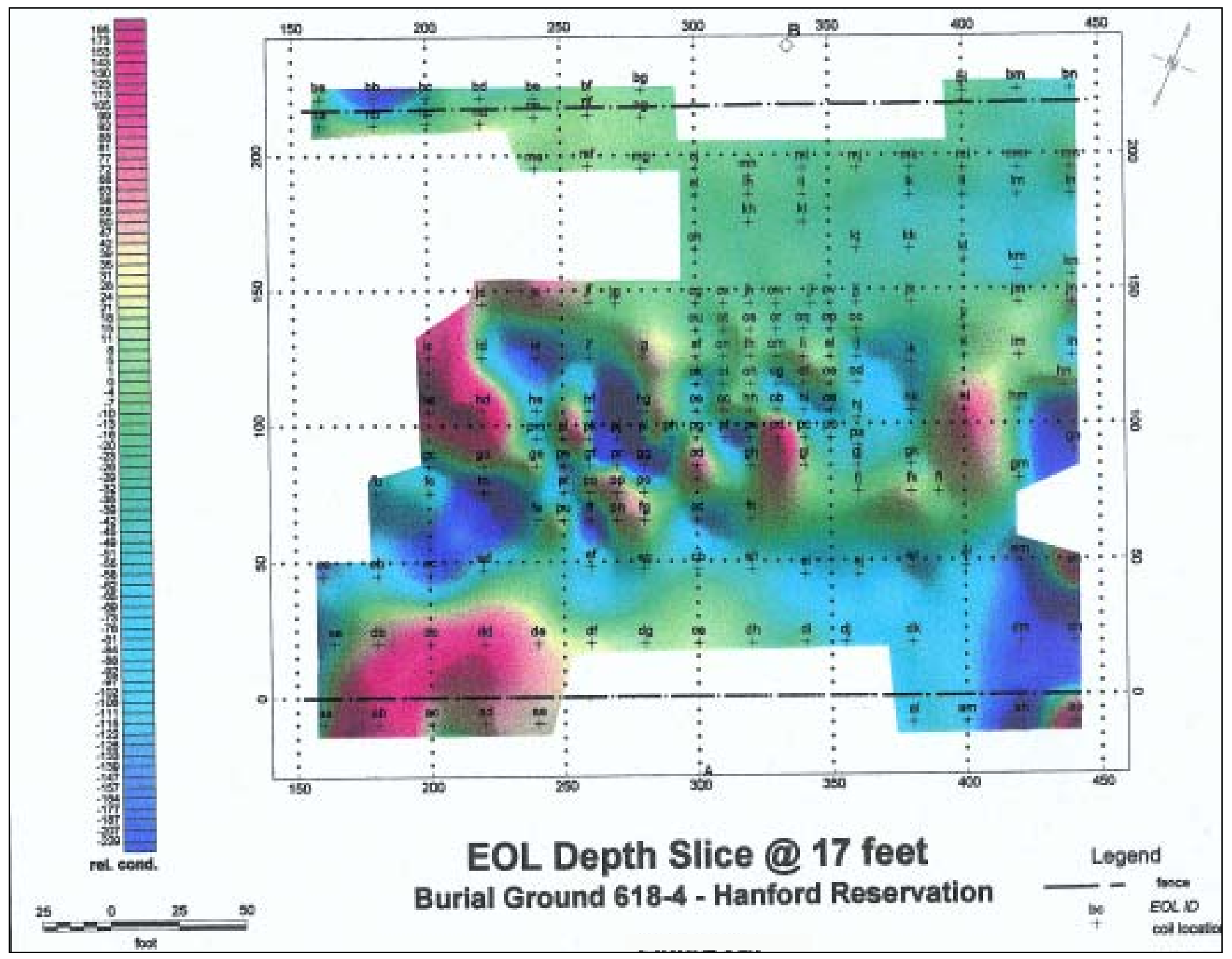

Figure 3. EOL horizontal slice at a depth of 17 feet $(5.2 \mathrm{~m})$, from WMI report 
areas where that reflection is highly irregular. In addition, the reflections below the uppermost flat reflection are also more regular and lower in amplitude than the reflections from other parts of the burial ground. Thus, the character of the GPR signals in the area of this anomaly isvisually quite distinct from the character of the signals in other areas. The GPR data were examined on a line-by-line basis to attempt to delineate the boundaries of the drum deposit. This reinterpretation was done separately for both the north-south and the east-west lines. The apparent boundaries derived from the north-south and east-west sets of GPR data are centered around the location $\mathrm{X}=104 \mathrm{~m}, \mathrm{Y}=38 \mathrm{~m}$ and are outlined in Figure 4 by irregularly shaped white and black solid lines. Where the anomaly is outlined by a solid gray line, the anomaly appeared to be present in both sets of lines; therefore, that area may have the greatest probability of containing drums.

The GPR profiles were scanned to determine if similar anomalies existed in other areas. Another anomaly, considered to be potentially associated with a deposit of drums was identified southwest of the first anomaly, with the center located at about $\mathrm{X}=75 \mathrm{~m}, \mathrm{Y}=30 \mathrm{~m}$. The GPR reflections within this anomaly have a character similar to that produced by the known drums, but the surface defined by the uppermost reflections is not as flat as it is where drums are known to be present. However, based on the overall similarity of the GPR anomalies, and the fact that the GPR anomaly at the second site occurs over an area with a strong magnetic anomaly (Figure 5), the possibility that a second cache of drums exists at the second site should be considered in planning for excavation of the remainder of the burial ground.

\section{Modeling of Magnetic Data}

One difficulty that exists with the interpretation of magnetic data is that the position of an anomaly is normally shifted in space from the actual location of the metallic object causing the anomaly. This shift is caused by the interaction of a magnetic dipole with the inclined axis of the earth's magnetic field. A modeling procedure known as reduction to the pole (RTP) can be used to model the magnetic response expected if the magnetic pole were vertical. This shifts the position of magnetic anomalies so that they are directly over the objects that cause them. This modeling procedure was employed by WMI for the magnetic data collected in 1991. The resulting data (Figure 5) more directly reflects the distribution of buried waste than the raw data.

Work is currently proceeding to produce preliminary physical and numerical models of the magnetic data from the 618-4 Burial Ground, focusing on the magnetic anomaly associated with the known deposit of drums. The goal of that work is to come up with a direct estimate of the number of drums that were buried at the site, by modeling the number of drums required to cause the observed response.

\section{Integration of GPR and Magnetic Data}

Cluster analysis was used to integrate the two data sets available for this study. The cluster analysis was performed on a subset of the two data sets (Figures 4 and 5). The subset was chosen to maximize coverage of the contaminated areas identified by the two geophysical methods, while avoiding artifacts caused by cultural objects. The major artifacts that were avoided were magnetic anomalies associated with the metallic fence surrounding the burial ground (Figure 5). Clustering was performed using the average linkage clustering algorithm. Four cluster types were identified by this process (Figure 6). The four clusters are well separated in terms of their magnetic properties and also show reasonable differences in the GPR values in 


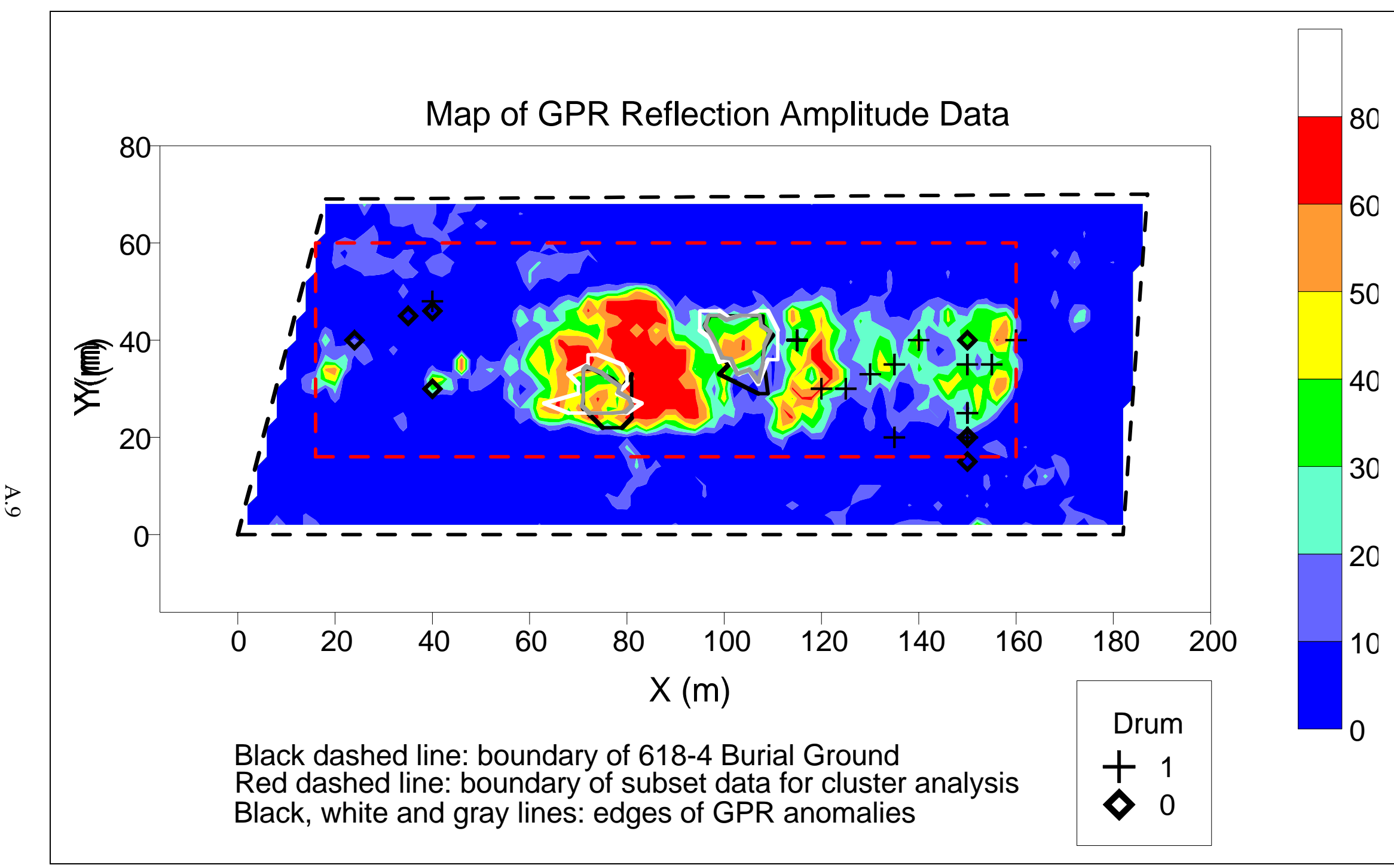

Figure 4. GPR reflection amplitudes in the 618-4 Burial Ground 


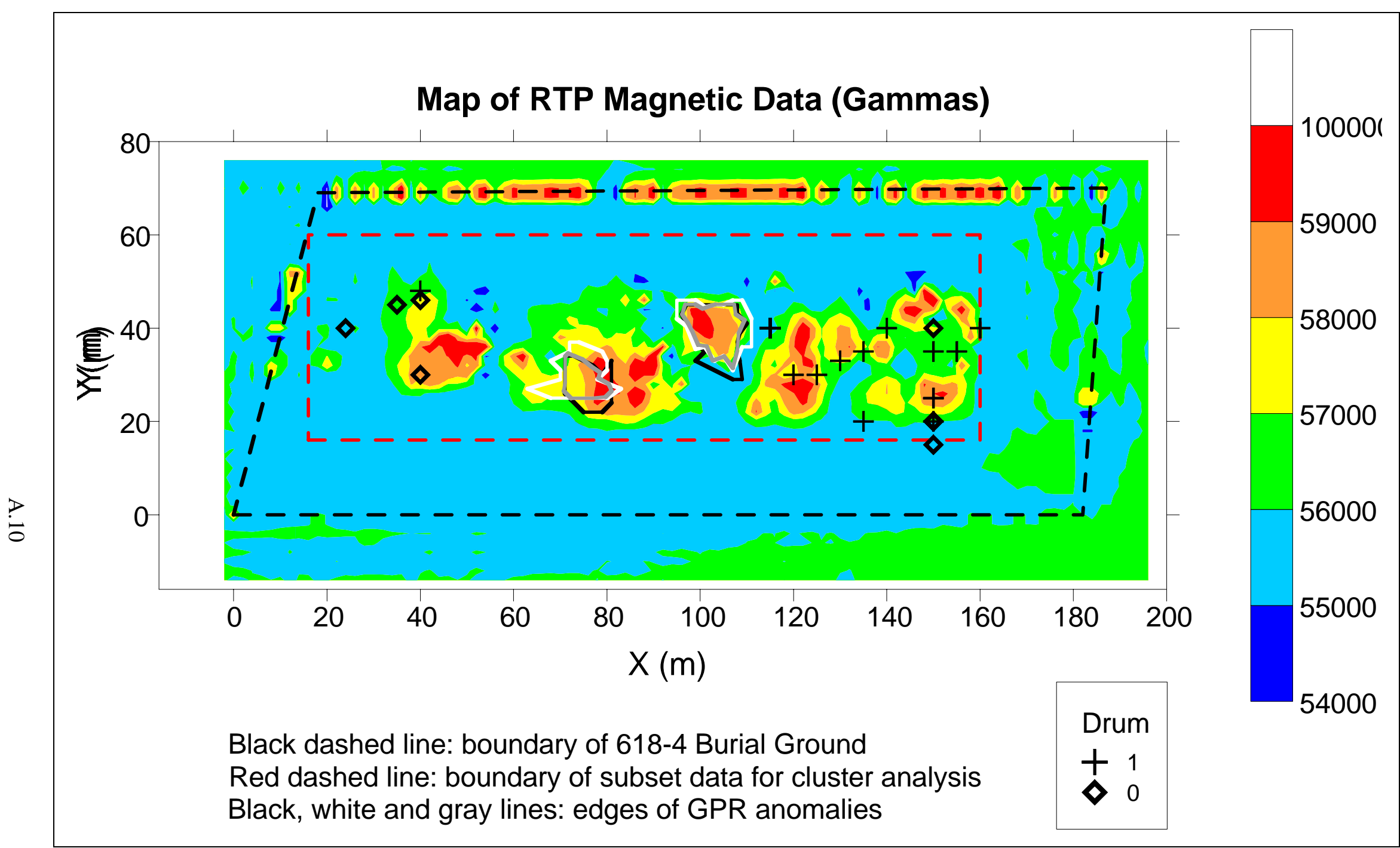

Figure 5. Total magnetic field intensity, and reduced to the pole 

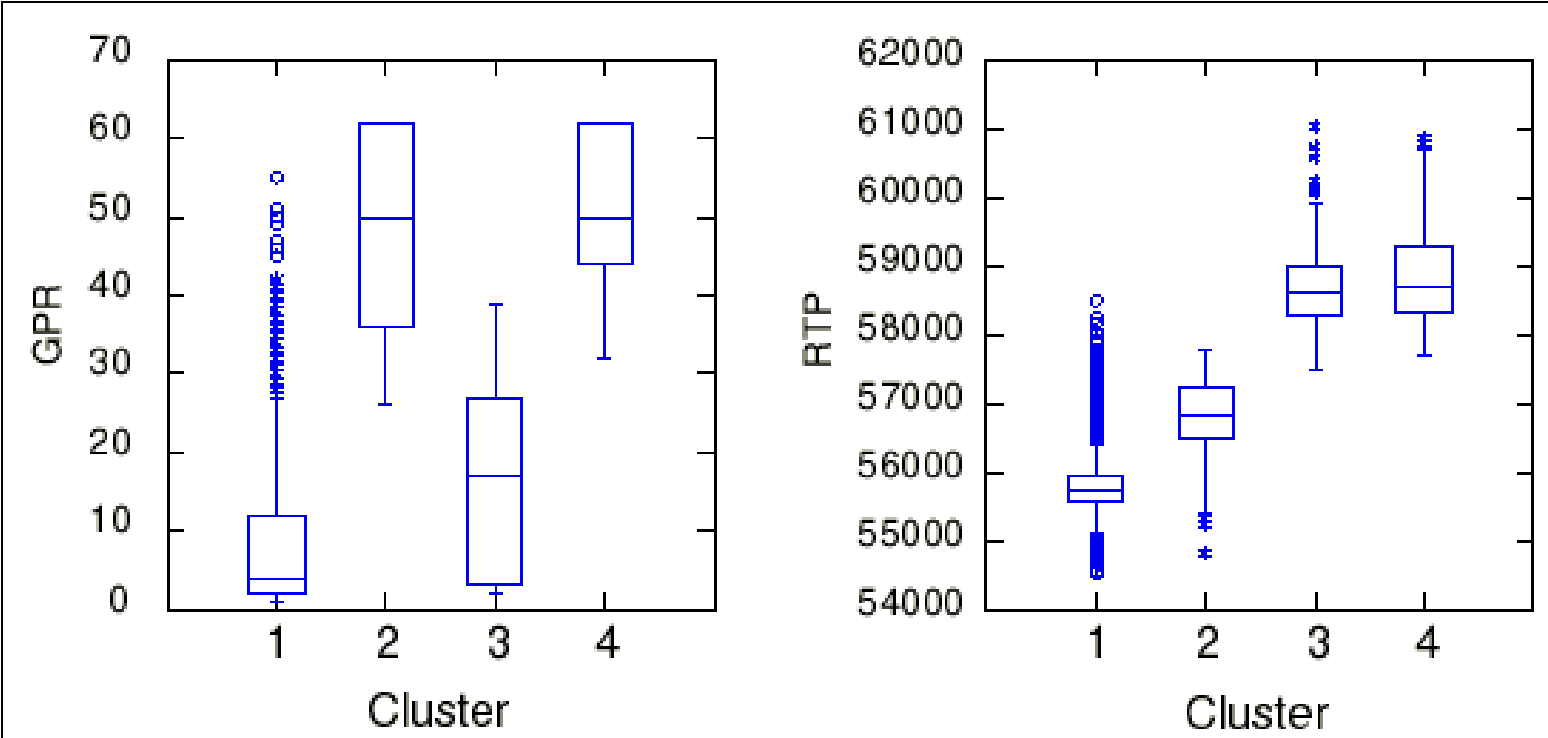

Box Plot of Geophysical Data Types Identified by Cluster Analysis

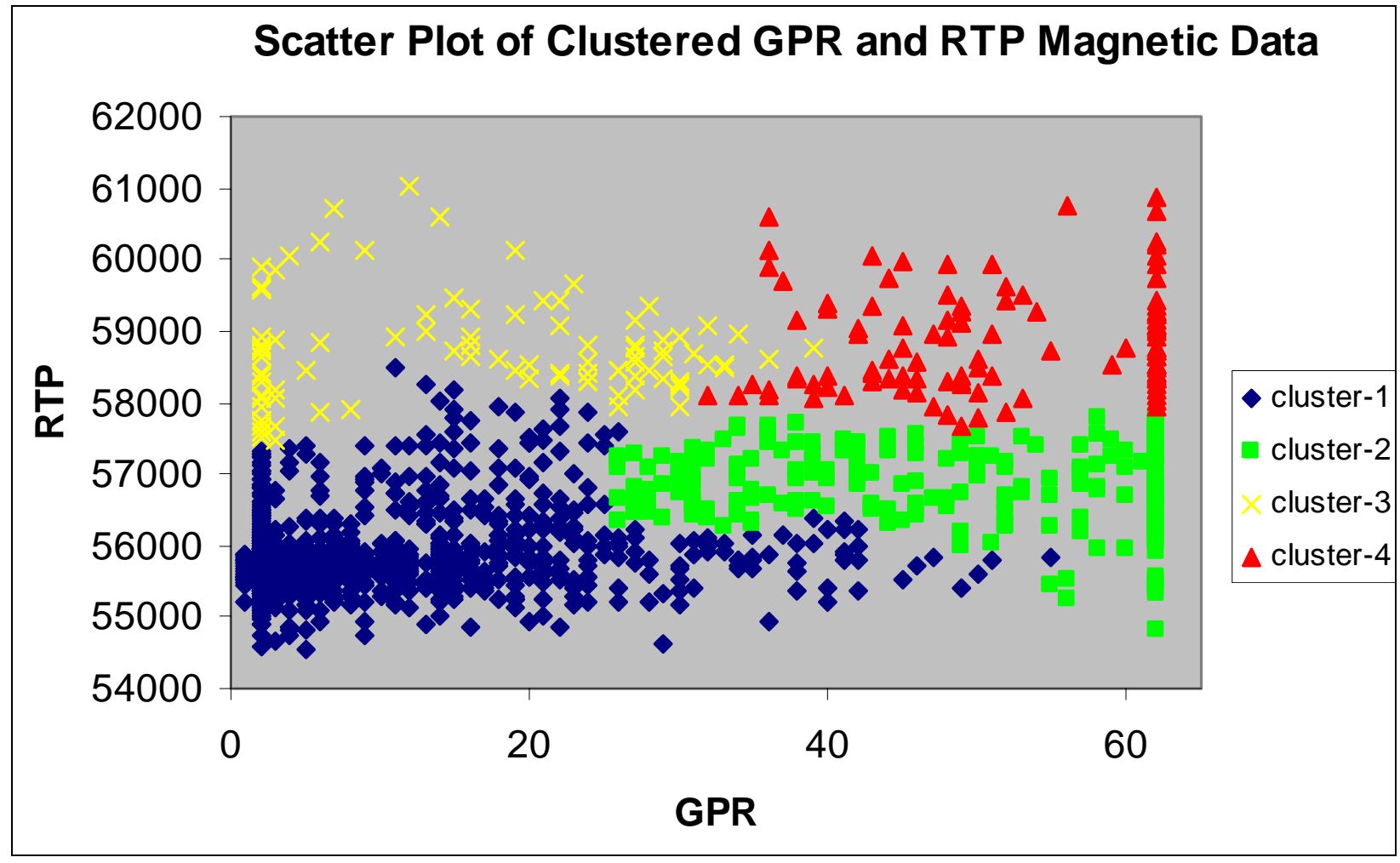

Figure 6. Scatterplots and boxplots of geophysical data types identified by cluster analysis 
each class (Figure 6). Data points falling in Cluster 1 consist of locations where both the GPR reflection amplitude and the total magnetic field strength are low. These areas would appear to have much lower concentrations of waste, or no waste at all for those areas outside the trench in which the wastes were buried. Cluster 4 consists of points with both high GPR reflection amplitudes and high total magnetic field strength. That cluster appears to be associated with locations that have high concentrations of metallic waste. The area where the drums filled with uranium shavings were found falls within that cluster type. Cluster 2 consists of sample points with relatively high GPR values, but low magnetic values. This appears to indicate areas that are contaminated, but do not contain high amounts of metallic waste. Cluster 3 consists of areas with relatively high magnetic values but where the GPR values are somewhat lower. The magnetic/GPR anomaly associated with the uranium-filled drums is composed predominately of cluster types 4 and 3 (Figure 7).

More detailed interpretation of the cluster types cannot be accomplished at this time because of the poor quality of the available ground truth data for wastes removed during the partial excavation, particularly on the locations of the wastes removed. Of the more than 400 pieces of anomalous waste recorded in a spreadsheet described in the 618-4 Burial Ground Report (Lerch 1998), only 83 had recorded locations, and of these, 60 waste items were assigned the same $\mathrm{X}, \mathrm{Y}$, and $\mathrm{Z}$ coordinates. This resulted in only about 24 potential ground-truth datapoints that can be compared to the geophysical data. These are shown in Figure 7 as +'s for drums and $\diamond ' s$ for other anomalous waste. In addition, the accuracy of the reported locations for the anomalous waste is highly questionable, because the locations were assigned by visually fixing the approximate location relative to grid markers placed on the fence (verbal communication with Rich Carlson and Jeff Lerch). For example, the location of the uraniumfilled drums removed during the partial excavation and listed in the spreadsheet is about 10 meters distant from the location estimated in the field during recent geophysical activities. The new estimated location falls within the magnetic and GPR anomalies identified with the deposit, while the location reported in the spreadsheet is not associated with any geophysical anomaly. Because of the lack of correctly located waste descriptions, we have very limited ground truth data. This means that we cannot determine distributions for the probability that particular waste types will be associated with the geophysical data types identified by the cluster analysis above. We recommend that GPS be used in the future to more accurately define the location and contents of waste excavated from the burial grounds, so that it can be calibrated with the geophysical data. This calibration data should be useful in interpretation of other burial grounds, not just the 618-4.

\section{Preliminary Conclusions}

EOL did not provide the 3-D waste definition hoped for, and provided little usable information. However, reprocessing and reinterpretation of the 1991 geophysical data did provide useful results. Of particular value were development of the GPR reflective amplitude data and reduction of the magnetic data to the pole. These data provided the foundation for the cluster analyses and identification of four different waste types within the burial ground. Reinterpretation of the reflective GPR signatures also proved useful in supporting interpretation of the two major type- 4 waste anomalies. These data also support BHI's previous estimate (Lerch 1998) that a total of up to 1500 drums may have been located at the first major type-4 anomaly, and suggest that a second major type-4 anomaly is present which may contain similar wastes (i.e., drums). 


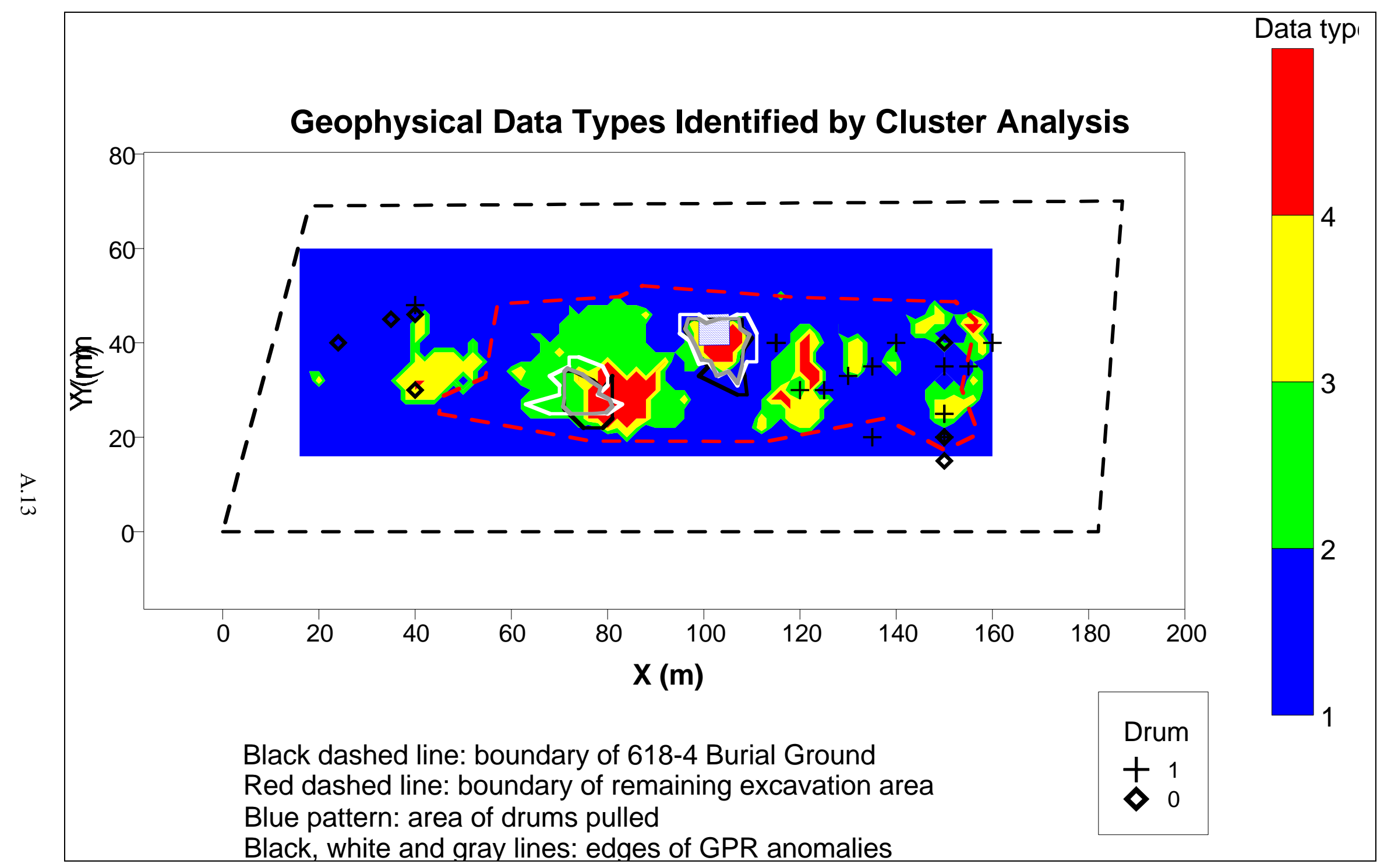

Figure 7. Map of geophysical data types from cluster analysis 


\section{Recommendations}

Given the changes in site conditions since the 1991 geophysical surveys were conducted, and the recent identification of a second GPR/magnetic anomaly of concern, we strongly recommend that additional high-resolution geophysical data (e.g., EM-61) be collected. The primary objective of these new surveys would be to define the boundaries of the two target anomalies and to compare and contrast their geophysical signatures. In addition, an effort should be made to provide detailed and accurate locations during excavation of the remaining wastes in the 618-4 Burial Ground, which can be used to establish a calibration with geophysical data from the site.

\section{References}

Lerch, J. A. August 1998. 618-4 Burial Ground Excavation Report BHI-01200, prepared by Bechtel Hanford, Inc., Richland, Washington.

WHC (Westinghouse Hanford Company). 1992. Geophysical Surveys Performed by the Automatic and Measurement Sciences Department of the Pacific Northwest Laboratory at Hanford Burial Grounds 618-4 and 618-5. WHC-SD-EN-TI-061, Rev.0. Westinghouse Hanford Company, Richland, Washington. 


\section{Appendix B}

\section{EOL Borehole Logs}




\begin{tabular}{|c|c|c|c|c|c|c|c|c|c|c|c|c|}
\hline Sample & $\begin{array}{l}\text { Smple } \\
\text { Length } \\
(\mathrm{cm})\end{array}$ & $\begin{array}{c}\text { Sample } \\
\text { Volume } \\
\text { (cm3) }\end{array}$ & $\begin{array}{c}\text { Gross Wt. } \\
\text { (g) }\end{array}$ & $\begin{array}{c}\text { Tare Wt. } \\
\text { (g) }\end{array}$ & $\begin{array}{c}\text { Moisture Wt. } \\
(\mathrm{g})\end{array}$ & $\begin{array}{c}\text { Net Wt. } \\
(\mathrm{g})\end{array}$ & $\begin{array}{c}\text { Bulk Density } \\
(\mathrm{g} / \mathrm{cm} 3)\end{array}$ & $\begin{array}{c}\text { Gravimetric } \\
\text { Moisture } \\
(\mathrm{Wt} \%)\end{array}$ & $\begin{array}{c}\text { Volume } \\
\text { Moisture } \\
\text { (Vol \%) }\end{array}$ & $E(V)$ & I (mA) & R (ohms) \\
\hline B8780-1--6.0'-6.5' & 15.00 & 1076.71 & 2007.37 & 174.12 & 75.97 & 1757.28 & 1.632 & $4.3 \%$ & $7.1 \%$ & 1.470 & 0.2620 & 5610.7 \\
\hline B8780-3 --16'-16.5' & 14.59 & 1047.28 & 2158.20 & 350.96 & 45.45 & 1761.79 & 1.682 & $2.6 \%$ & $4.3 \%$ & 2.261 & 0.3230 & 7000.0 \\
\hline B8780-4--21'-21.5' & 15.00 & 1076.71 & 2405.85 & 346.66 & 47.55 & 2011.65 & 1.868 & $2.4 \%$ & $4.4 \%$ & 0.970 & 0.1110 & 8738.7 \\
\hline B8780-5 --26'-26.5' & 14.52 & 1042.25 & 2747.10 & 447.20 & 45.73 & 2254.17 & 2.163 & $2.0 \%$ & $4.4 \%$ & 0.395 & 0.0640 & 6171.9 \\
\hline B8780-2 --10'-10.5' & 13.94 & 1000.62 & 2443.65 & 370.42 & 137.49 & 1935.74 & 1.935 & $7.1 \%$ & $13.7 \%$ & 1.895 & 0.7410 & 2557.4 \\
\hline B8780-6--31.5'-32' & 10.50 & 753.70 & 1735.35 & 333.70 & 42.73 & 1358.92 & 1.803 & $3.1 \%$ & $5.7 \%$ & 2.424 & 0.3200 & 7575.0 \\
\hline B8781-1--6'-6.5' & 15.00 & 1076.71 & 2180.80 & 409.55 & 59.09 & 1712.16 & 1.590 & $3.5 \%$ & $5.5 \%$ & 2.136 & 0.2250 & 9493.3 \\
\hline B8781-3--16'-16.5' & 14.63 & 1050.08 & 2701.55 & 371.43 & 46.62 & 2283.50 & 2.175 & $2.0 \%$ & $4.4 \%$ & NA & NA & NA \\
\hline B8781-3--15.5'-16' & 14.37 & 1031.13 & 2669.15 & 529.36 & 65.48 & 2074.31 & 2.012 & $3.2 \%$ & $6.3 \%$ & 1.424 & 0.2700 & 5274.1 \\
\hline B8781-2--10'-10.5' & 14.81 & 1063.36 & 2335.00 & 358.05 & 81.84 & 1895.11 & 1.782 & $4.3 \%$ & $7.7 \%$ & 2.761 & 0.4330 & 6376.4 \\
\hline B8781-4--21'-21.5' & 13.97 & 1002.63 & 2873.15 & 587.45 & 40.53 & 2245.17 & 2.239 & $1.8 \%$ & $4.0 \%$ & 0.958 & 0.1140 & 8403.5 \\
\hline B8781-5--25.5'-26' & 14.31 & 1027.32 & 2400.65 & 311.43 & 51.46 & 2037.76 & 1.984 & $2.5 \%$ & $5.0 \%$ & 1.144 & 0.1250 & 9152.0 \\
\hline B8781-6--30.5'-31' & 14.63 & 1050.15 & 2658.15 & 330.74 & 84.05 & 2243.36 & 2.136 & $3.7 \%$ & $8.0 \%$ & 4.010 & 0.3070 & 13061.9 \\
\hline
\end{tabular}




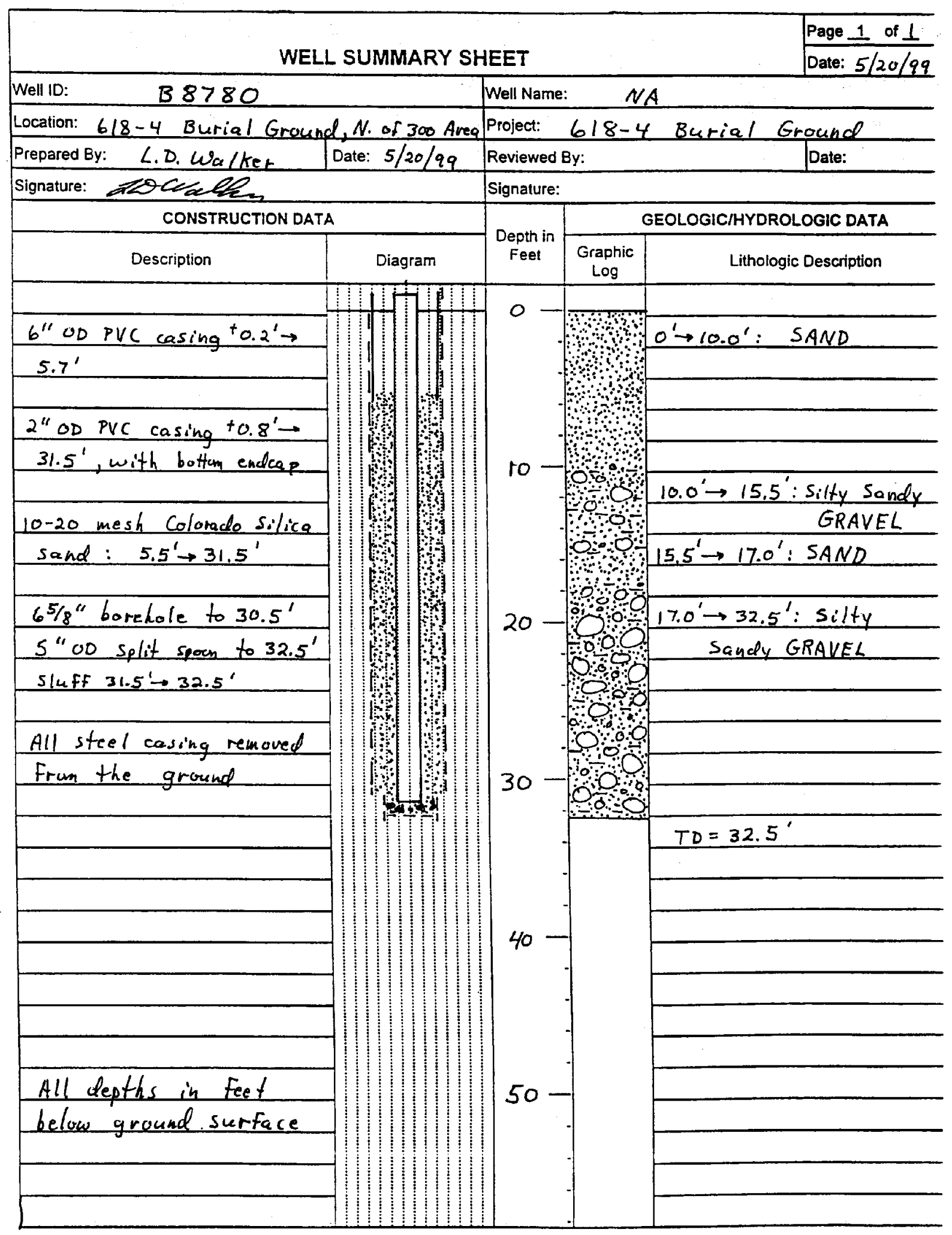

BHI-EE-189 (12/97) 


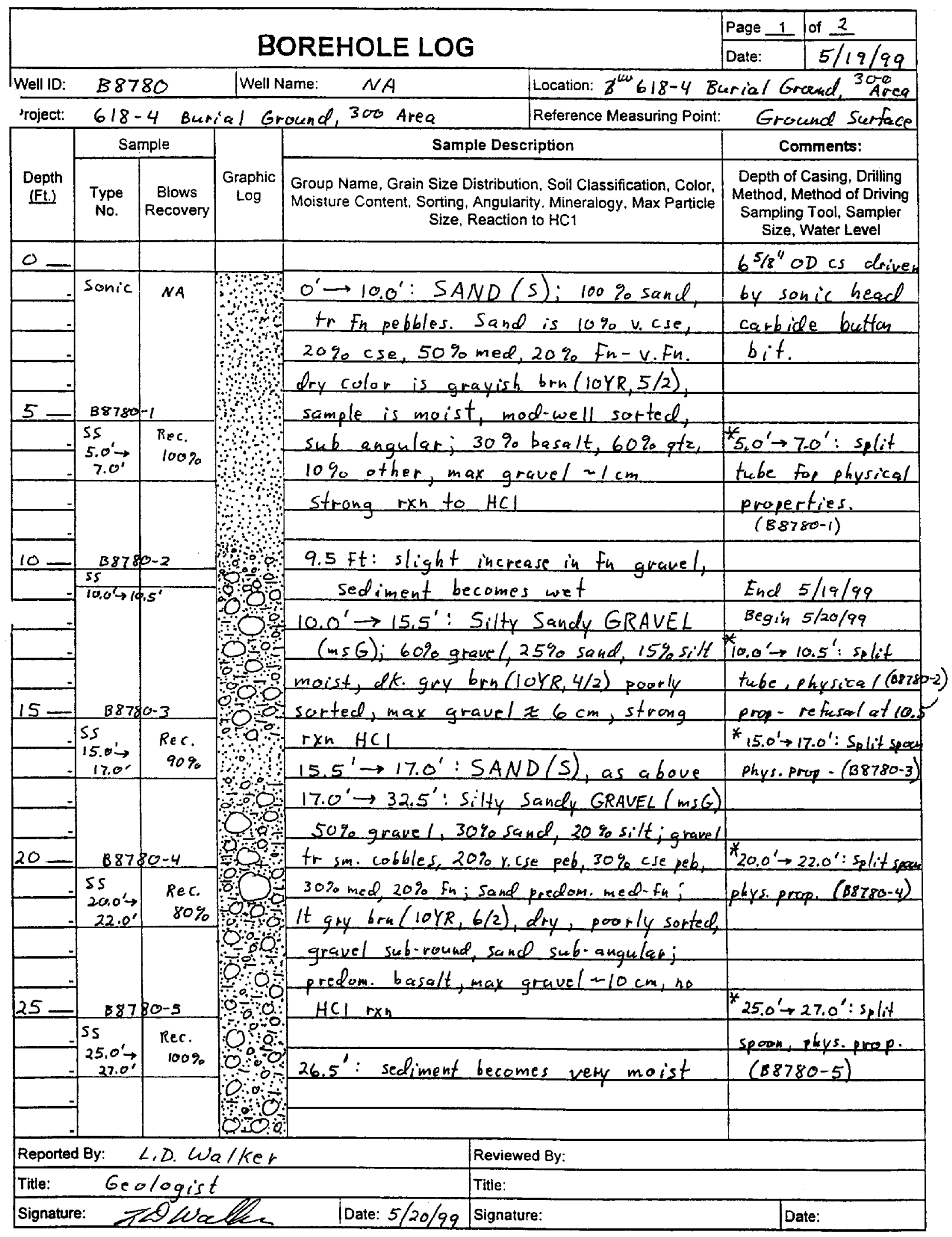

BHI-EE-183 (12/97) 


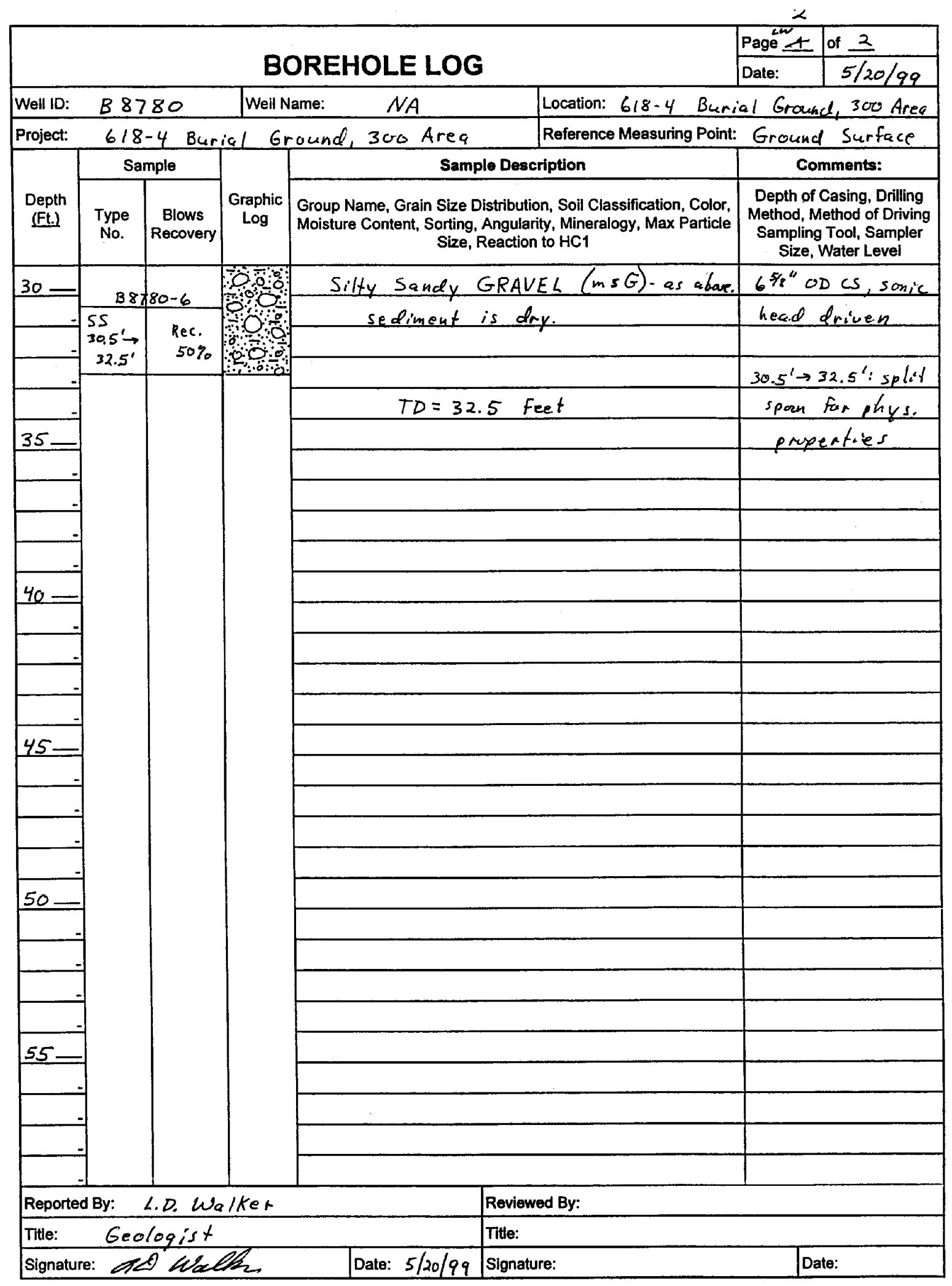

BHI-EE-183 (12/97) 


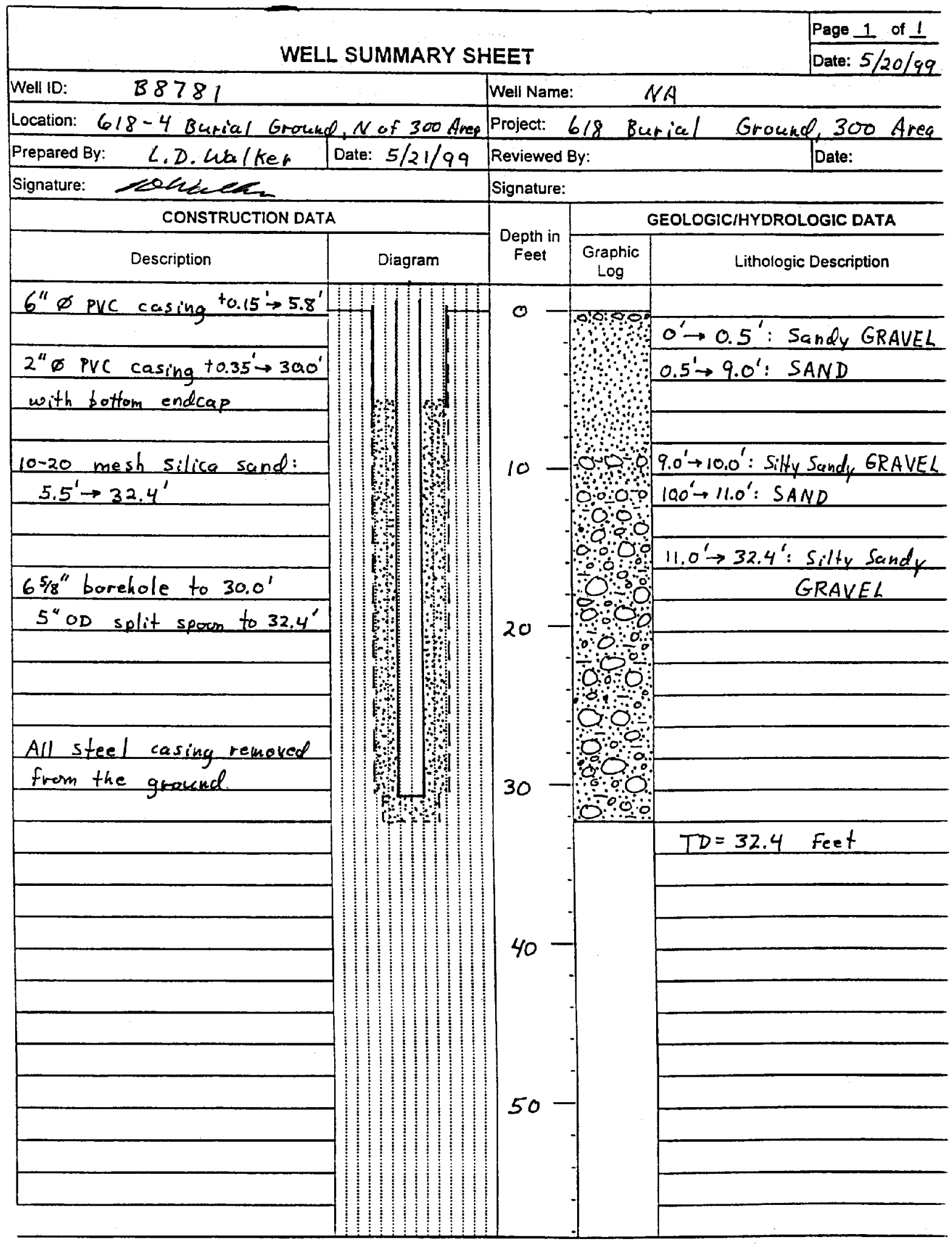

BHI-EE-189 (12/97) 


\begin{tabular}{|c|c|c|c|c|c|c|}
\hline \multirow{2}{*}{\multicolumn{6}{|c|}{ BOREHOLE LOG }} & Page 1 of 2 \\
\hline & & & & & & \begin{tabular}{|l|l} 
Date: & \\
\end{tabular} \\
\hline Well ID: & \multicolumn{2}{|c|}{ B8781 } & \multicolumn{2}{|c|}{ Well Name: $\quad N A$} & \\
\hline Project: & \multicolumn{2}{|c|}{$618-4$ Burie } & \multirow{2}{*}{\multicolumn{3}{|c|}{ a) Grand, 300 Area $\frac{\text { Reference Measuring Point: }}{\text { Sample Description }}$}} & \\
\hline \multirow[b]{2}{*}{$\begin{array}{l}\text { Depth } \\
\text { (Ft.) }\end{array}$} & \multicolumn{2}{|c|}{ Sample } & & & & Comments: \\
\hline & \begin{tabular}{c|c} 
Type & \\
No. & $F$
\end{tabular} & $\begin{array}{c}\text { Blows } \\
\text { Recovery }\end{array}$ & $\begin{array}{l}\text { Graphic } \\
\text { Log }\end{array}$ & \multicolumn{2}{|c|}{$\begin{array}{l}\text { Group Name, Grain Size Distribution, Soil Classification, Color, } \\
\text { Moisture Content, Sorting, Angularity, Mineralogy, Max Particle } \\
\text { Size, Reaction to HC1 }\end{array}$} & $\begin{array}{l}\text { Depth of Casing, Drilling } \\
\text { Method, Method of Driving } \\
\text { Sampling Tool, Sampler } \\
\text { Size, Water Level }\end{array}$ \\
\hline $0=$ & & & & & & $65 / 8^{\prime \prime O D}$ es casing \\
\hline & \multirow[t]{5}{*}{ Sonic } & \multirow[t]{5}{*}{ NA } & \multirow{5}{*}{ की } & \multicolumn{2}{|c|}{$0^{\prime} \rightarrow 0.5^{\prime}:$ Sandy GRAVEL $(s G)$} & driven by schic head \\
\hline & & & & \multicolumn{2}{|c|}{ construction fill } & \\
\hline & & & & \multirow{2}{*}{\multicolumn{2}{|c|}{$\frac{0.5^{\prime} \rightarrow 9.0^{\circ}: \operatorname{SAND}(5) \quad 100 \% \text { sand }}{10 \% \mathrm{v} \cdot \mathrm{cse}, 20 \% \mathrm{cu} 30 \% \mathrm{cse} 40 \% \mathrm{med}}$}} & \\
\hline & & & & & & \\
\hline 5 & & & & \multicolumn{2}{|c|}{$2090 f_{n}-v, f_{h}$, gryish brown $(10 Y 8,5 / 2)$} & $*_{5.0^{\prime} \rightarrow 7.0^{\prime}: \text { split }}$ \\
\hline & \multirow{2}{*}{$\begin{array}{c}55 \\
5.0^{\prime} \rightarrow \\
7.0^{\prime}\end{array}$} & \multirow{2}{*}{$\begin{array}{l}\operatorname{Rec} \\
100 \% \\
\end{array}$} & & \multirow{2}{*}{\multicolumn{2}{|c|}{$\begin{array}{l}\text { moist, mad-well sorted, sub angular, } \\
40 \% \text { basalt, } 5090 \text { atz, } 1090 \text { other, strang }\end{array}$}} & spoon for physical \\
\hline & & & & & & properties \\
\hline & & & & $\mathrm{rxn}$ to $\mathrm{HCl}$ & & \\
\hline & & & & $9.0^{\circ} \rightarrow 10.0^{\prime}: \mathrm{Sil}$ & Ity Sandy GRAVEL (msG) & \\
\hline $10=$ & $B 878$ & $81-2$ & $0: 00$ & $50 \%$ gravel, 30 & 90 sand, $20 \%$ silt & * $10,0^{\prime} \rightarrow 11.5^{\prime}:$ split \\
\hline & ss $10.0 \rightarrow$ & Rec. & in & $10.0^{\prime} \rightarrow 11.0^{\prime}: 5$ & AND (s)-as above & spom, plys prop. \\
\hline & & 10090 & $0 \%$ & tr gravel & & (reflesal af $\left.11.5^{\prime}\right)$ \\
\hline & & & 0 & $11.0^{\prime} \rightarrow 32.4^{\prime}: 5 i$ & Ity Sandy GRAVEL(mSG) & \\
\hline & & & $0: 0$ & $40 \%$ gravel, 50 & o\% sance, $10 \%$ silt & \\
\hline 15. & B8781 & -3 & 0 & gravel tr cobble & $=10 \%$ k cse, $30 \%$ cse, & $*_{15.0^{\prime} \rightarrow 17.0^{\prime}: \text { split }}$ \\
\hline & $3 s_{1}$ & Rec. & 0 & $30 \% \mathrm{med}, 30 \%$ & $f_{n}-v \cdot f_{4}$, sand $20 \%$ v.cse, & spows, phys. prob \\
\hline & $\begin{array}{r}15.0 \\
17.0^{\prime} \\
\end{array}$ & $80 \%$ & 00 & $40 \%$ cse, $30 \% \mathrm{~m}$ & ned, $10 \% f_{n}-6, f_{n}$, gryish & \\
\hline & & & 00 & brown, dry, & poorly sorted, gravel & \\
\hline & & & 0 & sub-round, san & nd sub-angular, max & \\
\hline 20 & 88781 & -4 & 00 & gravel $=10 \mathrm{~cm}$ & 4 ; sand $40 \%$ basalt $60 \%$ & ${ }^{*} 20.0^{\prime} \rightarrow 22.0^{\prime}:$ splift \\
\hline & $\begin{array}{l}55 \\
20.0 \rightarrow\end{array}$ & Rec. & OQ: & gtalother, no & $\mathrm{rxnH} H \mathrm{Cl}$ & sporn, phys prop. \\
\hline & $22.0^{\prime}$ & $100 \%$ & $=0 ;$ & $21.5^{\prime}:$ sediment & moist, silt decrease & \\
\hline & & & 0 & to $\approx 590$ & & \\
\hline & & & 00 & & & $*_{25.0^{\prime} \rightarrow 27.0^{\prime}: \text { split }}$ \\
\hline $25=$ & 88781 & -5 & $0: 0.0$ & & & spoen, phys prop. \\
\hline & $\begin{array}{l}55 \\
25,0\end{array}$ & Rec. & 00 & & & \\
\hline & $27.0^{\prime}$ & $100 \%$ & 000 & & & \\
\hline & & & 000 & & & \\
\hline Reported & & L.D. Wo & alker & & Reviewed By: & \\
\hline Title: & Geo & logist & & & Title: & \\
\hline Signature & : TC & $0 \mathrm{Wa}$ & $l_{2}$ & Date: $5 / 20 / 99$ & Signature: & Date: \\
\hline
\end{tabular}

BHI-EE-183 (12/97) 


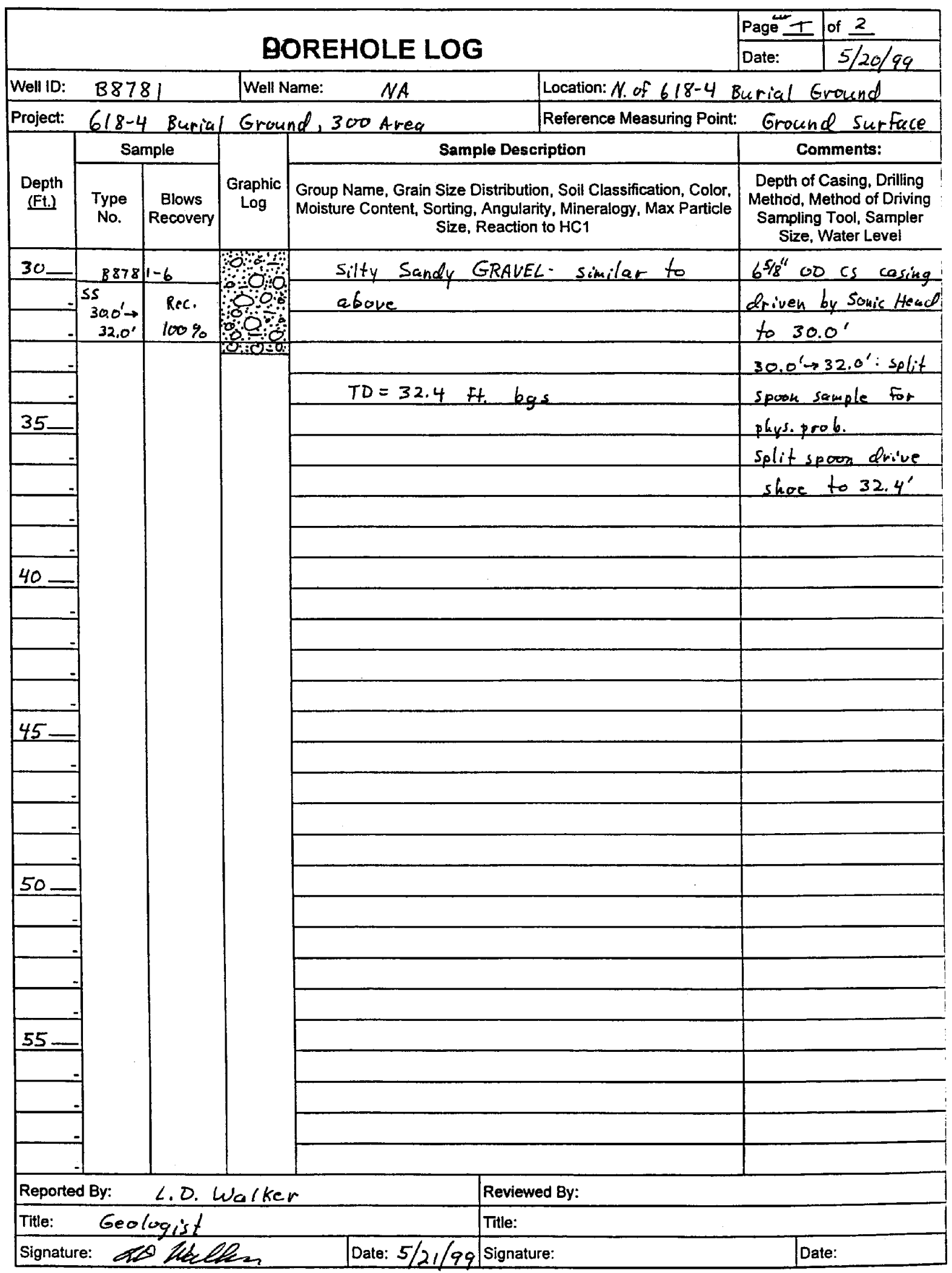

BHI-EE-183 (12/97) 
Appendix C

EOL Data Report 


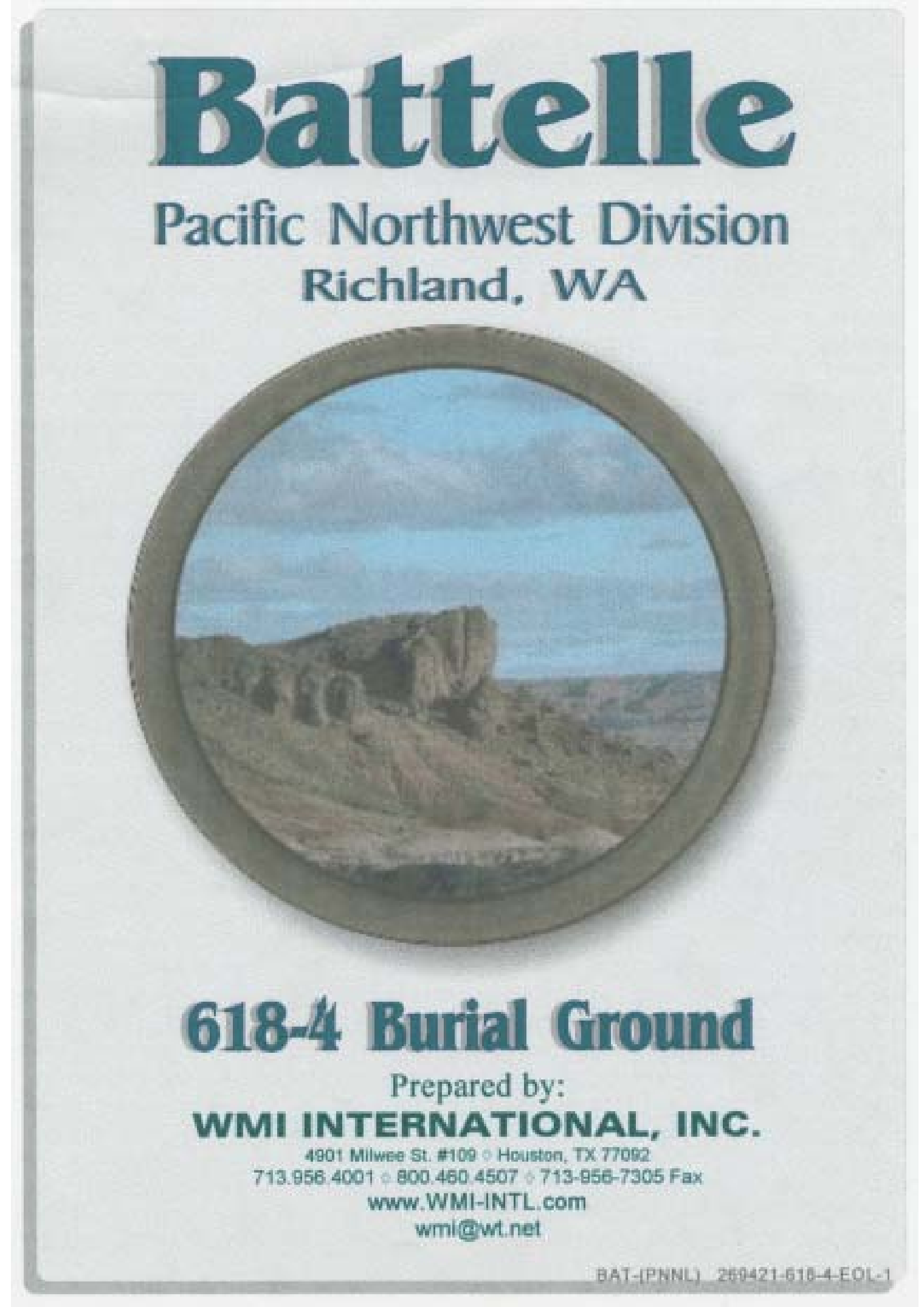

C. 1 
List of Figures $\ldots \ldots \ldots \ldots \ldots \ldots \ldots \ldots \ldots \ldots$

Z Slices $\ldots \ldots \ldots \ldots \ldots \ldots \ldots \ldots$ ii

X Slices $\ldots \ldots \ldots \ldots \ldots \ldots \ldots \ldots \ldots$ iii

Y Slices . . . . . . . . . . . . . . . . . . . . iv

W Slices $\ldots \ldots \ldots \ldots \ldots \ldots \ldots \ldots \ldots \ldots$

Block Model \& Chair Cut ............... vi

RTP Magnetic Data .................. vii

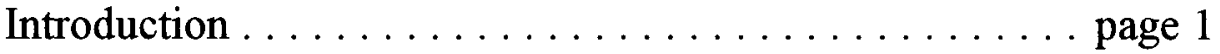

Background of Site $\ldots \ldots \ldots \ldots \ldots \ldots$ page 2

Electromagnetic Offset Logging $\ldots \ldots \ldots \ldots \ldots$ page 3

EOL Survey Grid @ Burial Ground 618-4 ........... page 5

EOL Survey Logistics . . . . . . . . . . . . . page 5

EOL Data Processing procedures $\ldots \ldots \ldots \ldots \ldots$ page 6

EOL Data Visualization $\ldots \ldots \ldots \ldots \ldots \ldots$ page 7

Ground Magnetic Data $\ldots \ldots \ldots \ldots \ldots \ldots$ page 8

Discussion of Results $\ldots \ldots \ldots \ldots \ldots \ldots$ page 8

Summary Conclusions \& Recommendations $\ldots \ldots \ldots$ page 9

References ..................... page 11 


\section{LIST OF FIGURES}

Figure 1 . . . . . . . . Layout of the 618-4 Burial Ground

Figure $1 \mathrm{a} \ldots \ldots \ldots$. . . . Transmitter Loop at Data Point "HG"

Figure $1 \mathrm{~b} \ldots . . \ldots \ldots$. . . . Transmitter Look at Data Point "MK"

Figure 1c ............. WMI Van \& Transmitter Loop at "CK"

Figure $2 \ldots \ldots \ldots \ldots$. . . Suite of Response Curves

Figure $3 \ldots \ldots \ldots$. . . . Secondary Field Response

Figure $4 \ldots \ldots \ldots \ldots$ EOL Location Map

Figure $5 \ldots \ldots \ldots \ldots$. . . Reduced to Pole (RTP) Magnetic Data

Figure $6 \ldots \ldots \ldots \ldots \ldots$ Reduced to Pole (RTP) Magnetic Data (Window)

Figure $7 \ldots \ldots \ldots \ldots$ Interpretation Map 


\section{Z SLICES}

$Z-1 \ldots \ldots \ldots \ldots \ldots$ Depth of 10 feet

$Z-2 \ldots \ldots \ldots \ldots \ldots \ldots$ Depth of 11 feet

$Z-3 \ldots \ldots \ldots \ldots$ Depth of 12 feet

$Z-4 \ldots \ldots \ldots \ldots$ Depth of 13 feet

$Z-5 \ldots \ldots \ldots \ldots$ Depth of 14 feet

$Z-6 \ldots \ldots \ldots \ldots$ Depth of 15 feet

$Z-7 \ldots \ldots \ldots \ldots \ldots$ Depth of 16 feet

$Z-8 \ldots \ldots \ldots \ldots \ldots \ldots$ Depth of 17 feet

$Z-9 \ldots \ldots \ldots \ldots$ Depth of 18 feet

$Z-10 \ldots \ldots \ldots \ldots$ Depth of 19 feet

$\mathrm{Z}-11 \ldots \ldots \ldots \ldots$ Depth of 20 feet

$\mathrm{Z}-12 \ldots \ldots \ldots \ldots \ldots$ Depth of 21 feet

$Z-13 \ldots \ldots \ldots \ldots$ Depth of 22 feet

$Z-14 \ldots \ldots \ldots \ldots$ Depth of 23 feet

$Z-15 \ldots \ldots \ldots \ldots \ldots \ldots$ Depth of 24 feet

$Z-16 \ldots \ldots \ldots \ldots$ Depth of 25 feet

$Z-17 \ldots \ldots \ldots \ldots$ Depth of 26 feet

$Z-18 \ldots \ldots \ldots \ldots$ Depth of 27 feet

$Z-19 \ldots \ldots \ldots \ldots \ldots$ Depth of 28 feet

$\mathrm{Z}-20 \ldots \ldots \ldots \ldots \ldots$ Depth of 29 feet

$Z-21 \ldots \ldots \ldots \ldots$ Depth of 30 feet 


\section{$X$ SLICES}

$X-1 \ldots \ldots \ldots \ldots \ldots$ X Slice at 160 feet East $\mathrm{X}-2 \ldots \ldots \ldots \ldots \ldots \ldots$. $\ldots$ Slice at 180 feet East

$\mathrm{X}-3 \ldots \ldots \ldots \ldots \ldots$. . . . Slice at 200 feet East

$X-4 \ldots \ldots \ldots \ldots \ldots$ Slice at 220 feet East

$X-5 \ldots \ldots \ldots \ldots \ldots \ldots$ X Slice at 240 feet East

$\mathrm{X}-6 \ldots \ldots \ldots \ldots \ldots$. X Slice at 250 feet East

$\mathrm{X}-7 \ldots \ldots \ldots \ldots \ldots \ldots$ X Slice at 260 feet East

$\mathrm{X}-8 \ldots \ldots \ldots \ldots \ldots \ldots \ldots$ X Slice at 270 feet East

$\mathrm{X}-9 \ldots \ldots \ldots \ldots \ldots \ldots$ Slice at 280 feet East

$\mathrm{X}-10 \ldots \ldots \ldots \ldots \ldots \ldots$ X Slice at 300 feet East

$\mathrm{X}-11 \ldots \ldots \ldots \ldots \ldots$ X Slice at 310 feet East

$\mathrm{X}-12 \ldots \ldots \ldots \ldots \ldots \ldots$ Slice at 320 feet East

$\mathrm{X}-13 \ldots \ldots \ldots \ldots \ldots$. $\ldots$ Slice at 330 feet East

$\mathrm{X}-14 \ldots \ldots \ldots \ldots \ldots \ldots$ X Slice at 340 feet East

$\mathrm{X}-15 \ldots \ldots \ldots \ldots \ldots$ X Slice at 350 feet East

$\mathrm{X}-16 \ldots \ldots \ldots \ldots \ldots \ldots$ X Slice at 360 feet East

$\mathrm{X}-17 \ldots \ldots \ldots \ldots \ldots \ldots$ Slice at 380 feet East

$X-18 \ldots \ldots \ldots \ldots \ldots \ldots$ Slice at 400 feet East

$\mathrm{X}-19 \ldots \ldots \ldots \ldots \ldots \ldots$ X Slice at 420 feet East

$\mathrm{X}-20 \ldots \ldots \ldots \ldots \ldots \ldots$ Slice at 440 feet East 


\section{Y SLICES}

\begin{tabular}{|c|c|}
\hline $\mathrm{Y}-1$ & Y Slice at -10 feet North \\
\hline $\mathrm{Y}-2$ & Y Slice at 20 feet North \\
\hline$Y-3$ & Y Slice at 45 feet North \\
\hline$Y-4$ & Y Slice at 65 feet North \\
\hline$Y-5$ & Y Slice at 75 feet North \\
\hline Y -6 & Y Slice at 85 feet North \\
\hline$Y-7$ & Y Slice at 95 feet North \\
\hline$Y-8$ & Y Slice at 105 feet North \\
\hline Y - 9 & Y Slice at 115 feet North \\
\hline$Y-10$ & Y Slice at 125 feet North \\
\hline$Y-11$ & Y Slice at 135 feet North \\
\hline$Y-12$ & Y Slice at 145 feet North \\
\hline$Y-13$ & Y Slice at 155 feet North \\
\hline$Y-14$ & Y Slice at 165 feet North \\
\hline$Y-15$ & Y Slice at 185 feet North \\
\hline$Y-16$ & Y Slice at 195 feet North \\
\hline Y - 17 & Y Slice at 210 feet North \\
\hline Y -18 & Y Slice at 220 feet North \\
\hline
\end{tabular}




\section{W SLICES}

W $-1 \ldots \ldots$. Relative Conductivity Data - Depth 10 Feet

W $-2 \ldots \ldots$ Relative Conductivity Data - Depth 12 Feet

W $-3 \ldots \ldots$. . . Relative Conductivity Data - Depth 14 Feet

W $-4 \ldots \ldots$. . Relative Conductivity Data - Depth 16 Feet

W $-5 \ldots \ldots$. Relative Conductivity Data - Depth 18 Feet

W $-6 \ldots \ldots$. . Relative Conductivity Data - Depth 20 Feet

W $-7 \ldots \ldots$. . . Relative Conductivity Data - Depth 22 Feet

W $-8 \ldots \ldots \ldots$ Relative Conductivity Data - Depth 24 Feet

W $-9 \ldots \ldots$. . . . Relative Conductivity Data - Depth 26 Feet

W $-10 \ldots \ldots$. . . Relative Conductivity Data - Depth 28 Feet

W $-11 \ldots \ldots \ldots$ Relative Conductivity Data - Depth 30 Feet 


\section{BLOCK MODEL E CHAIR CUT}

B $-1 \ldots \ldots \ldots \ldots$ Conducting Block Model

B $-2 \ldots \ldots \ldots \ldots$ Conducting Block Model View from SE

CC $-1 \ldots \ldots \ldots \ldots$ Zone 1 View from SE Corner

$\mathrm{CC}-2 \ldots \ldots \ldots \ldots$ Zone 2 View from SE Corner

$\mathrm{CC}-3 \ldots \ldots \ldots \ldots$ Zone 1 View from $\mathrm{NE}$ Corner

$\mathrm{CC}-4 \ldots \ldots \ldots \ldots \ldots$ Zone 2 View from NE Corner

ISO $-1 \ldots \ldots \ldots \ldots$. $\ldots \ldots$ View from SE Corner 


\section{R. T. P. MAGNETIC DATA}

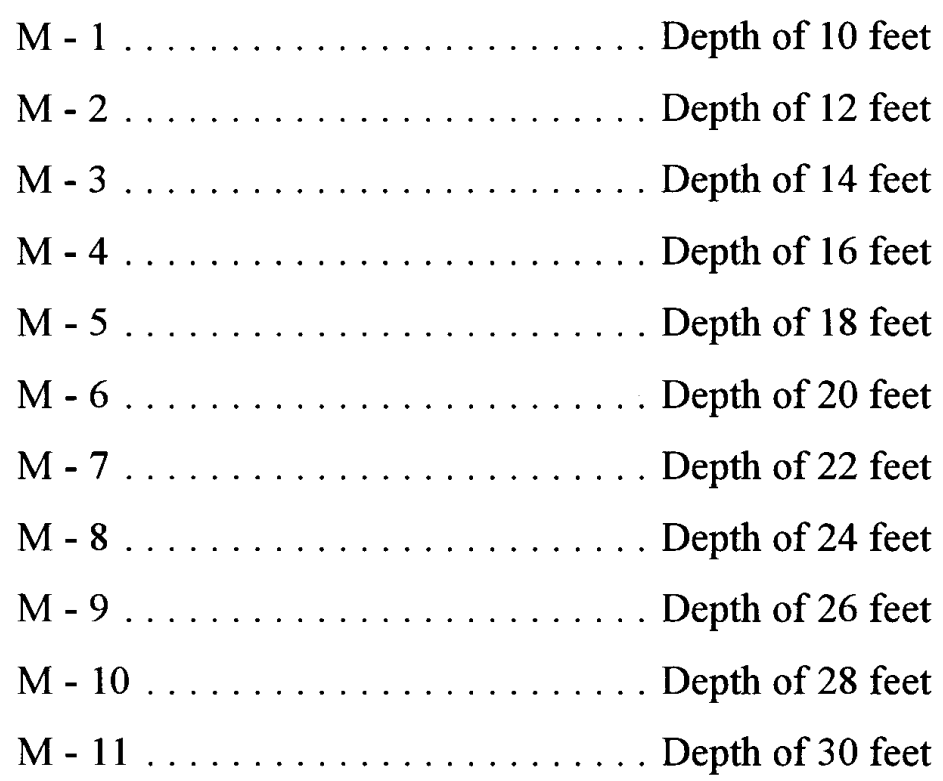

-vii-

C.9 


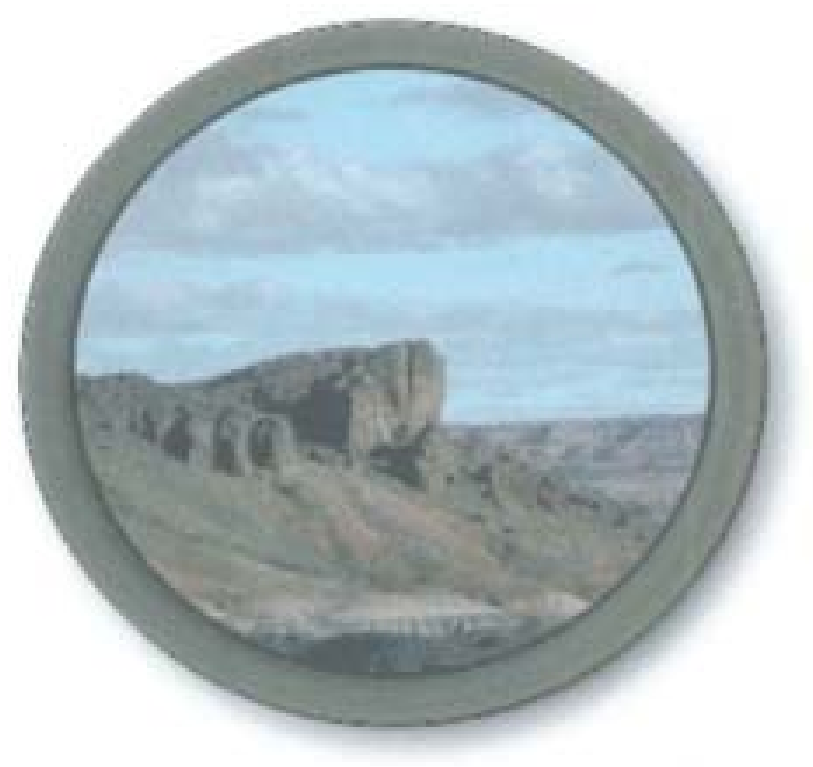

\section{INTRDDUCTIDN}

WMI International, Inc. (WMI) conducted an Electromagnetic Offset Logging (EOL) survey over Burial Ground 618-4 to delineate the depth and lateral extent of the conductive zones within the subsurface. Such zones are assumed to be due to buried waste and debris with the primary constituents being ferromagnetic and non-magnetic metallic material.

EOL data were acquired utilizing a multiplicity of EOL transmitter locations from June $4^{\text {th }}$ through June $12^{\mathrm{a}}, 1999$. The data were processed by ENW Services of Denver, Colorado to obtain a data set corresponding to the volumetric variation in conductivity. ENW then visualized the results as a series of multiple views reflecting the spatial variation in conductivity within the subsurface. They are included in the appendices of this report as a) color contour plan maps of conductivity at various depth levels (Z Slices), b) cross-sectional fence diagrams in the grid-north ( $\mathrm{Y}$-slice) and grid-east ( $\mathrm{X}$-slice) directions, and c) 3D volumetric renderings as block, chair cut, and iso-surfaces views. In addition, ground magnetic data acquired in 1991 were re-processed and visualized as a suite of color contour maps with fine contours of the relative conductivity data with respect to depth (W Slices).

BaI-(PNAL) 269421-618-4EO-1

C.10 


\section{BACKGRDUND QN GITE}

The site is located just north of the Hanford Site's 300 Area, approximately $1.6 \mathrm{~km}$ (1 mile) north of Richland, WA. (Figure 1) It is a low-level radioactive waste landfill within a restricted area controlled and operated by Bechtel Hanford, Inc. (HBI). This burial ground received uranium contaminated materials from nuclear fuel manufacturing processes. Previous geophysical investigations included ground penetrating radar, magnetometer, and metal detector surveys. Of these, the magnetic data strongly suggests the presence of buried ferromagnetic material later confirmed through excavation.

This burial ground was partially excavated as part of the $300 \mathrm{FF}-1$ Operable Unit Environmental Restoration Activities. Excavated material consisted mostly of uraniumcontaminated soil and metallic debris, although asbestos, wood, glass, and lead debris were unearthed. Excavation was halted when numerous 132-L (35. gallon) drums containing uranium shavings in oil were encountered at the site of a strong magnetic anomaly near the center of the burial ground.

Only the central portion of the burial ground, which is estimated to be approximately $83.3 \mathrm{~m}(275 \mathrm{ft})$ long $x 70 \mathrm{~m}(230 \mathrm{ft})$ wide and to occupy an area of approximately $5,845 \mathrm{~m}$ ${ }^{2}\left(62,890 \mathrm{ft}^{2}\right.$ or $\sim 1.4$ acres $)$ was examined through excavation. The long axis of the burial ground is oriented in a NE-SW direction approximately $\mathrm{N} 67^{\circ} \mathrm{E}$. The main part of the disposal pit is estimated to be at least $6 \mathrm{~m}(19 \mathrm{ft})$ deep. Excavation resulted in an uneven topographical surface. A coarse wire (hog wire) fence with wooden posts marks the perimeter of the burial ground, and two power lines are located approximately $30 \mathrm{~m}(100 \mathrm{ft})$ west of the study area.

The native geologic materials of the site consist of a thin veneer $(-1.5 \mathrm{~m}(5 \mathrm{ft})$ thick) of poorly graded sand overlying well graded sandy gravel. The water table depth is estimated

Bat-(PNNL) 269421-618-4-EOL-1 
to be around 10 meters ( -32 feet). The moisture content of these soils is expected to be very low, perhaps on the order of $5-10 \%$ by weight.

Two PVC cased boreholes, Well A (\#B8780) and Well B (\#B8781), were installed

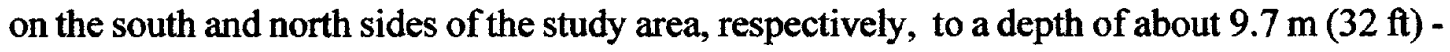
the expected depth to groundwater - in order to acquire the EOL data. Well $\mathrm{A}$ is located at EOL survey grid coordinates 300 East and -30 North; Well B is located at grid coordinates 334 east and 230 North.

\section{Electromagnetic DfFset LqGging}

Electromagnetic Offset Logging (EOL) is a surface-to-borehole electromagnetic induction method for delineating targets within the near surface. Maxwell's equations regarding the behavior of electromagnetic fields for exploration of the subsurface as detailed by Grant and West (1965) describes the application of the method.

An alternating current vertical magnetic dipole is established by passing an constant 6 amps of current at a frequency of 263 hertz through a multiple turn $6 \mathrm{ft}$ by $6 \mathrm{ft}$ rectangular loop. Figures 1A \& 1B show the transmitter loop used for the survey as well as provide a view of the site conditions. The Total Magnetic Field is measured within the borehole utilizing a ferrite cored coil and a digital recording voltmeter. The data are sampled every 0.1 foot from the bottom of the hole to the top, nominally from a depth of $32 \mathrm{ft}$. to a depth of 4 ft. then saved to a computer. Figure $1 \mathrm{C}$ shows the WMI vehicle housing the data acquisition equipment, computer, etc. The measured response is a complex function resulting from induced secondary magnetic fields due to eddy current flow within conductors as well as displacement currents flowing due to finite conductivity of the earth materials.

The field of the magnetic dipole radiates outward from the center of the coil transmitting diminishing in magnitude as the inverse of the distance cubed $\left(1 / R^{3}\right.$, where $R$

Bat-(PNNL) 269421-618-4EOL-1 


$$
\begin{aligned}
& \mathrm{H}_{\mathrm{z}}=\mathrm{m} / 4 \pi\left[\left(2 \mathrm{z}^{2}-\rho^{2}\right) /\left(\left(\rho^{2}+\mathrm{z}^{2}\right)^{5 / 2}\right] i_{z}\right. \\
& \text { where: } \quad \begin{aligned}
\mathrm{m}=\text { dipole moment of source coil } \\
\mathrm{z}=\text { depth of receiving coil } \\
\rho=\text { distance between coil and borehole } \\
i_{x}=\text { unit vector in } \mathrm{Z} \text { direction }
\end{aligned}
\end{aligned}
$$

is the distance from the center of the coil). The intensity of the vertical component of the magnetic field due to an oscillating magnetic dipole in free space can be calculated at any point using the following equation. (Grant \& West, pp 476 )

The equation is formatted for a cylindrical coordinate system with its origin at the center of the coil. In free space, displacement currents are neglected. The solution assumes no conductors are within the field of influence of the source dipole or receiving coil.

Using the equation above, the primary magnetic field within a vertical borehole due to a oscillating magnetic dipole placed on the surface of the earth can be determined. Figure 2 shows a suite of response curves for several transmitter offsets where the half-space conductivity is assumed to be small so that the free space solution applies. A more conductive host would attenuate the field strength but the shape of the host curve would remain the same. The response curve passes through a zero point which is a function of the source receiver geometry. Note that as the distance between the transmitter and receiver increases, location zero point shifts to greater depth while the curve shape flattens. 
Figure 3 shows the secondary field response for a conductive target at depth. It was calculated using the above equation assuming the target that can be approximated as a alternating vertical magnetic dipole. For simplicity, the inducing field strength was set equal to the magnitude of the primary field at the source dipole reduced by a factor equal to inverse of the distance cubed. The maximum number inducing primary magnetic field flux lines passing through the target occurs when the transmitter is directly above the target. The wavelength of the resulting anomaly increases with increased distance between the source and receiver.

\section{EDL SuRVEY GRID@ Burial Ground618-4}

Figure 4 is a map of the EOL transmitter locations utilized at Burial Ground 618-4. The origin of the grid is at the southwest corner post of the fence surrounding the burial ground. Grid North is oriented N $23 \mathrm{E}$ which is perpendicular to the direction of the southern fence line. The EOL survey grid shares a common origin and orientation with the 1991 geophysical work. The EOL survey grid is in feet while the previously established geophysical survey grid is in meters.

The irregular sample density for the transmitter locations is due to the topography variations as well as extracted material placed on the surface.

\section{ELL SURVEY LGGISTICS}

EOL data were acquired along geophysical traverse grid lines established over the burial ground. A nominal 20 foot station spacing was utilized with 10 foot in-fill EOL's over select portions of the site. The transmitter coil was centered at each measurement location and leveled. The location of each EOL station was established using a tape measure. The elevation of each EOL primary (i.e. 20 foot) station was measured using a survey level and rod. Elevations for intermediate stations were estimated.

Bat-(PNNL) 269421-618-4-EOL-1 
On May $29^{\text {th }}, 1999$, a QA/QC test was run at the Colorado School of Mines to verify the operation of the equipment. In addition to regular quality assurance routines, a noise log was acquired at quasi-periodic intervals daily (start, midday, and end). Noise logs were run with and without the tool operating in the borehole.

EOL walk away test data were acquired on June 6, 1999. For this test, the transmitter coil was placed at 10 foot stations from 30 feet to 180 feet south of the MW-A along the 300 E line.

Data acquisition phase of the program was completed on June $12^{\text {th }}, 1999$.

\section{edl data Procegging Procedureg}

Following are the processing procedures applied to the observed EOL data to obtain a relative conductivity $\log$ verses depth for each transmitter location.

1) remove spikes and spurious high frequency noise

2) apply smoothing filters and resample to 0.25 foot interval

3) trend removal ( $2^{\text {nd }}$ order polynomial)

4) apply geometric correction

5) apply scaling correction

6) apply low pass filtering

Steps 1 and 2 condition the observed data by selective removal of spikes and high frequency noise due to instrumentation, winch, man-made sources, etc. Step 3 removes the primary field leaving the secondary field response. Steps 4 and 5 normalizes the data with a geometric correction factor based on the equation above and a scaling factor. Step 6 is a filter applied to enhance the target response and attenuate signal due to sources close to the borehole.

Bat-(PNNL) 269421-618-4-EOL-1 
Elevation data for each transmitter location were obtained in anticipation that they would be required to remove the effect of the primary field due to variations in transmitterreceiver geometry. However, the processing procedures listed above do not require knowledge of the elevation of the transmitter coil, thus the data were not utilized.

EOL data are related to the conductivity variations within the subsurface but are not a measure of true earth conductivity. Thus, they are termed "relative conductivity". In comparison, electromagnetic terrain conductivity meters such as those made by Geonics Ltd. are calibrated based on the measurement of the quadrature phase component for a fixed transmitter-receiver geometry at low induction numbers to provide a direct measure of terrain conductivity (McNeill (1980)). The WMI EOL data acquisition system is designed to provide only a measure of the magnitude of the Total Magnetic Field with no phase reference. Thus, there is no way to directly obtain an accurate measure of terrain conductivity, since there is no phase information with which to extract the quadrature phase response. The best the system can provide is a measure of the relative changes in conductivity. This allows for both negative and positive values of relative conductivity.

\section{EqL Data Visualization}

The EOL data were visualized several ways in order to glean the most information from the data. The lateral variations in relative conductivity for each depth layer are presented as color shaded relief plan maps and are provided in Appendix I. The "Z-" series show the results for the entire survey area set while the "W-" series maps are for only the central portion of the survey area. Fence diagram cross section perspective views were created to show the variation with depth and direction across the entire survey area. The "Y-" series shows the variation with respect to depth for east-west slices while the "X-" series are similar presentations for north-south slices. They are found in Appendices II and III, respectively. Appendix IV contains a select set of 3D volumetric block, chair cut, and iso-surface views. Appendix V contains the "M-" series of maps where the RTP magnetic data are presented in

Bat-(PNNL) 269421-618-4-EOL-1 
color contour plan maps with an overlay of line contours of relative conductivity for a specific depth.

\section{grdund maignetic data}

The ground magnetic data acquired prior to excavation activities were converted to the EOL survey grid units and re-processed to reduce the data to the magnetic pole. This, in effect, removes the spatial shift due to angle and direction of the inducing earth's magnetic field. An inclination of $68^{\circ}$, a declination of $20^{\circ}$ east , and the inducing field strength of $56000 \mathrm{nT}$ were utilized for this processing. Figure 5 is a plan view color contour map of Reduced to Pole (RTP) magnetic data for the portion of the burial ground covered by the EOL survey. Figure 6 is a plan view color contour map Reduced to Pole (RTP) magnetic data for the central portion of the EOL survey block and burial ground.

\section{Digcusaidn dF Results}

The EOL Relative Conductivity data are presented in several visualization formats in their respective appendices of this report. These various views of the data were interpreted in qualitative fashion by noting the spatial variations in relative conductivity. In addition, the results were compared with the RTP magnetic data for correlation. Figure 7 is a plan view presentation of the interpreted results.

There are two zones of increased conductivity striking parallel with the long axis of the burial ground, an upper zone (outlined with a red dashed line) and a lower zone (outlined with a blue dotted line). The southern edge of the conductivity zones appears to be bounded by a low conductivity zone.

The upper zone is centered at an approximate depth of approximately 15 feet from the top of the borehole. Within the upper zone is an area of significantly greater conductivity centered at $260 \mathrm{E}, 100 \mathrm{~N}$ (outlined by a solid red line). If appears as an apopheses protruding

Bat-(PNNL) 269421-618-4-EOL-1 
towards the surface on iso-surface renderings ( see ISO-1) suggesting source of the conductive zone is shallower at that point.

The lower zone is at a depth of approximately 25 feet but appears to be not as well defined at the upper zone leading to some suspicion regarding its actual existence. There are also two additional conductive zones within the lower zone along the east boundary of the survey grid.

The relative conductivity data correlate reasonably well with the anomalous zones seen in the RTP magnetic data. Since the magnetic data indicate areas of increased magnetic susceptibility which is taken to mean areas of a reasonable mass of ferromagnetic metallic materials, such as steel. Such materials are often conductive, but not always. A direct coincidence of a conductive anomaly with a magnetic anomaly is a strong indication of ferromagnetic materials. A magnetic anomaly alone also indicates ferromagnetic materials, but not necessarily conductors. Such a situation may occur as a result of oxidation. A conductive anomaly without a coincident magnetic anomaly simply indicates a conductive, non-magnetic source, for example aluminum, lead, copper, groundwater contamination, etc.

Of particular note is the area centered at 320 East, 140 North. It is outlined with a green dashed line on Figure 7 and described as a non-conductive zone. It is significant because it is directly coincident with a magnetic anomaly. It is assumed that this was the area where a large quantity of the steel barrels containing uranium shavings in oil were extracted. Therefore, the lack of relative conductivity anomaly, thus a non-conductive zone, would be expected.

\section{SUMMARY CONCLUSIONS AND RECOMMENDATIONS}

Clearly, the EOL data appear to have identified areas of increased conductivity which in conjunction surface geophysical data provide a better characterization of the site prior to remediation. It must be noted, however, that the data acquisition system was not designed Bat-(PNNL) 269421-618-4-EOL-1 
for mapping conductive targets. The preferred data acquisition system should allow for the resolution of the vertical component of the measured magnetic field into In Phase and Quadrature Phase components at several discrete frequencies. Thus, the results are subject to interpretation biases, errors in data acquisition, and noise within the measured data.

Because this is the first attempt at applying the EOL technique to burial site characterization, it is recommended that a EM31 or EM34 terrain conductivity survey or a EM61 deep penetrating metal detector survey be completed to confirm the EOL results prior to additional excavation on the site. Direct correlation of EOL anomalies with surface EM anomalies will serve to confirm the methodology and improve the confidence level of those tasked with extracting the buried waste.

Bat-(PNNL) 269421-618-4-EOL-1 


\section{REFERENCES:}

Grant, F. S. and West, G. F. (1965), Interpretation Theory in Applied Geophysics, McGrawHill, New York, NY

McNeill, J. D. (1980), Technical Note TN-6, Electromagnetic Terrain Conductivity Measurement at Low Induction Numbers, Geonics Ltd., Mississauga, Ont Canada

Bat-(PNNL) 269421-618-4-EOL-1 


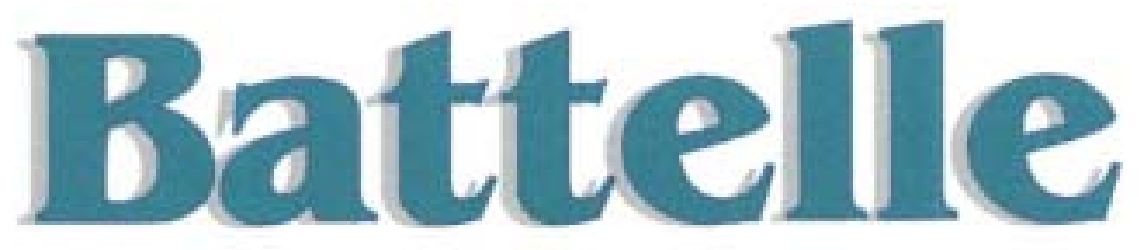

\section{Pacific Northwest Division Richland, WA}

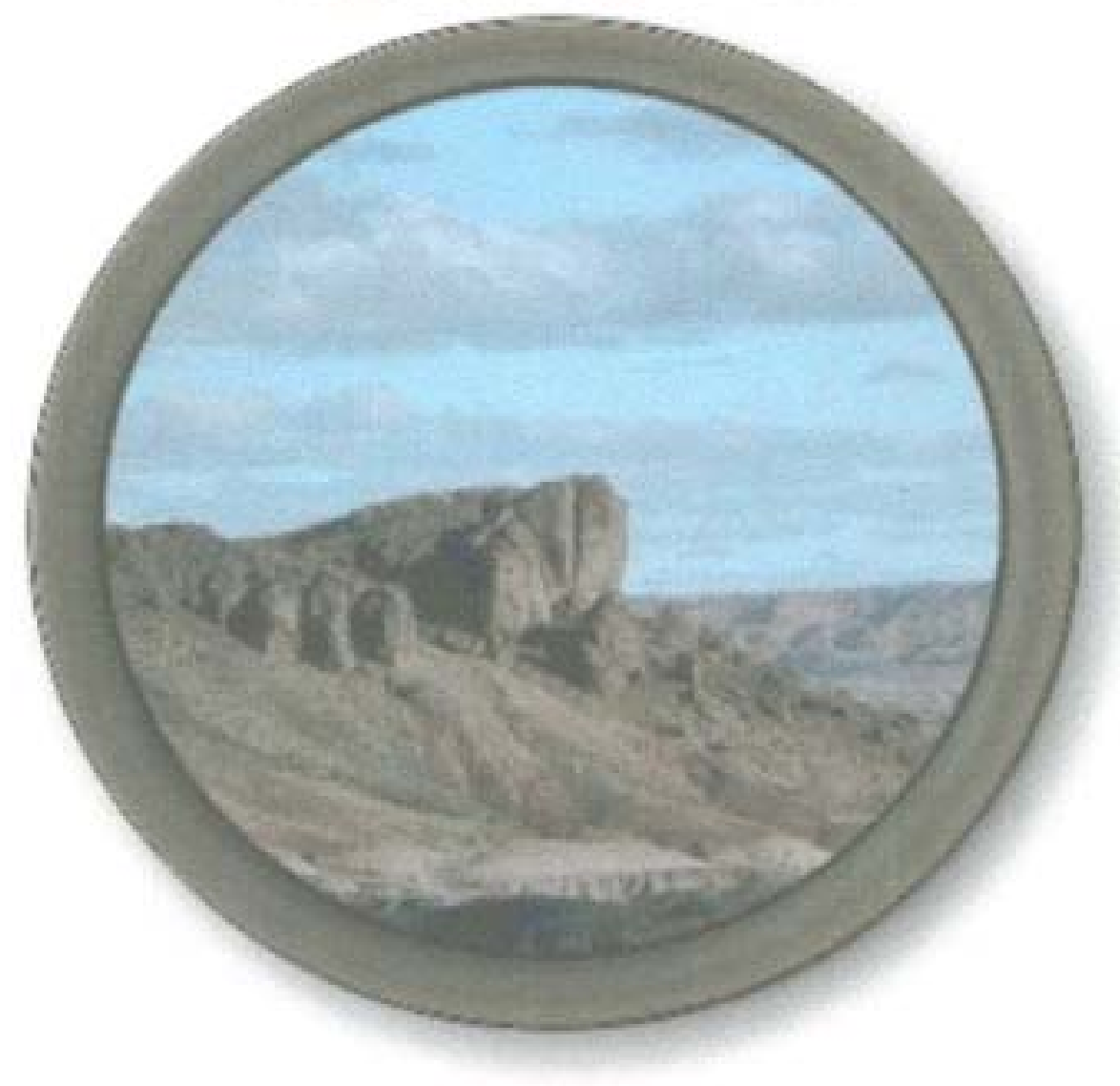

\section{8-4 Burial Ground}

Prepared by:

\section{WMI INTERNATIONAL, INC.}

4901 Milwee St. H109 o Houston, TX 77092

$713956.4001 \circ 800.460 .4507 \circ 713-958-7305$ Fax

WWW.WMI-INTL.com

wmi@wt.net

BAT-(PNNL) 269421-618-4-EOL-1

C. 21 


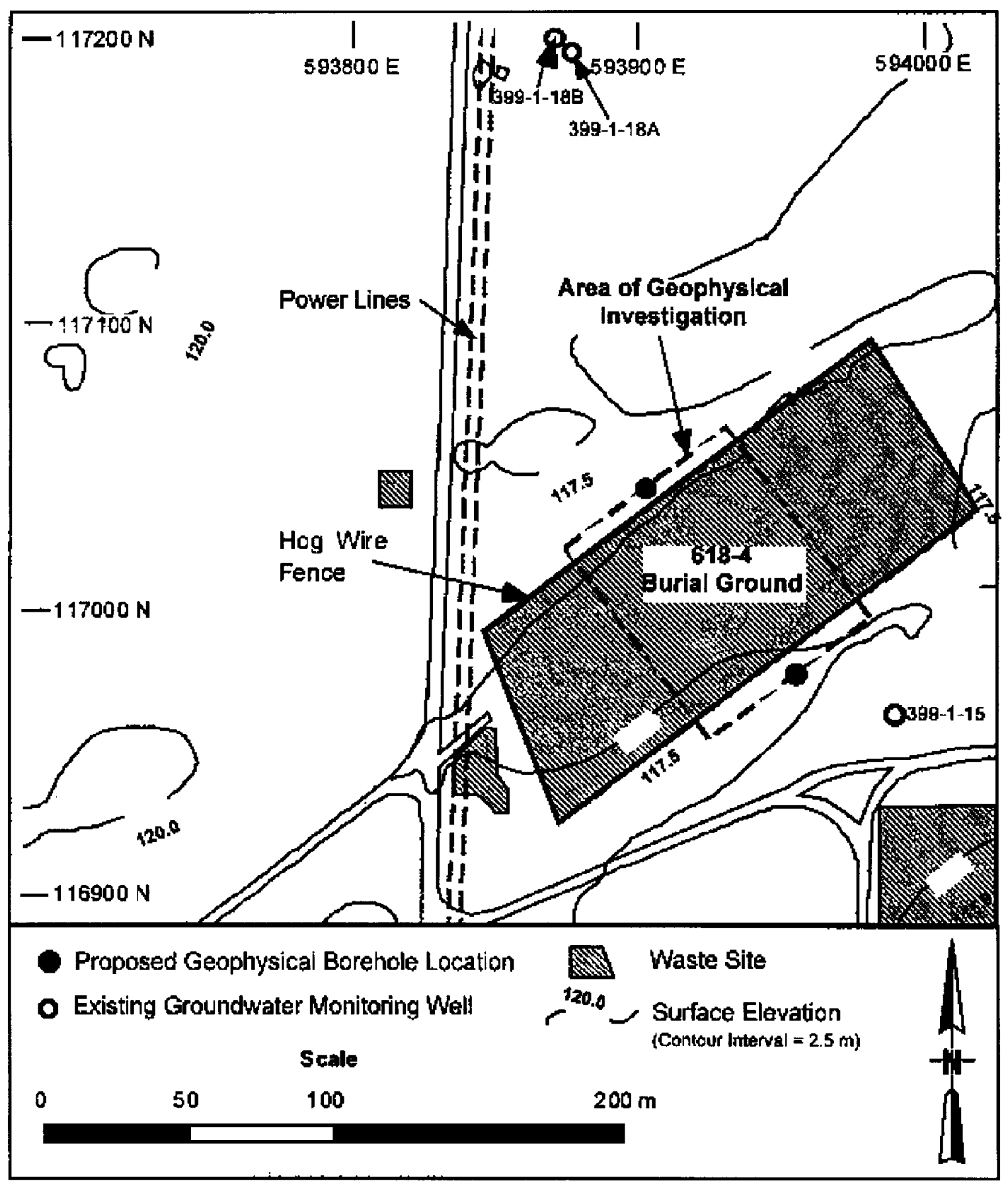

Layout of the 618-4 Burial Ground

Figure 1 


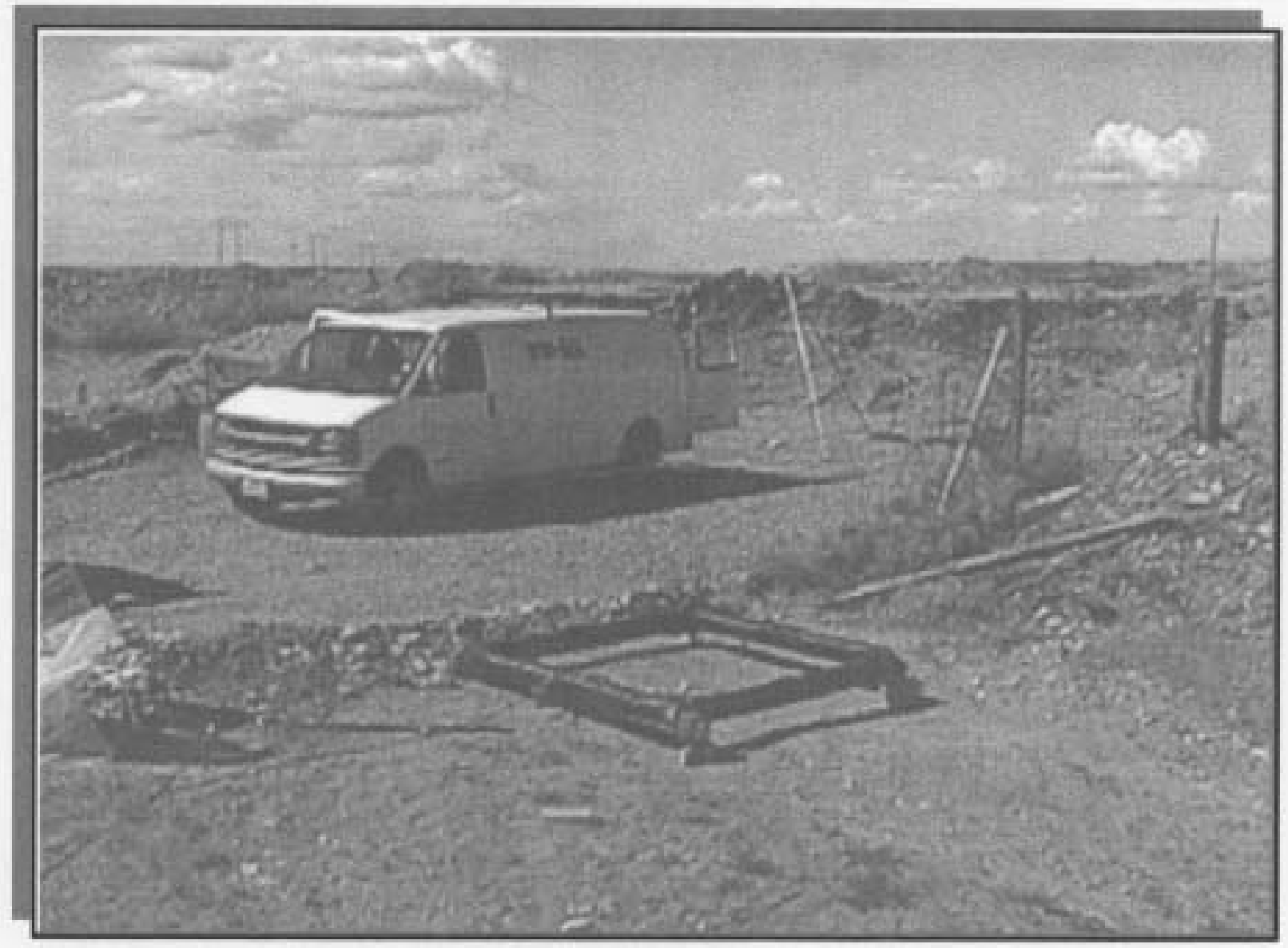

View of Coil \& Van at Data Point "CK" (X 225 Y 300)

Bat-(PNNL) 269421-618-4-EOL-1

C. 23 


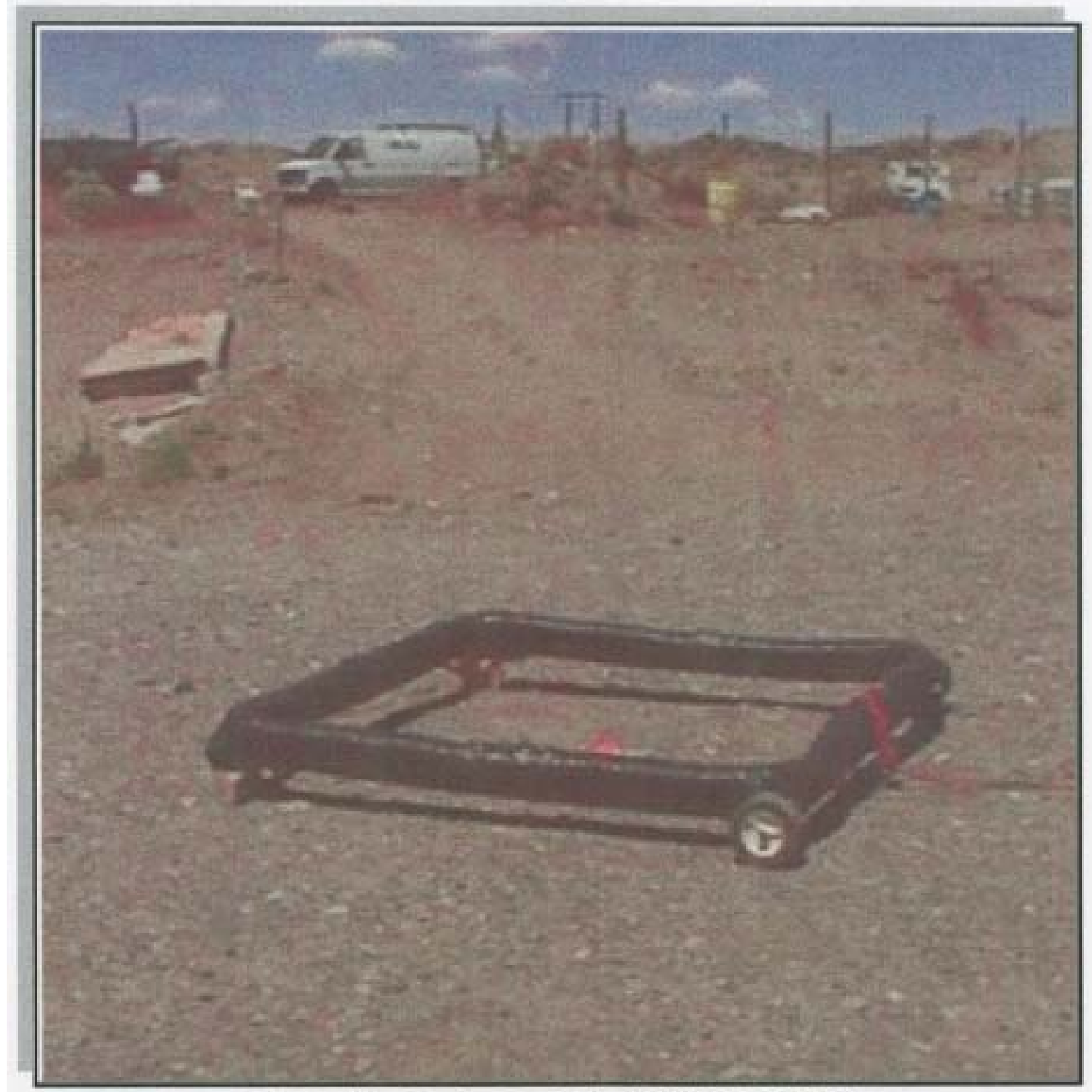

View Looking North at Data Point "HG" (X 280 Y 115)

C. 24 


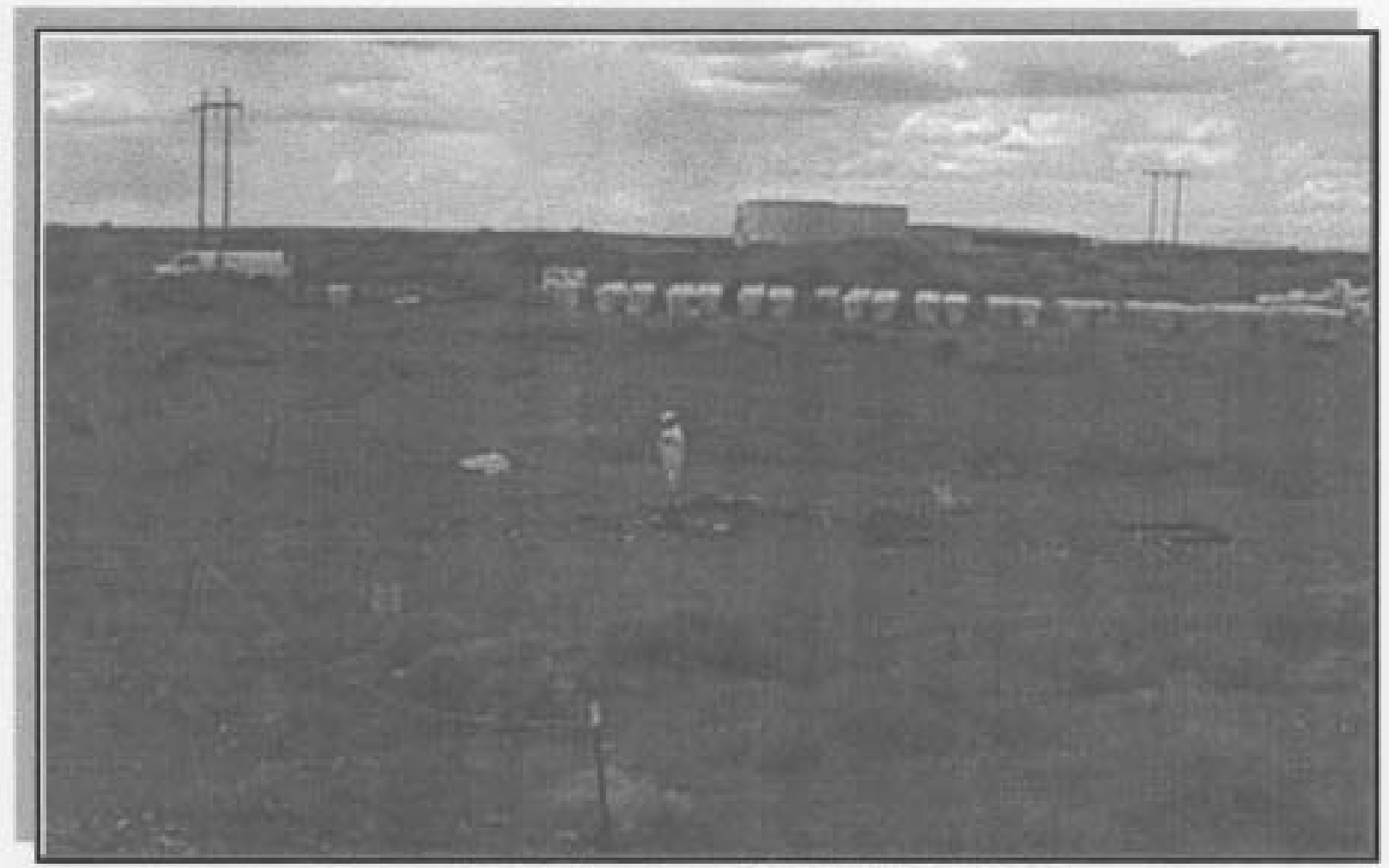

View Looking North at Data Point "IK" (X 380 Y 155)

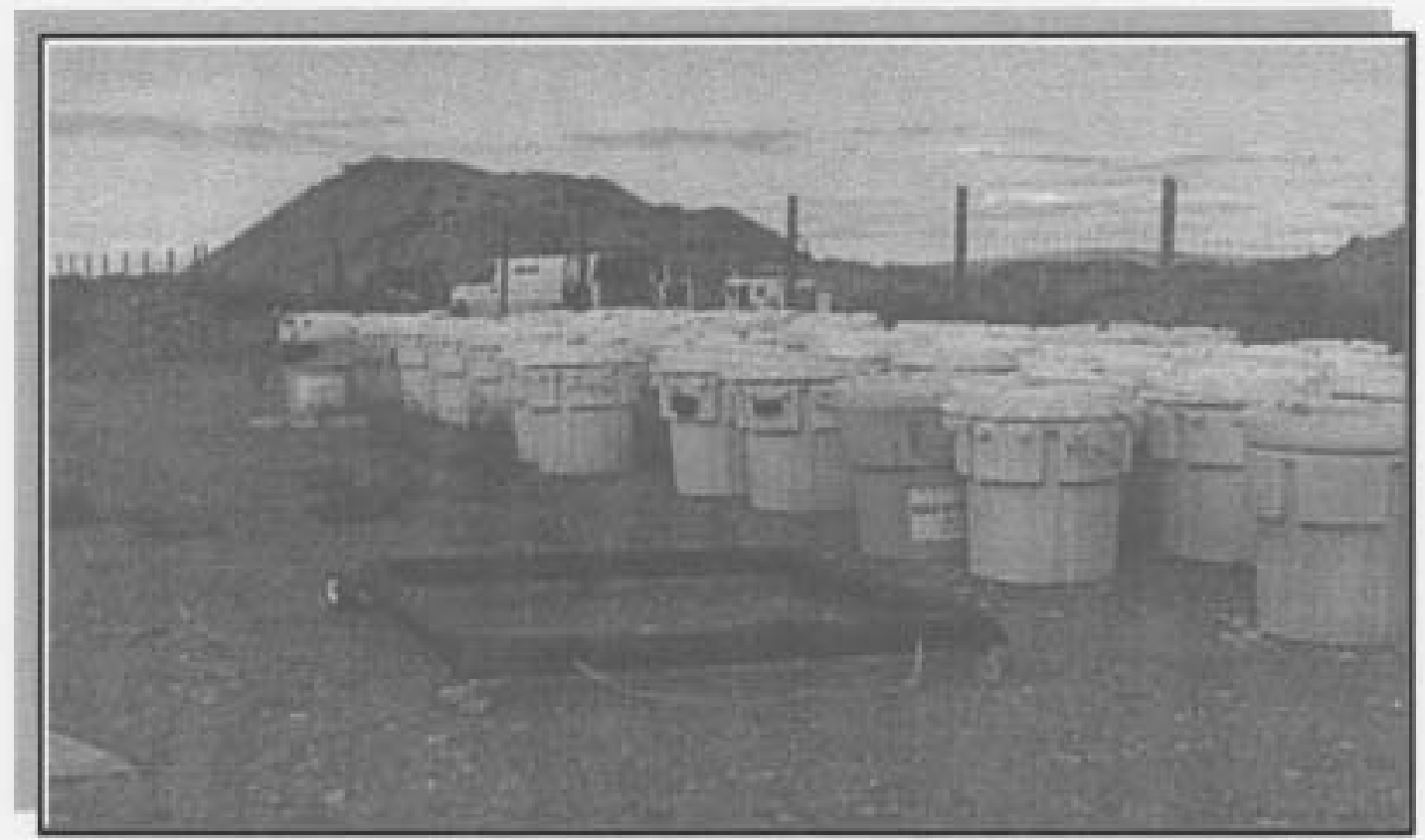

View looking NW at Data Point "MK" (X 380 Y 205) overpack drums

Bat-(PNNL) 209421-618-4-EOL-1 


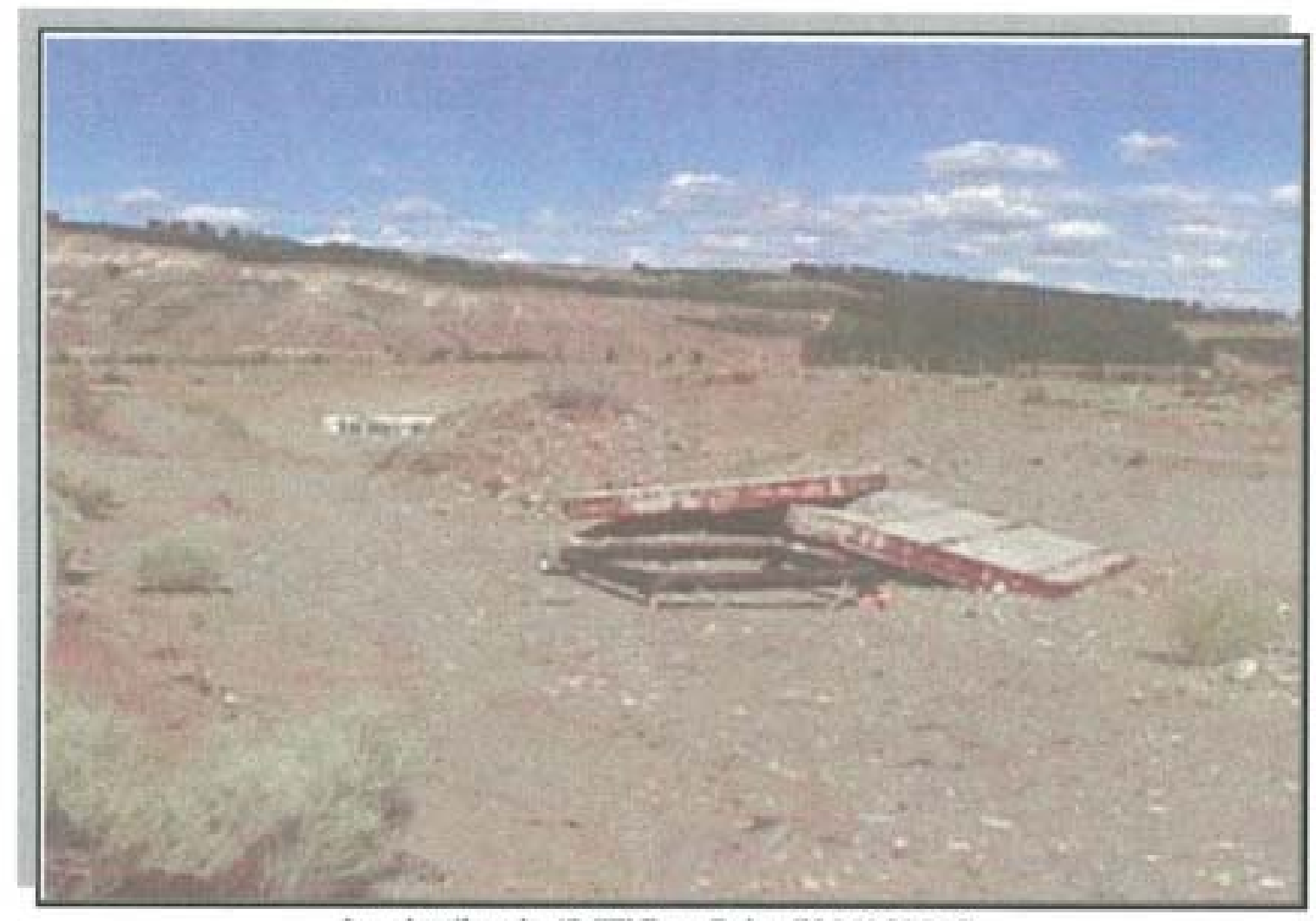

Level coil at the "MF" Data Point (X 260 Y 205)

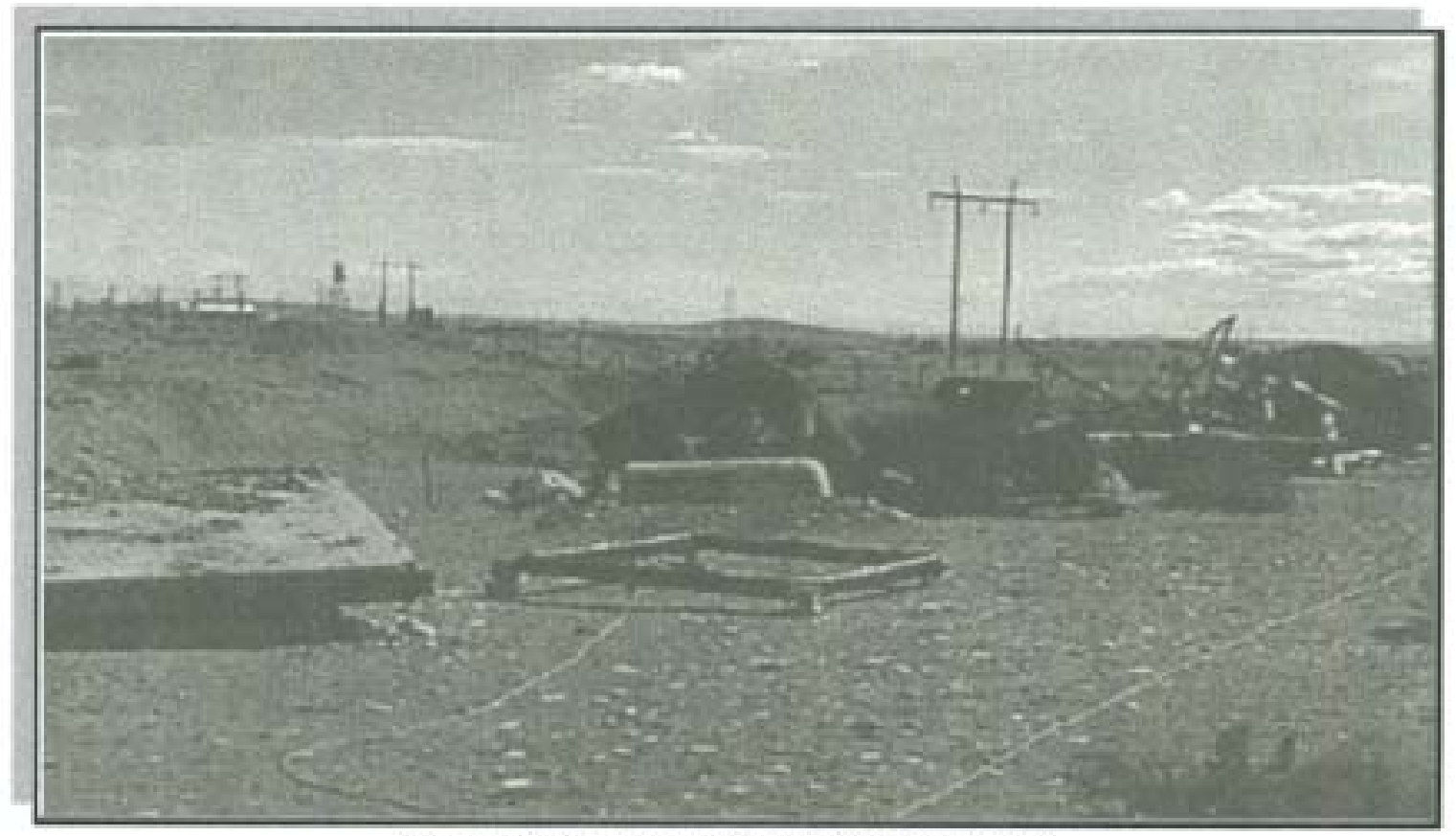

View of coil at Data Point "MF" looking SW

Bat-APNLL) 289421-618-4-EOL-1 


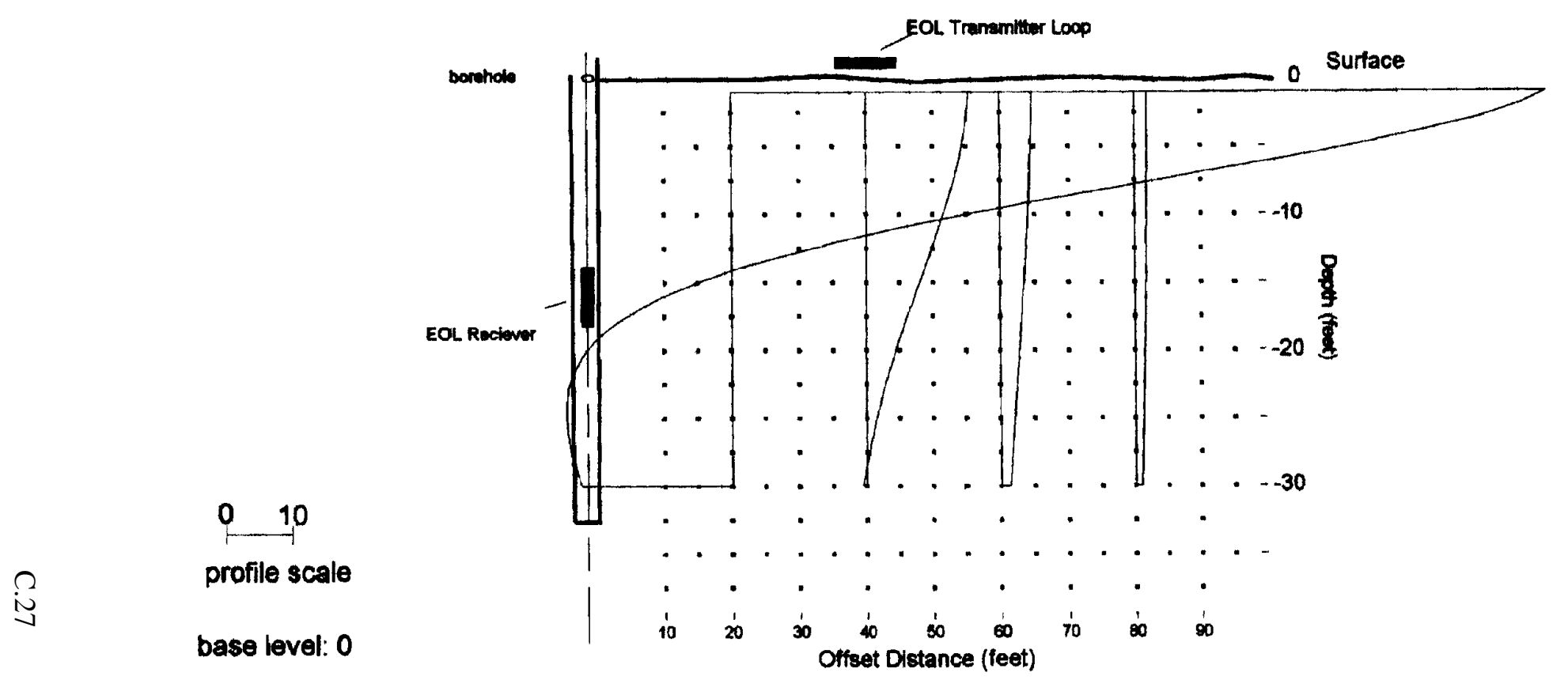

\section{Variation in Primary Magnetic Field with Transmitter Loop Offset}

Figure 2 


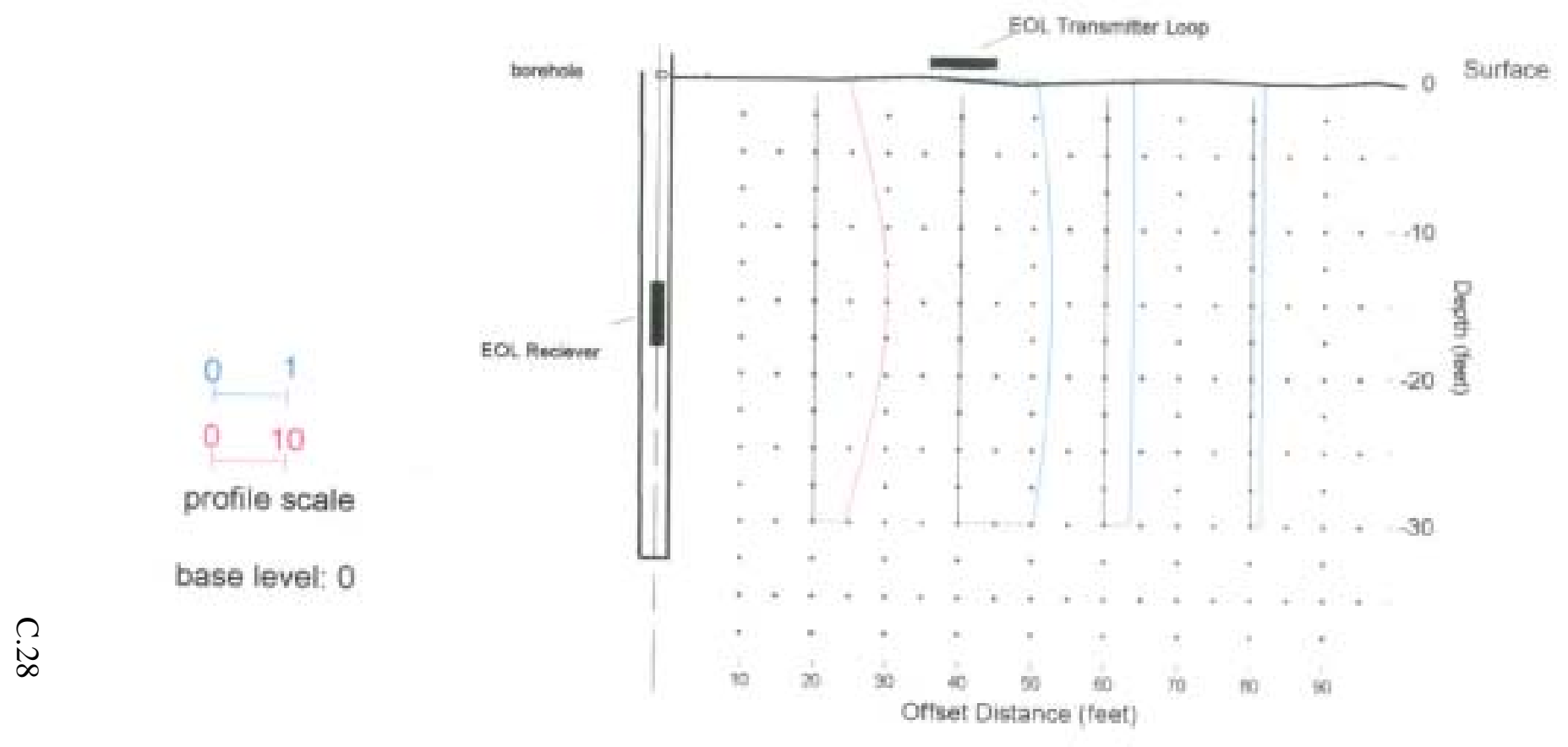

\section{Calculated Response for Buried Conductor with Transmitter Loop Offset}

Figure 3 


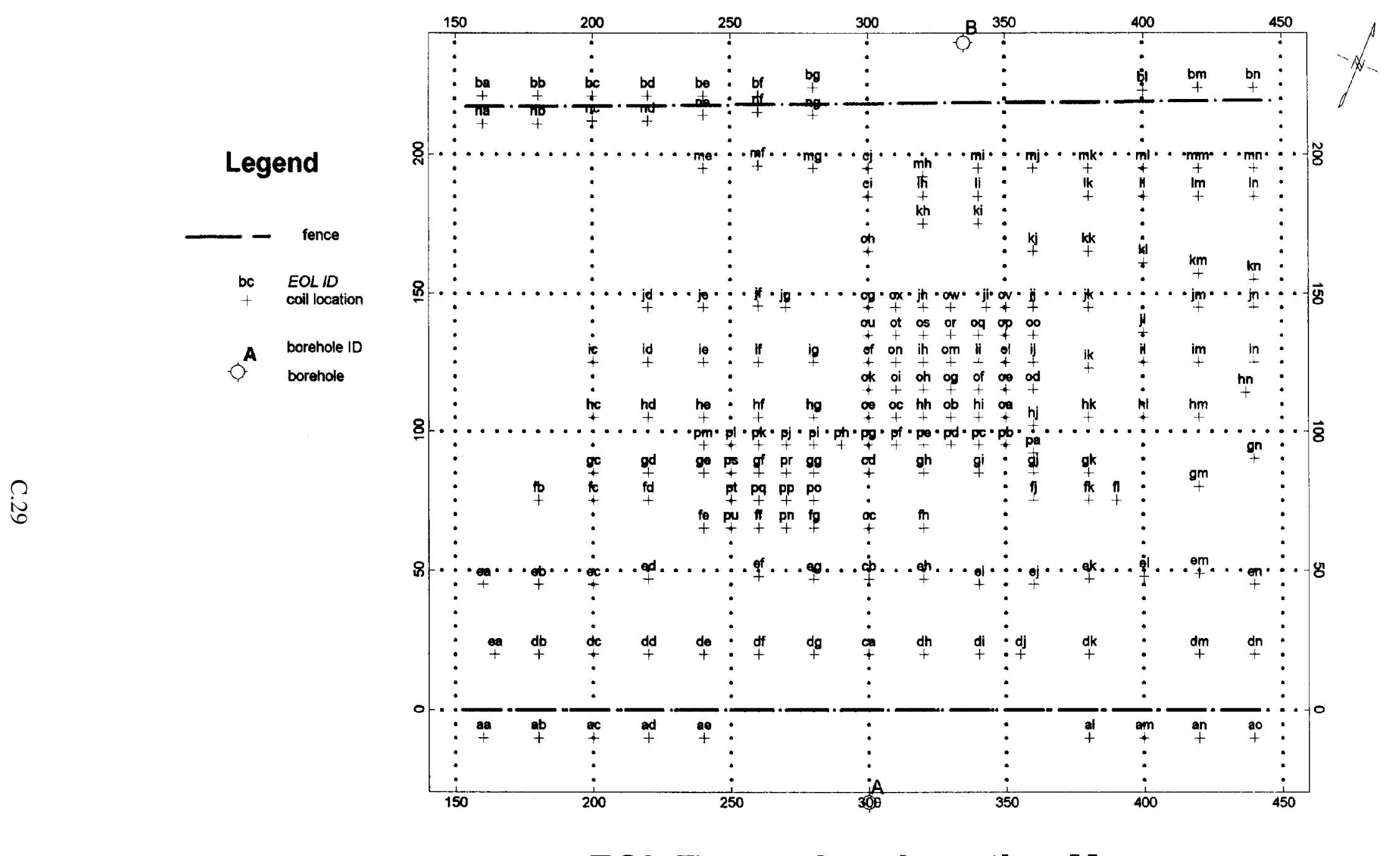

\section{EOL Transmitter Location Map}

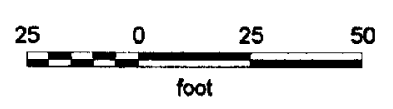

Burial Ground 618-4 - Hanford Reservation 

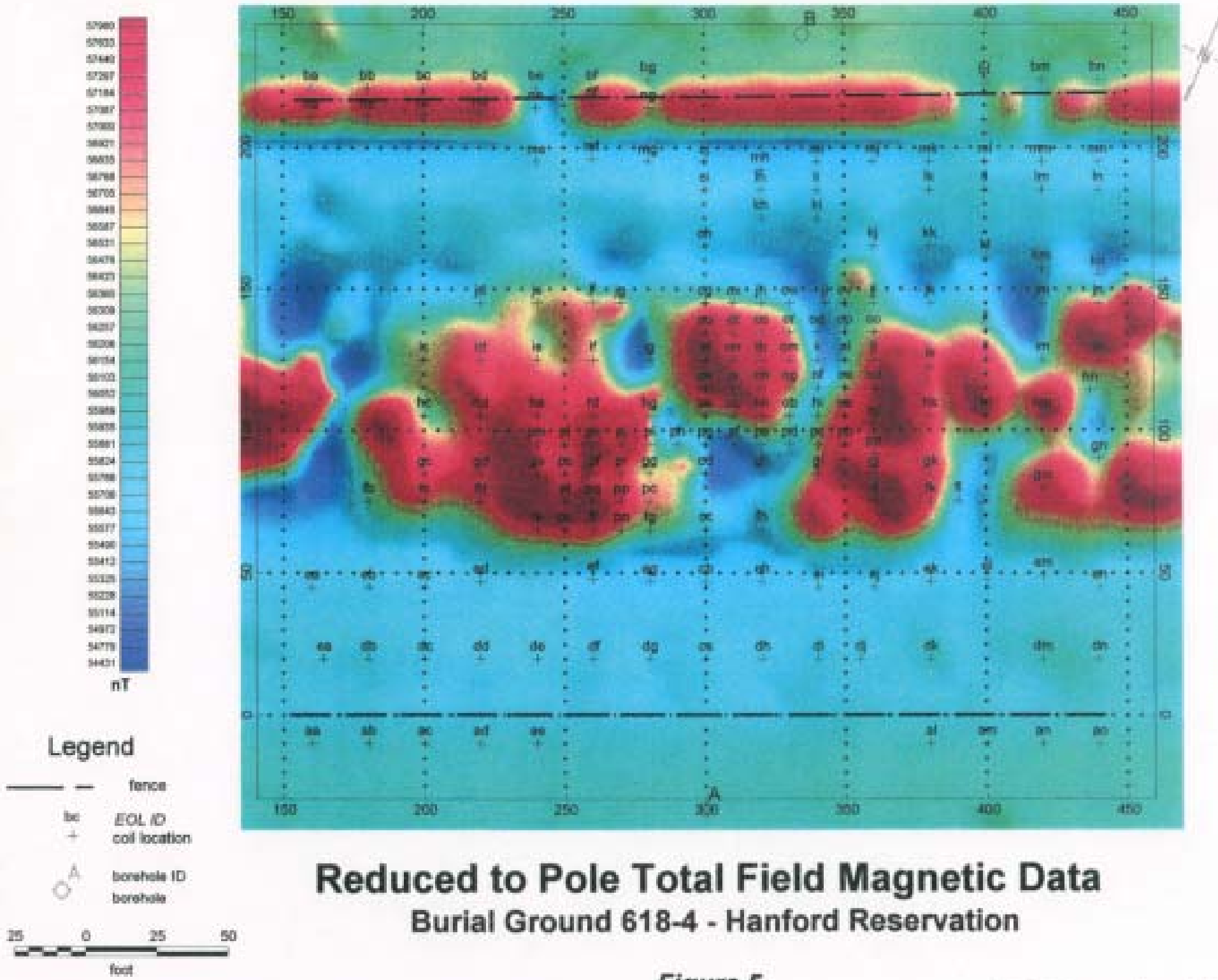

\section{Reduced to Pole Total Field Magnetic Data} Burial Ground 618-4 - Hanford Reservation

\section{Figure 5}

WMI International, Inc. 


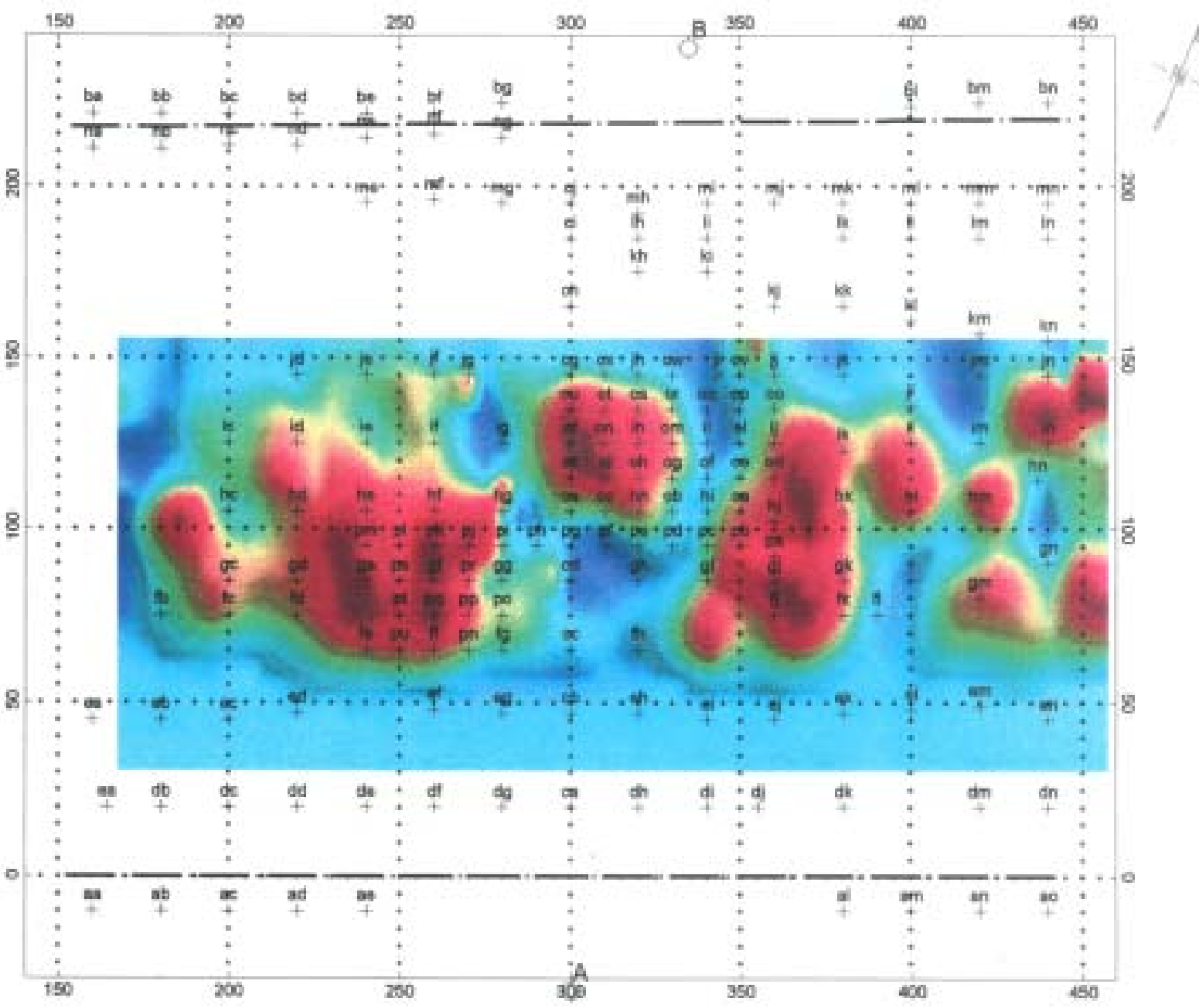

\section{Reduced to Pole Total Field Magnetic Data} Burial Ground 618-4 - Hanford Reservation

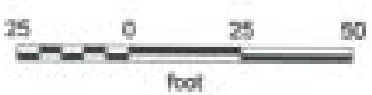




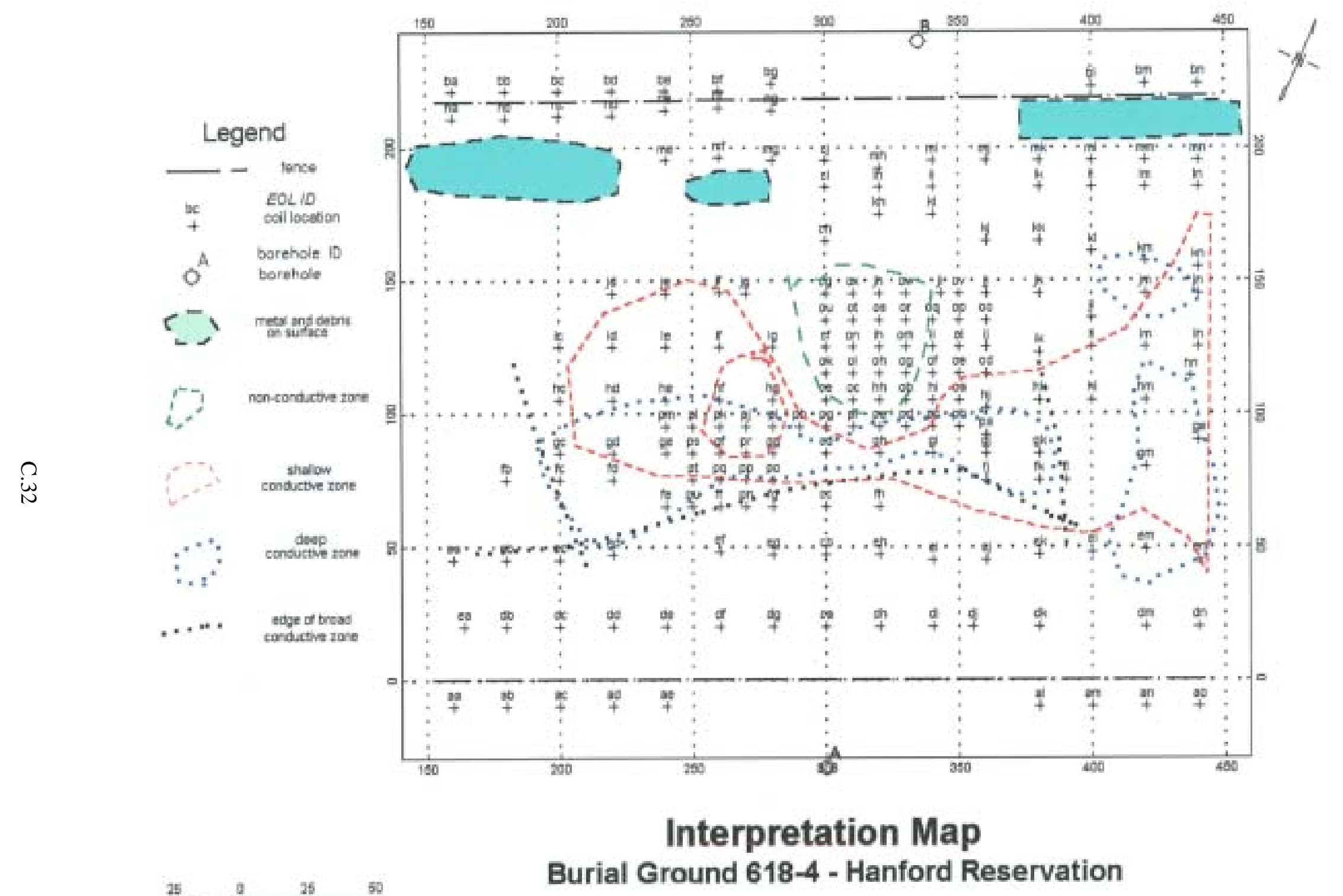

Figure 7 


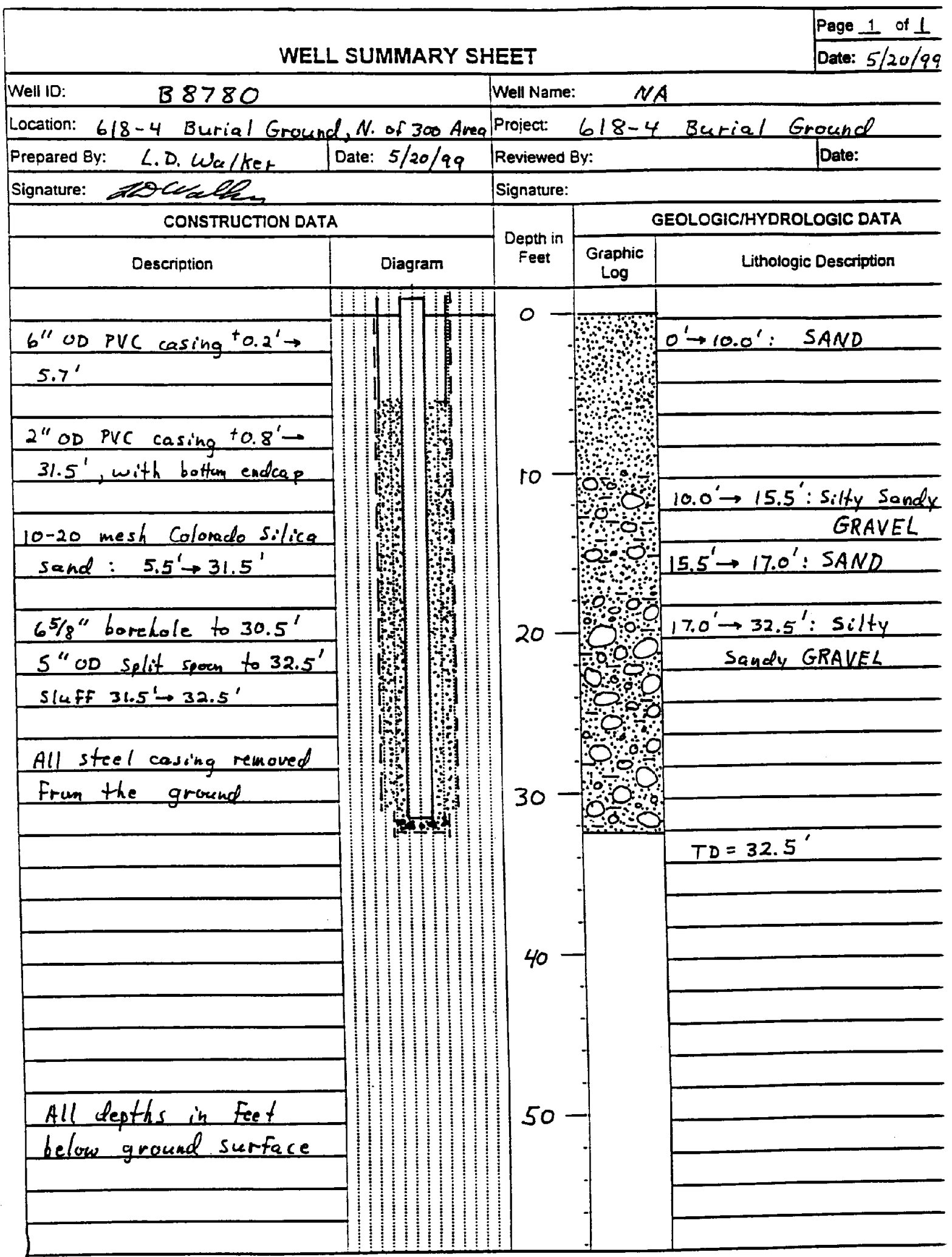

Fiqure 4 


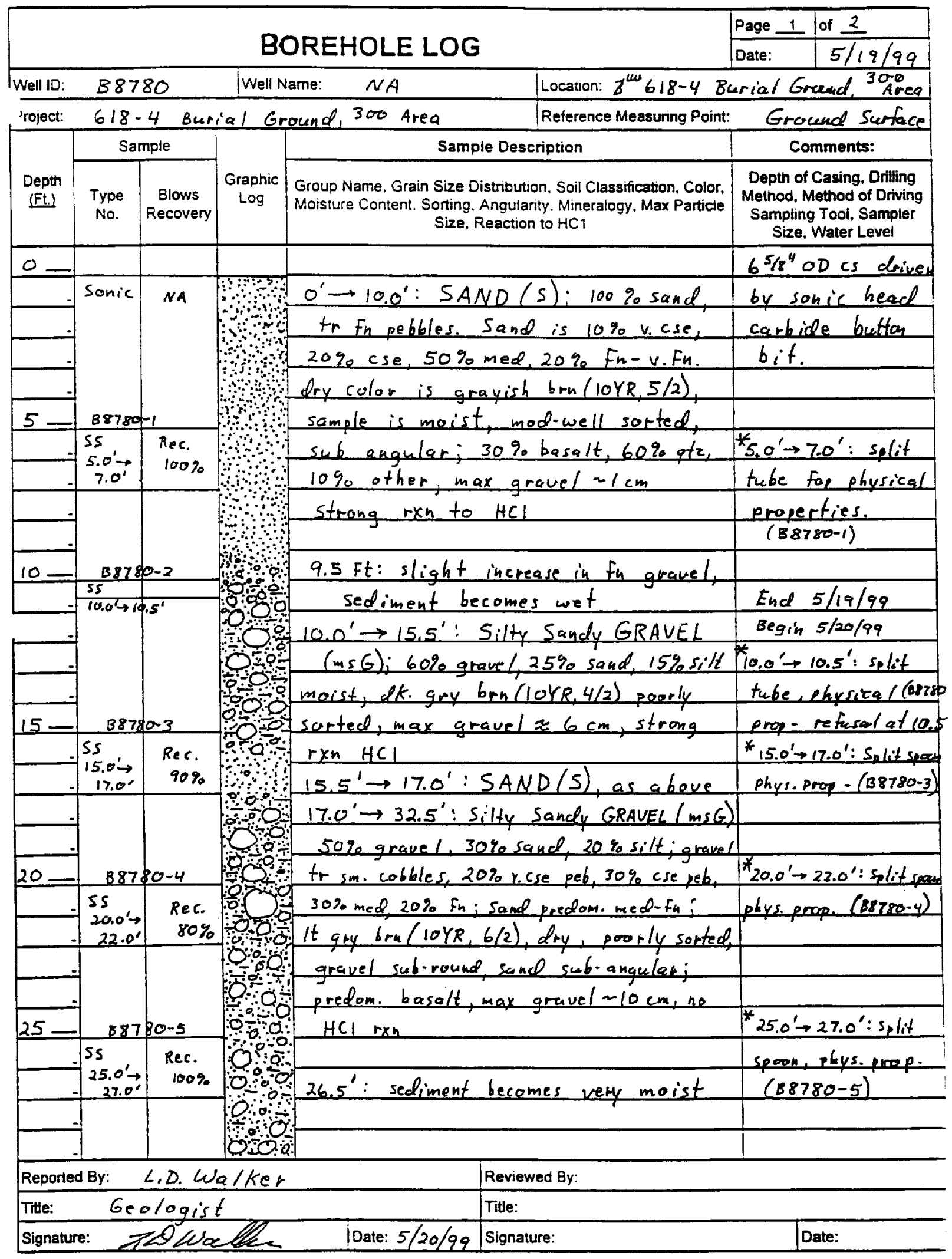




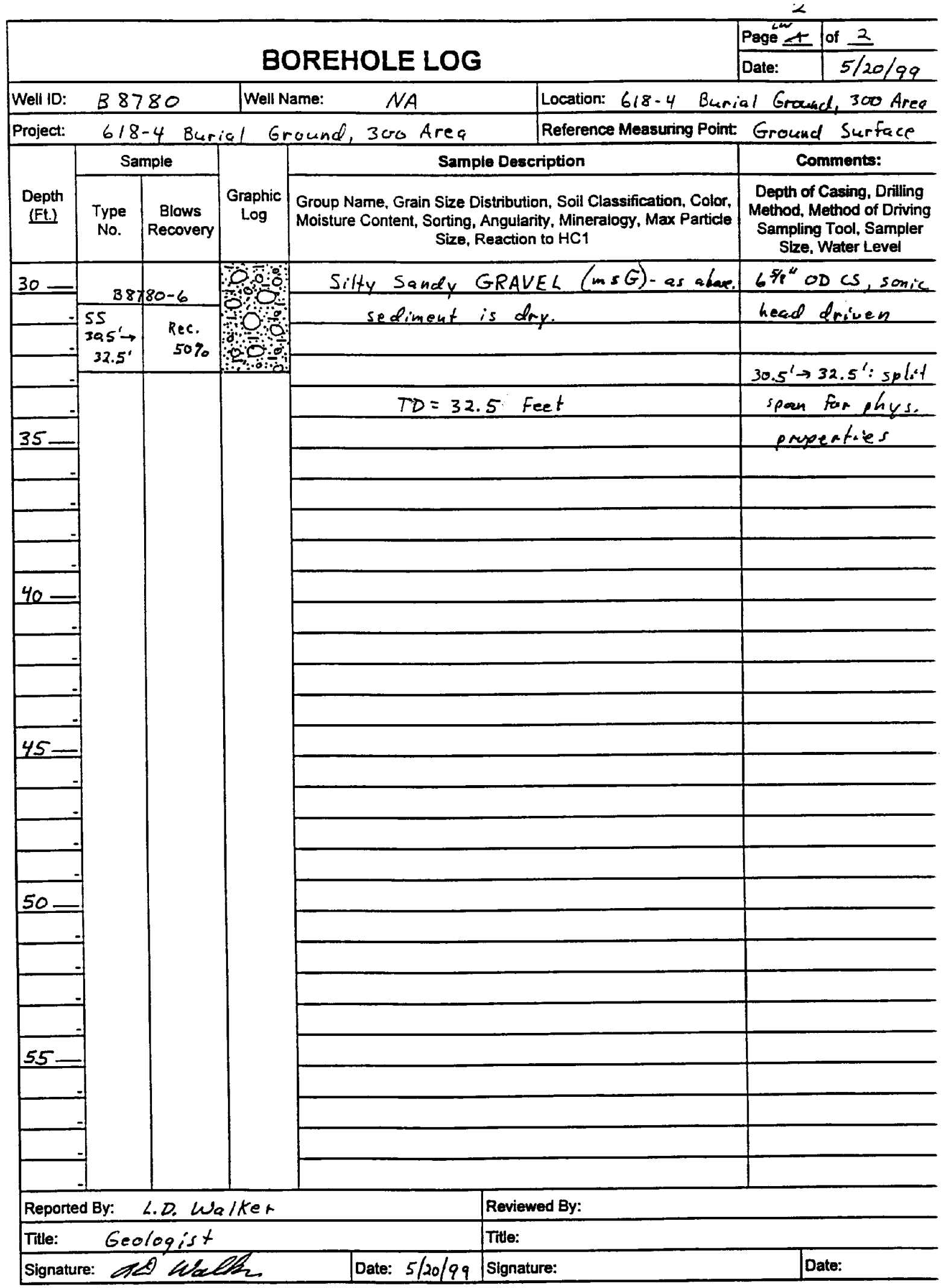

C. 35 


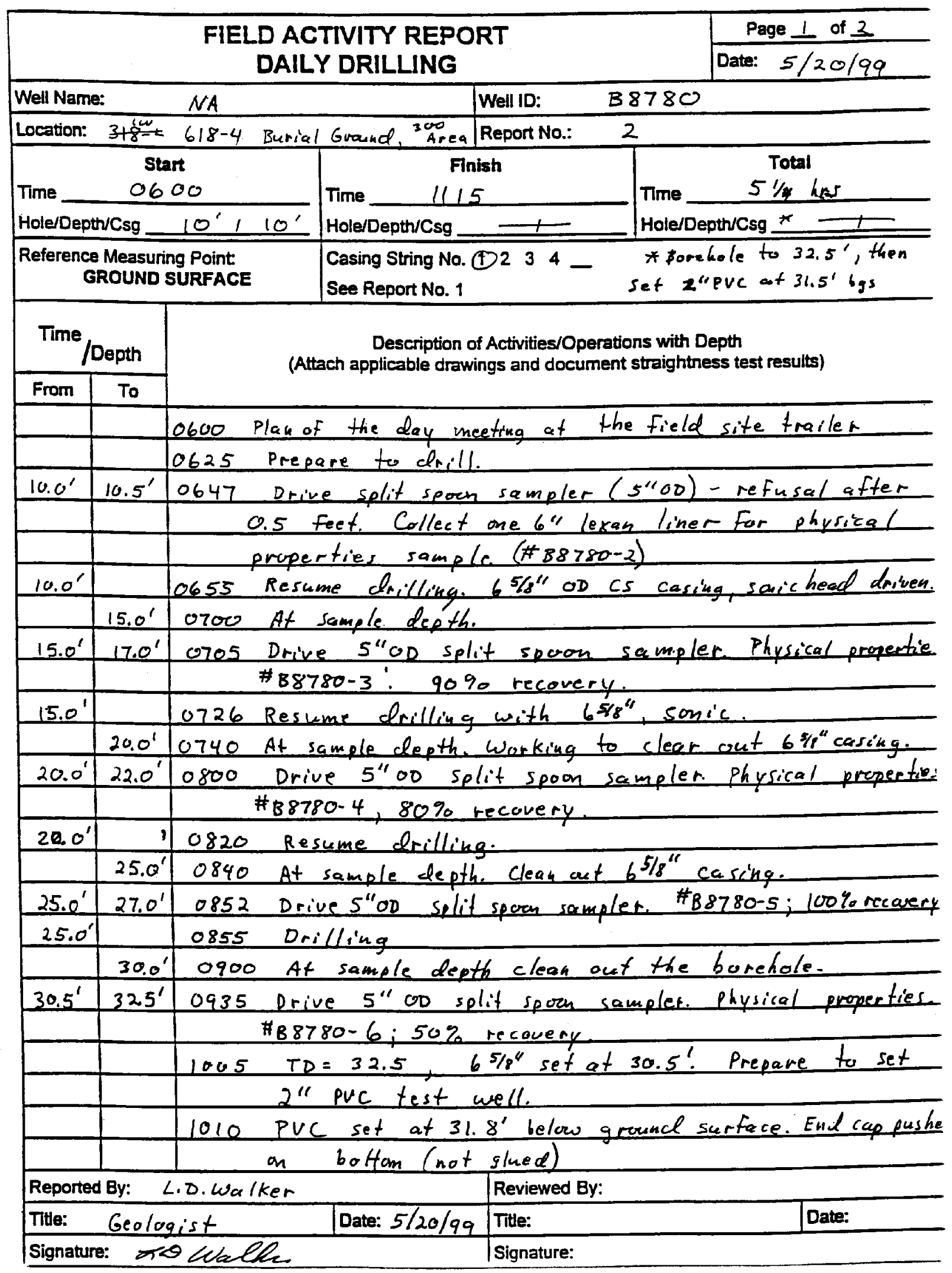




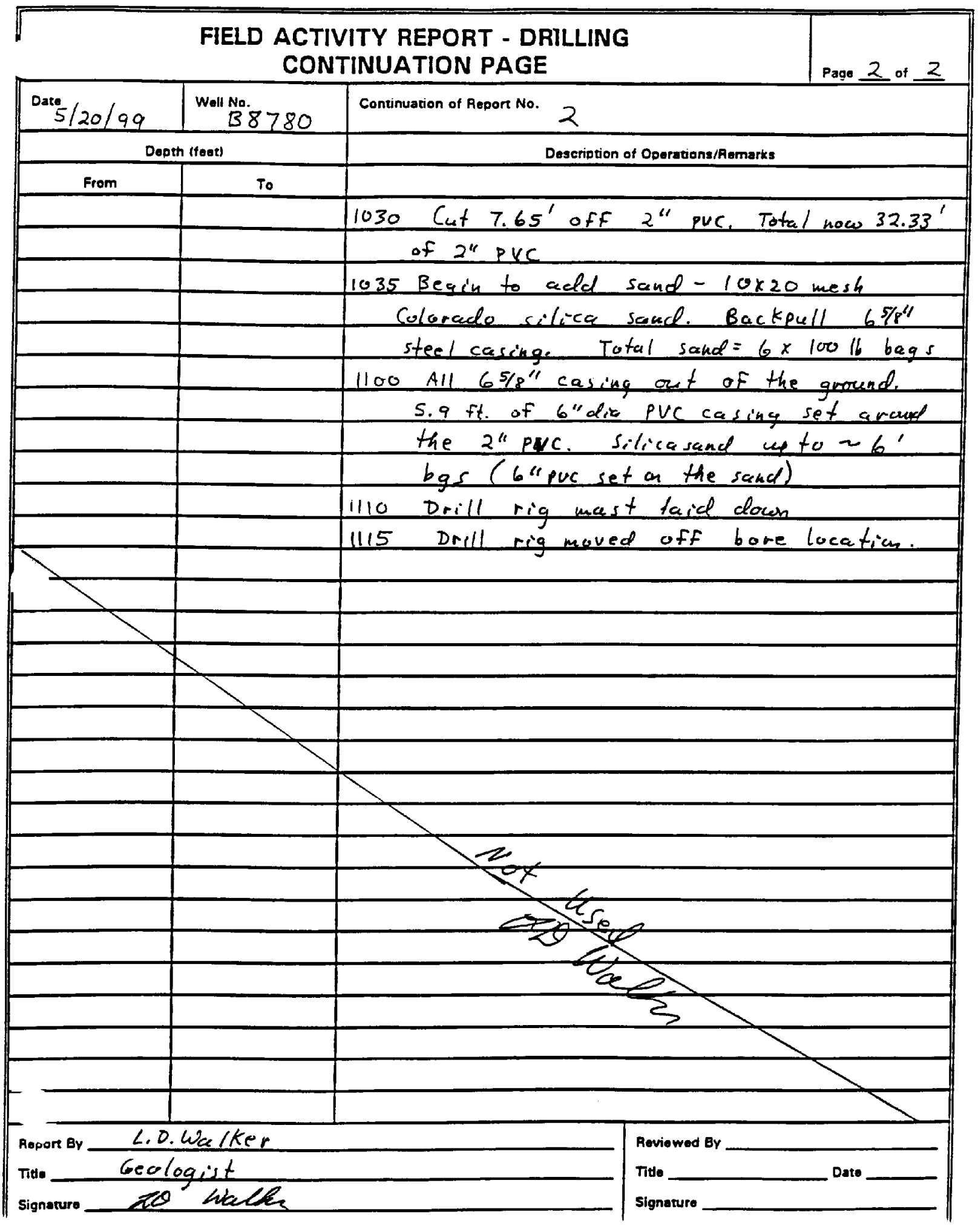




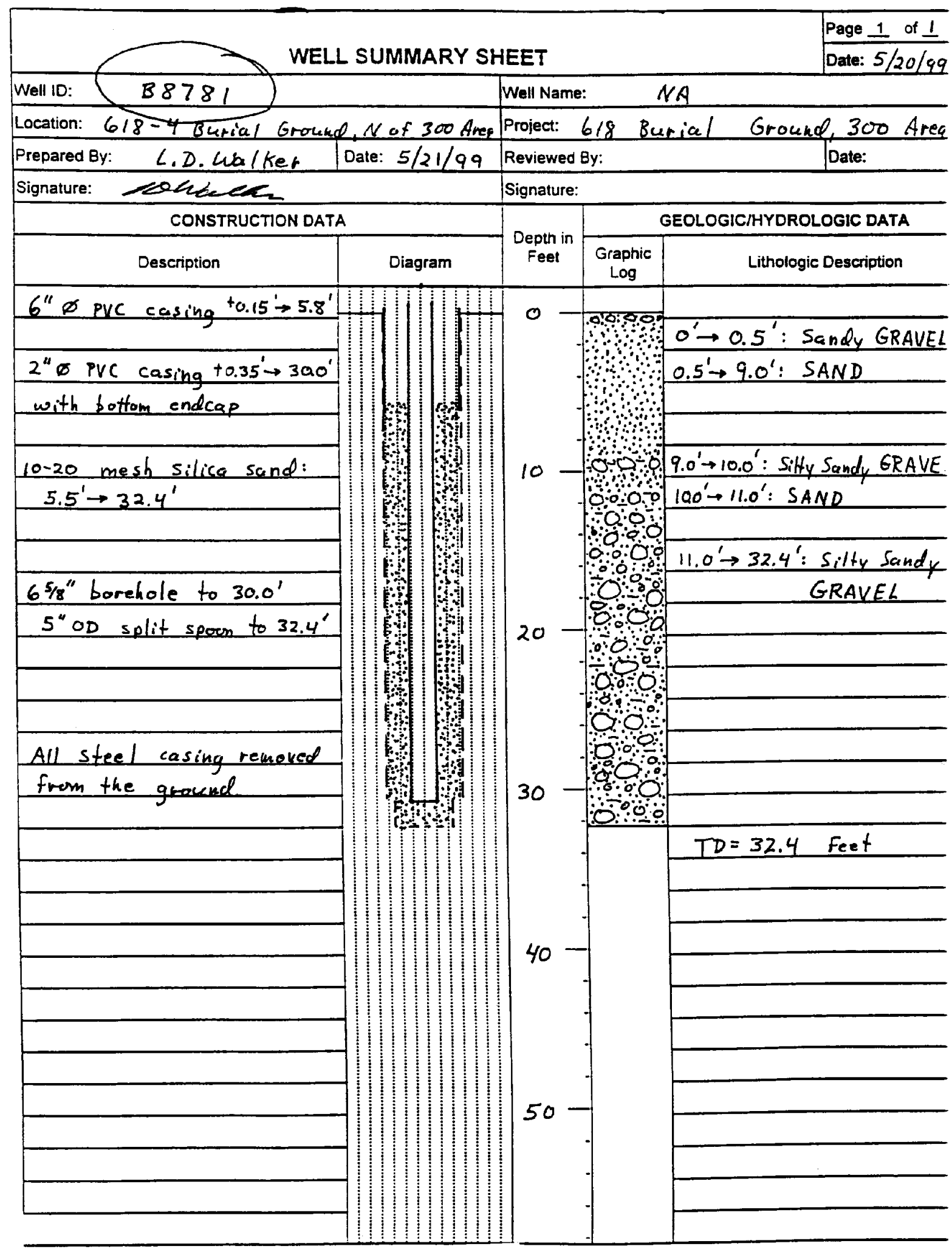

Figure 5 


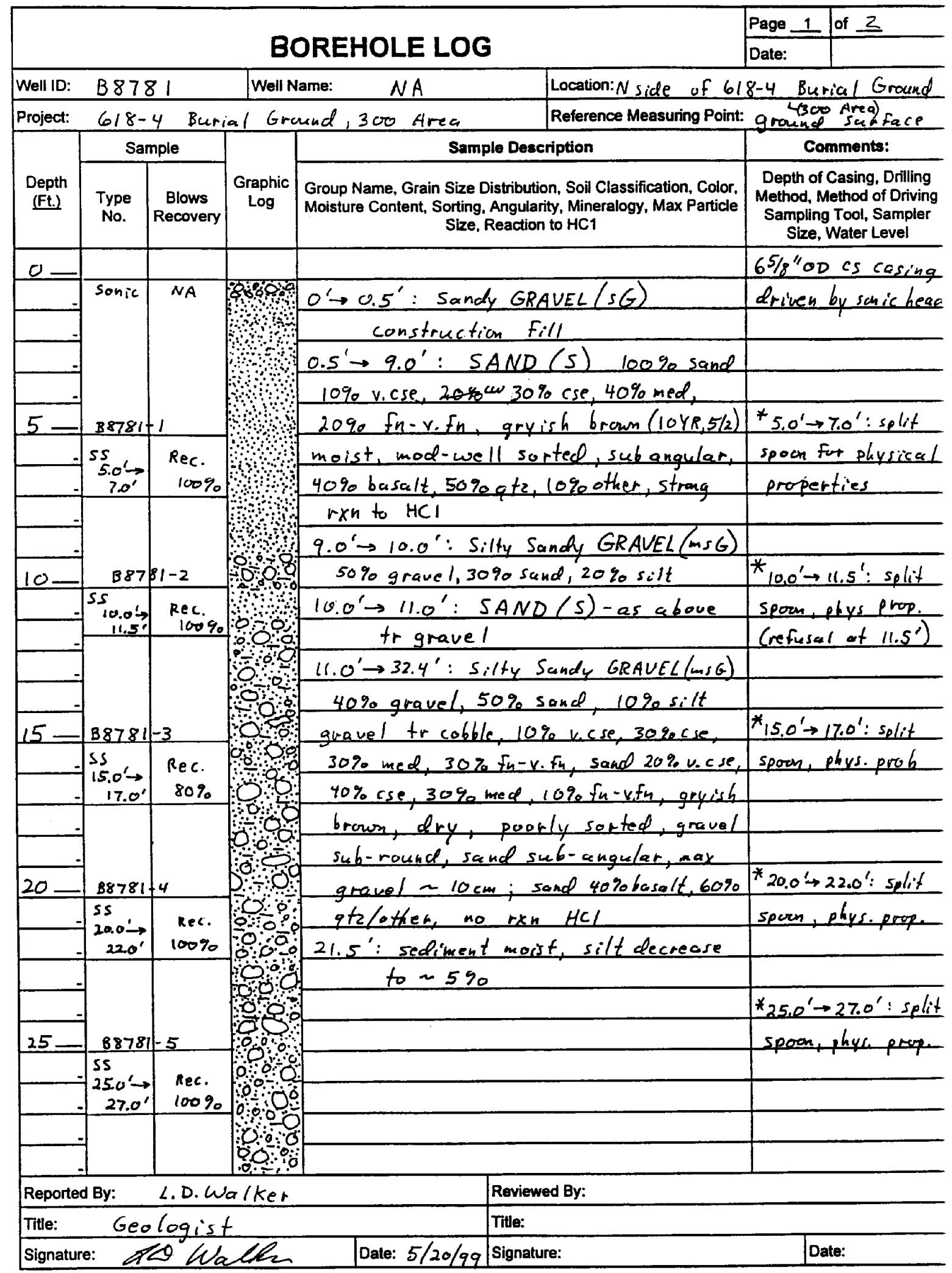

口HI-EE-183/42/97) 


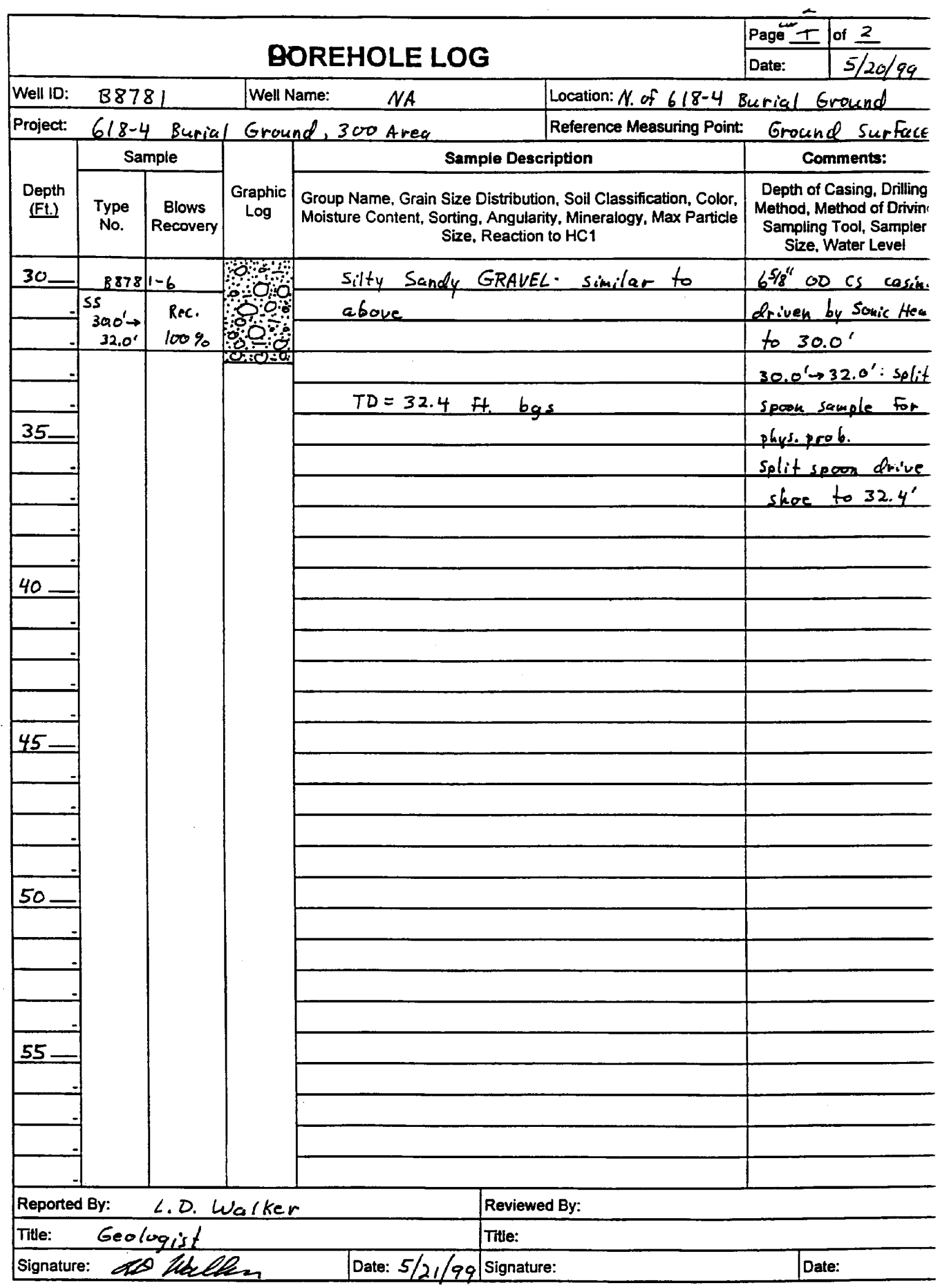




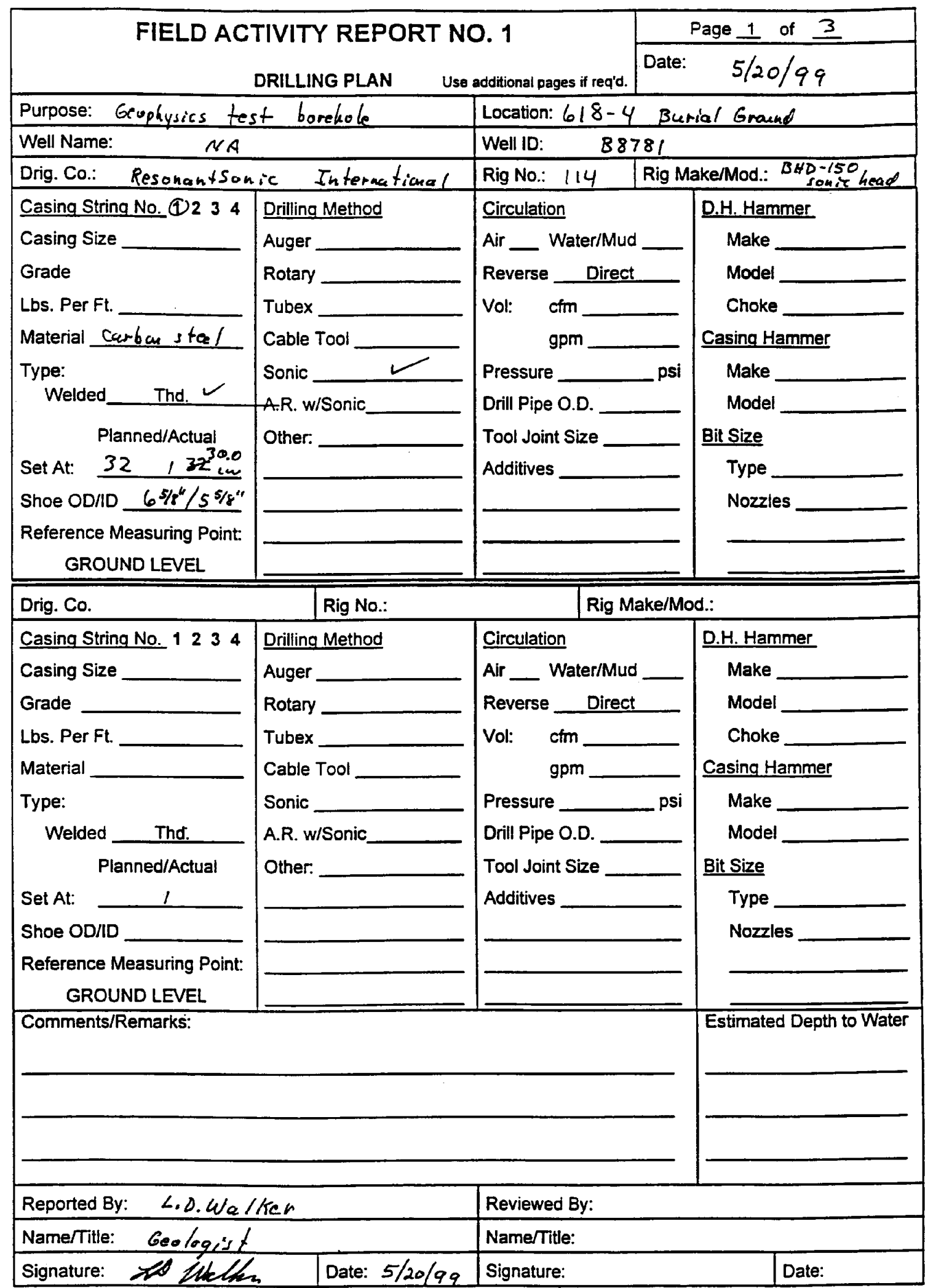

$\cdots,==\ldots . ., n$. 


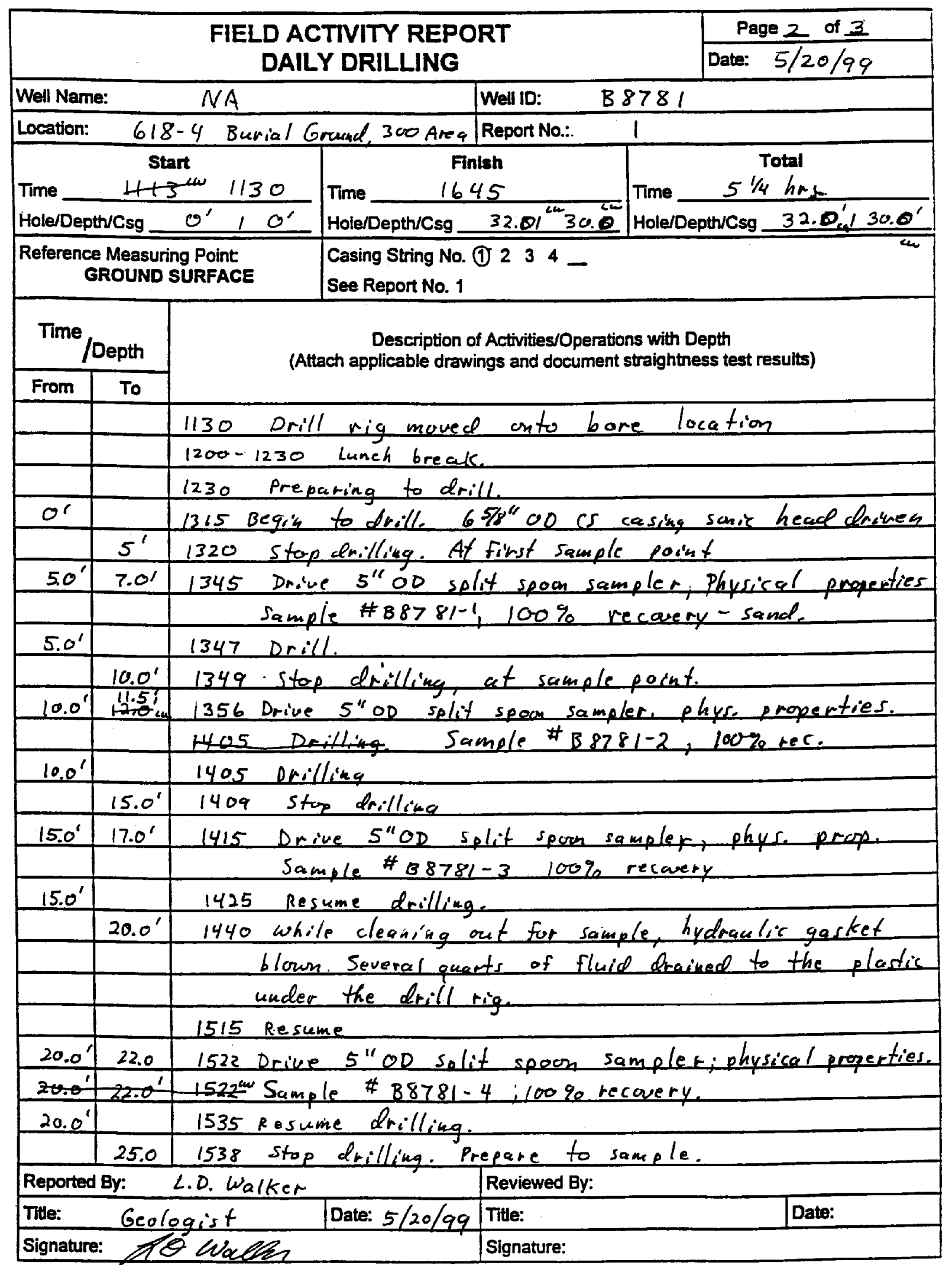




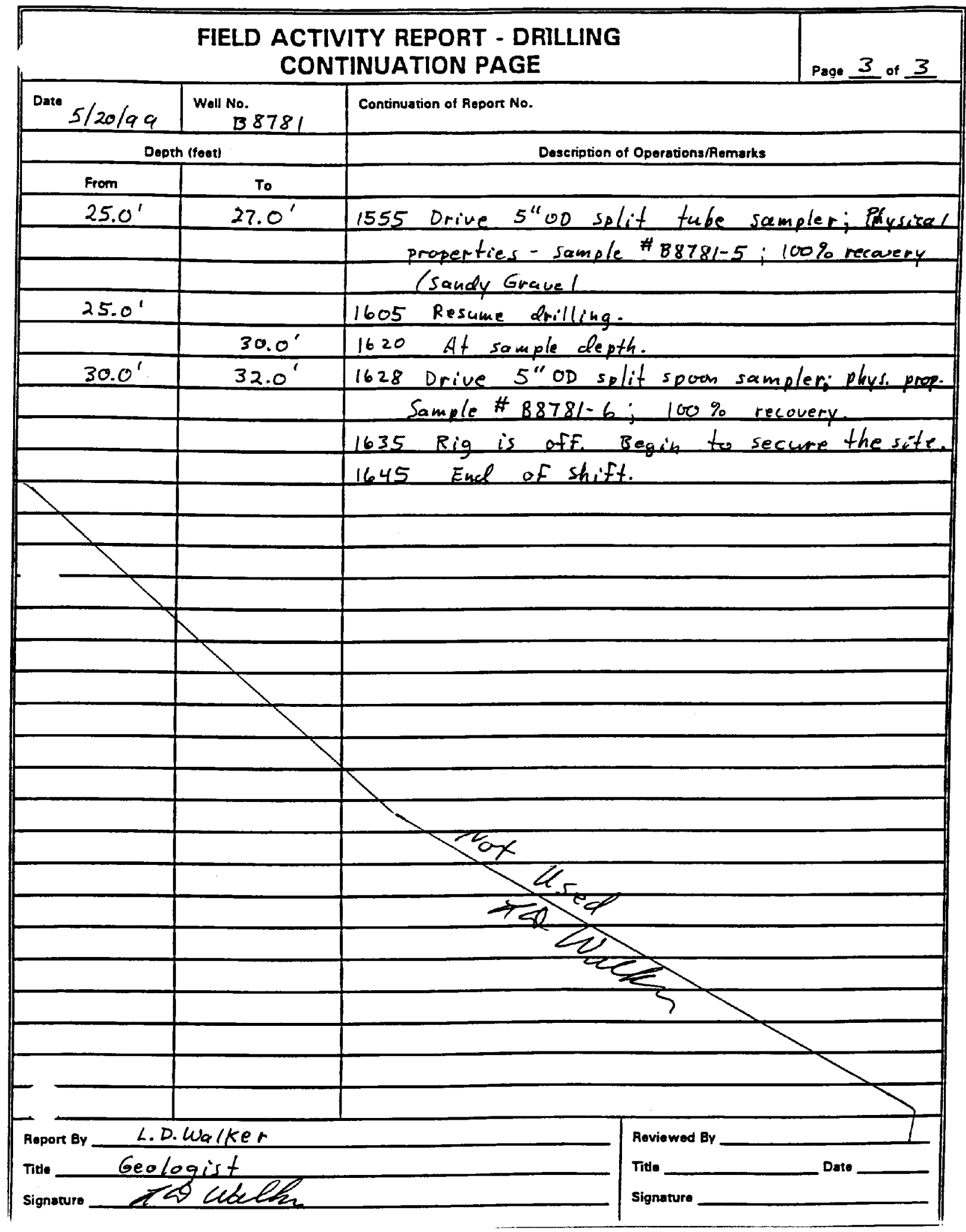

C. 43 


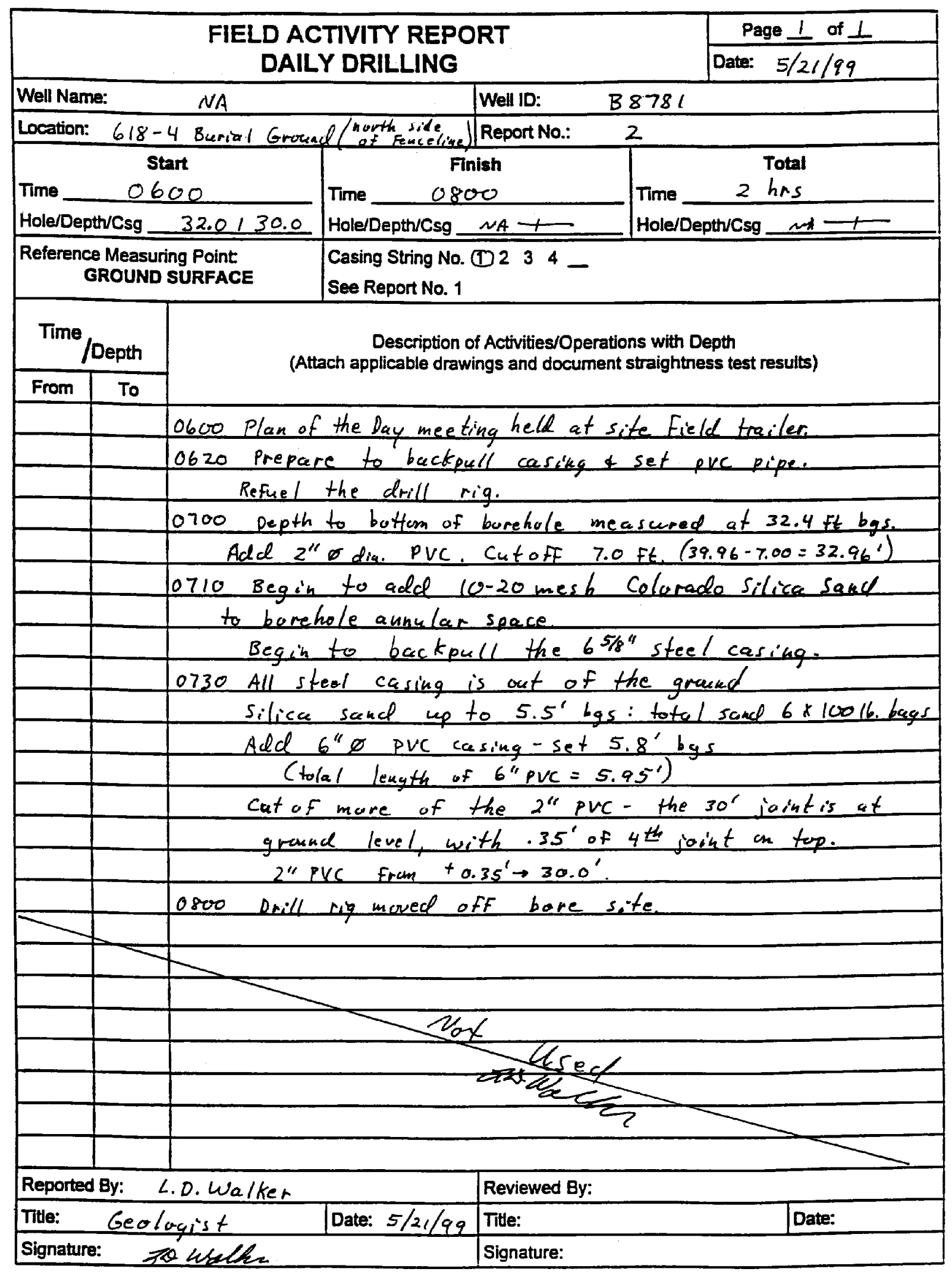




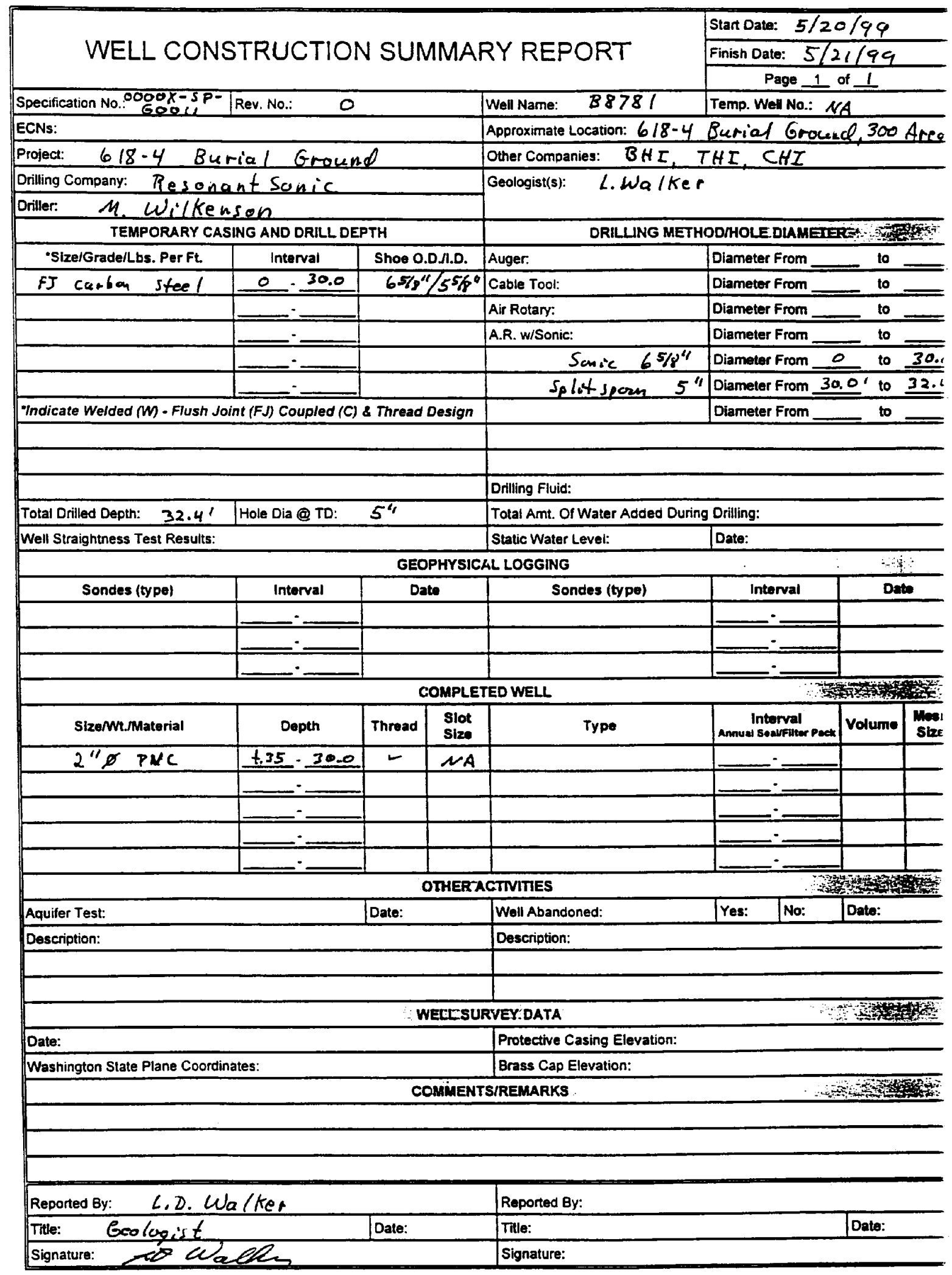

BHI-EE-181 (12/97) 


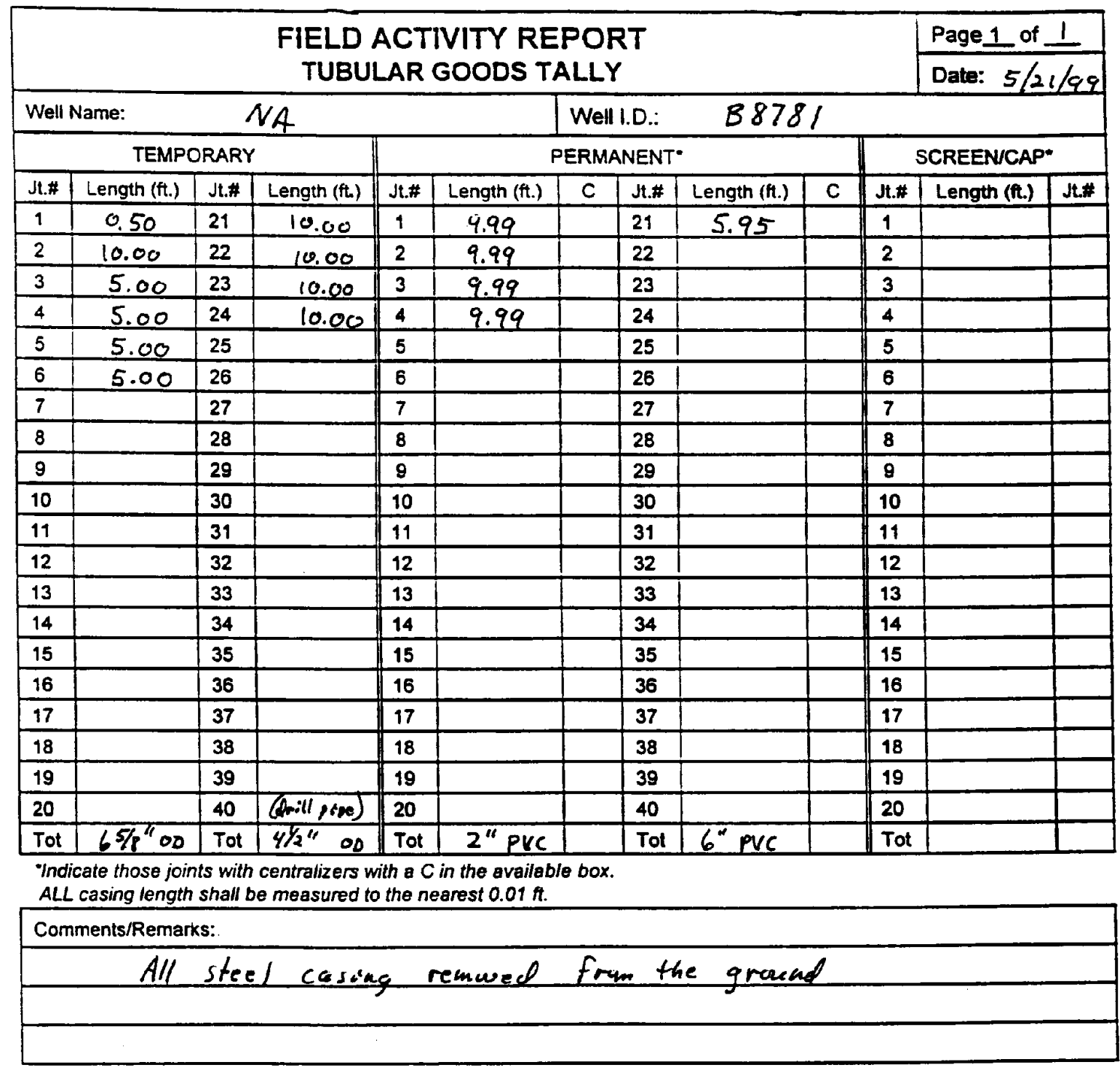

\begin{tabular}{|l|l|l|}
\hline Temporary: O.D.A.D. $65 / 8^{\prime \prime} / 55 / 8^{\prime \prime}$ & Permanent: O.D.N.D. $21 / 4^{\prime \prime} / 2^{\prime \prime}$ & Screen: O.D.A.D. \\
\hline & \\
\hline \\
\hline \\
\hline \\
\hline
\end{tabular}

\begin{tabular}{|l|l|l|l|}
\hline Reported By: L.D. Walker & Reviewed By: & \\
\hline Title: Geologtist & Date: $5 / 21 / 99$ & Title: & Date: \\
\hline Signature: ME Cebelhe & Signature: \\
\hline
\end{tabular}


Regularized Grid

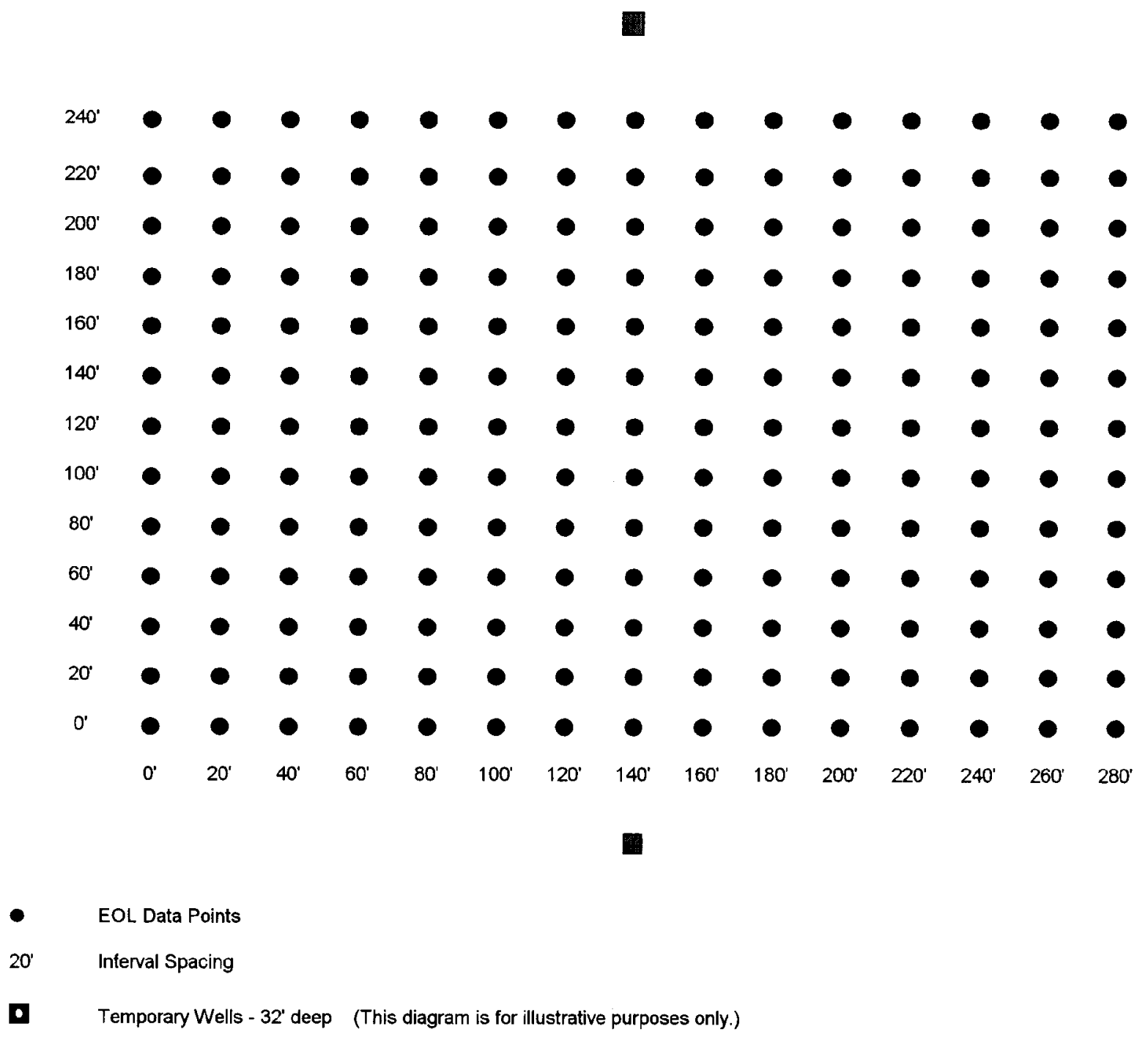

Figure 6 
Data Points A Wells with Overlaps to B Wells

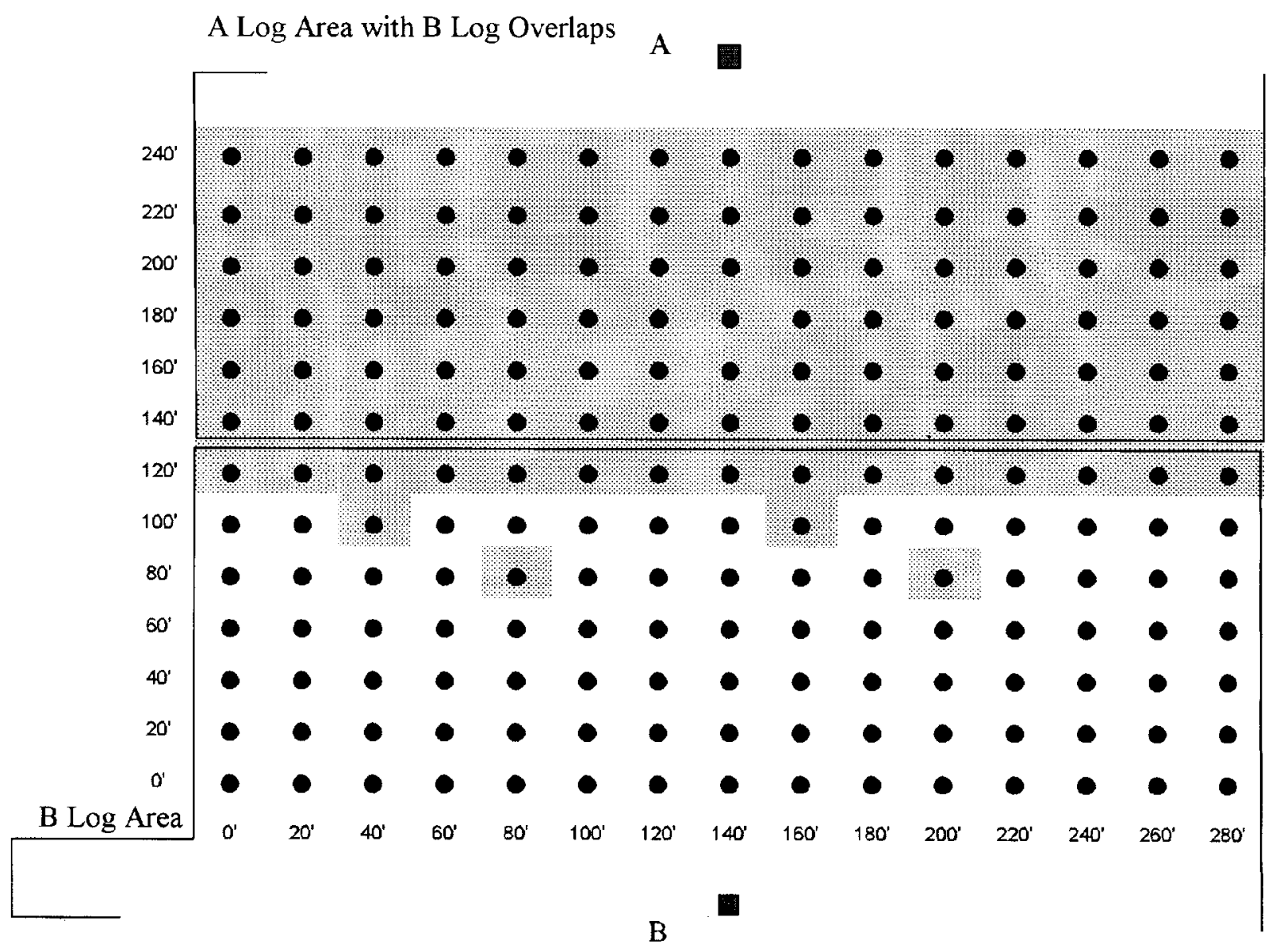

- EOL Data Points

$20^{\prime} \quad$ Interval Spacing

- Temporary Wells - 32' deep (This diagram is for illustrative purposes only:)

Figure 6 - A 
Data Points B Wells with Overlaps to A Wells

A
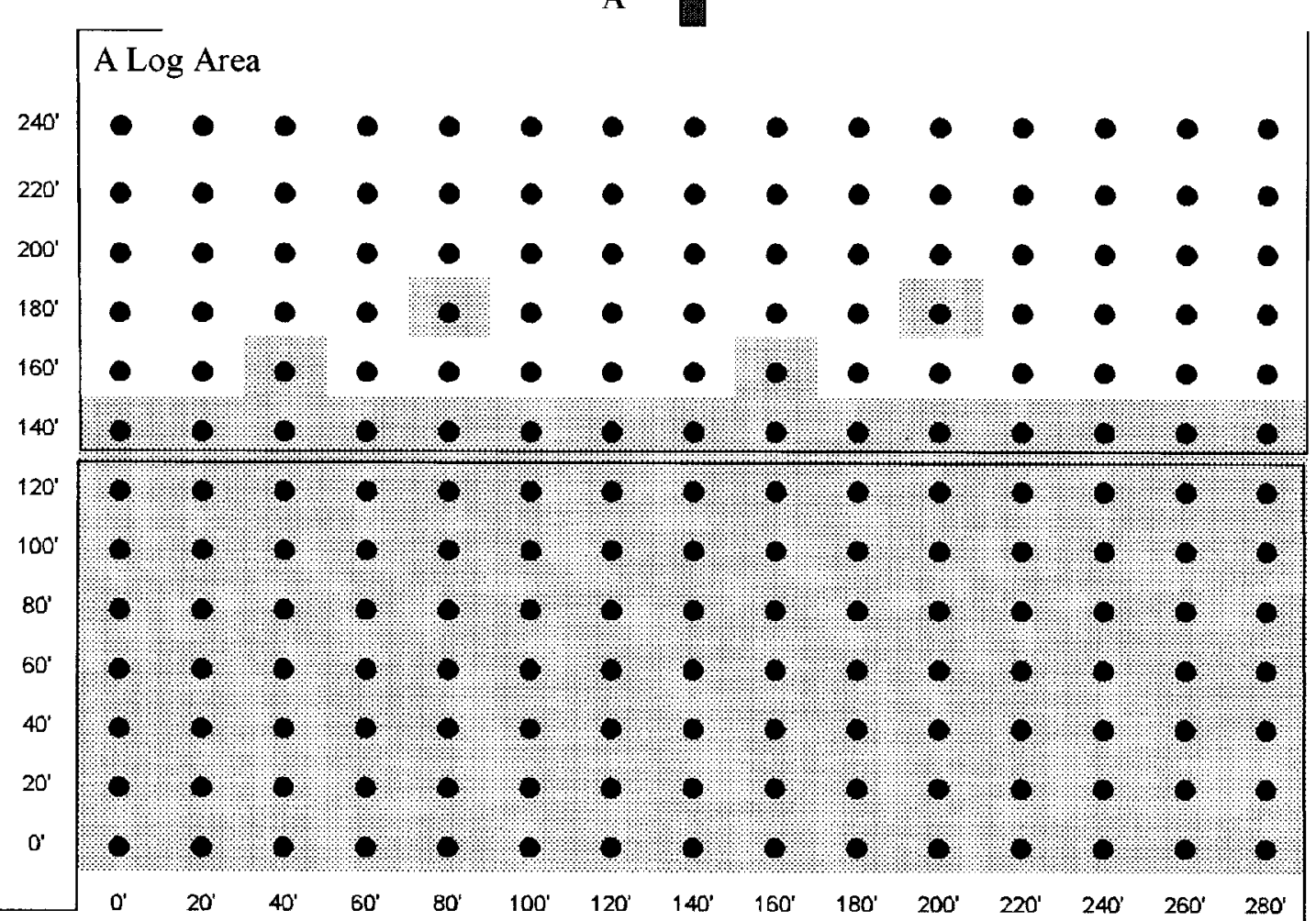

B Log Area with A Overlaps

B

- EOL Data Points

20' Interval Spacing

4 Temporary Wolls - 32' deep (This diagram is for illustrative purposes only.)

Figure 6 - B 


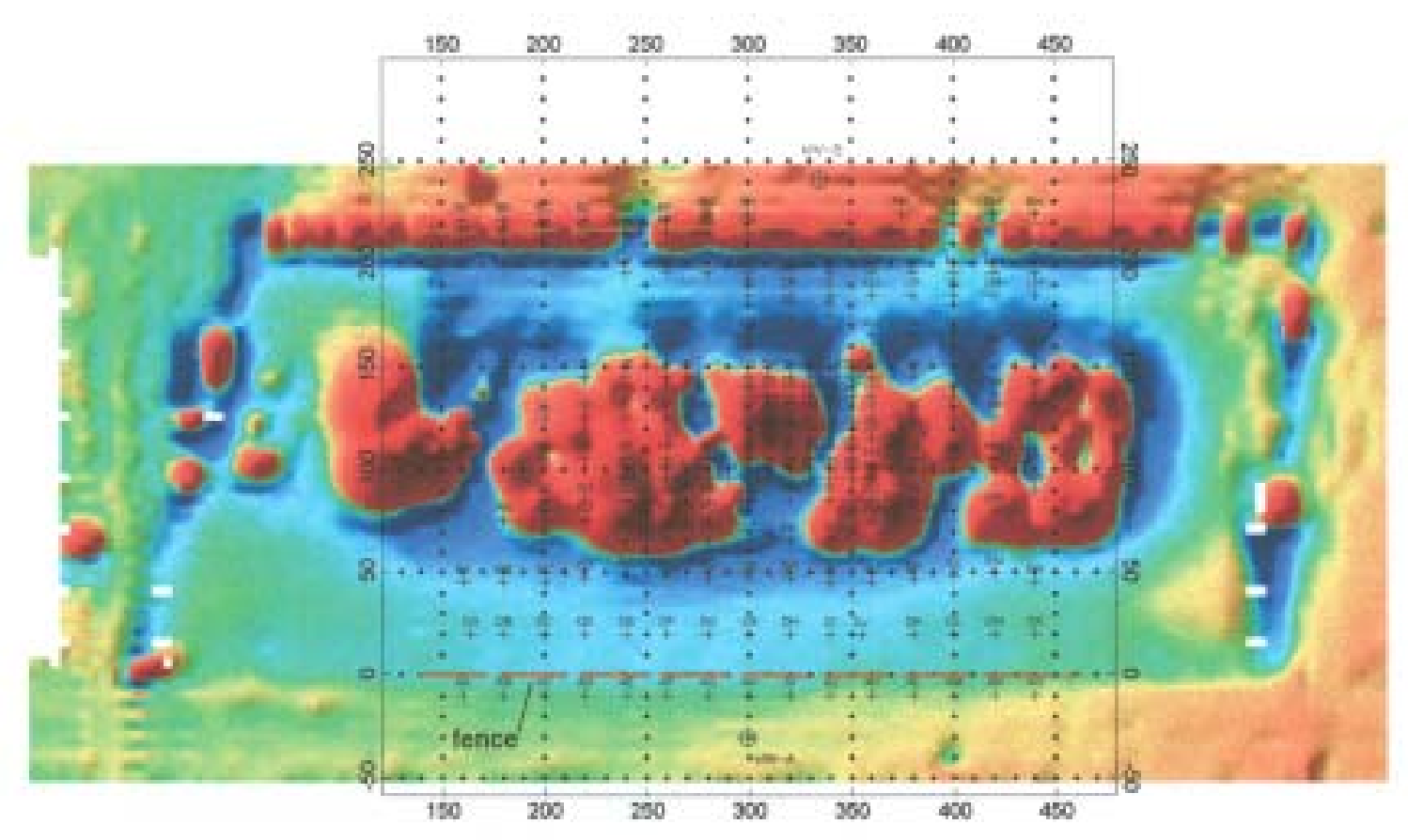

\section{Reduced to Pole Total Field Ground Magnetic Data}

Burial Ground 618-4 Hanford Reservation

WMI International, Inc.

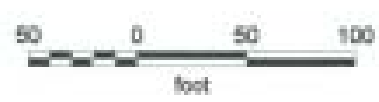

FIGURE 7 Msgnetometer: Geometrics Qes6 Proton Pracassion

houcing Fieid Inclination 6 Inducing Fied strength: $86000 \mathrm{nT}$ 


\section{Appendix D}

\section{High Resolution Geophysical Survey}


George Last

Pacific Northwest National Laboratory

902 Battelle Blvd MSIN K6-81

Richland WA 99352

\section{Subject: GEOPHYSICAL INVESTIGATION AT BURIAL GROUND 618-4}

Dear Mr. Last:

Enclosed are the results of the Geophysical investigation that was conducted at the $618-4$ Burial Ground. Electronic copies of the Time Domain Electromagnetic (TDEM), magnetic, and ground penetrating radar (GPR) data have been sent to Chris Murray.

Please contact Tom Mitchell at $372-9690$ or Kevin Bergstrom at $372-9591$ with any questions

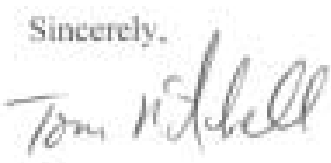

T. H. Mitchell

Design and Geoscience

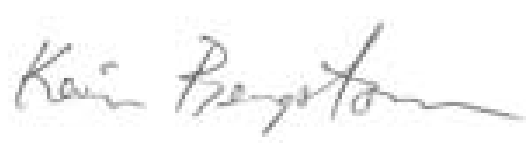

K. A. Bergstrom

Design and Geoscience

KAB:mre

Attachments: Attachment 1. Geophysical Investigation Results Summary Attachments 2-5. Surfer Plot Summary

Attachment 6. EM-61 Plots

Attachment 7. Magnetic Plots

Attachment 8. GPR and Elevation Plots

Electronic Files: Magnetic Data Spread Sheet

TDEM Data Spread Sheet

GPR and Elevation Data Spread Sheet

Attachments 2-8 Listed Above.

Copies to:

J. G. April (BHI) L6-06

C. Murray (PNNL) K6-81

S. W. Petersen (BHI) H0-23 


\section{8-4 Burial Ground, 300 Area Geophysical Investigation Summary}

Site: Center of 618-4 Burial Ground

Date: March 2001

Contract: Work Order through BHI

Sponsor/Client (Contact, phone):

Pacific Northwest National Laboratory

George Last, 376-3961, george.last@pnl.gov

Investigators (Name, Company, Phone, E-mail):

CH2MHill

Kevin Bergstrom (509) 372-9591 kabergst@bhi-erc.com

Tom Mitchell (509) 372-9690 thmitche@bhi-erc.com

Location:

Middle portion of 618-4 Burial Ground, north of the 300 Area. GPS coordinates for the geophysical grid were collected by PNNL personnel. The topographic survey data was not tied to MSL elevations.

Objective(s): To locate and map major concentrations of buried debris and identify potential stock piles of buried drums.

\section{Site Description}

Terrain: The site has been partially excavated from earlier ERC remediation activities creating a topographic low where the survey was focused. Within the low, the terrain was relatively flat with 1-2 meters of relief across the entire site. A relative topographic elevation survey was conducted as part of this investigation.

Vegetation: None

Hydro Properties (water table, moisture etc.):

The soil was dry when the data were collected. The water table was not a factor.

Soil/sediments/rock type:

Fill material consisting of gravel, sand, and silt.

Anticipated Bedrock:

None

Site limitations:

The site was in a contamination zone. Level C "Anti-C" protection was required. Preventive measures were necessary to minimize equipment contamination potential.

Overall assessment of site for geophysical investigations:

GPR, TDEM and magnetics were all effective for mapping buried debris. However, all three were limited when trying to isolate individual anomalies within the primary mass of debris in which they were buried.

\section{Type/model:}

\section{Equipment:}

- Magnetics: Geometrics G-858G magnetometer. Two cesium vapor magnetometers, with a one meter separation, in a vertical configuration. A base station was not used and no diurnal corrections were made

- Electromagnetics:

- Geonics EM61-MK2 Time Domain Metal Detector. The data were stored on a Pro 4000 Polycorder.

- Geonics EM-31 Ground Conductivity Meter. The data were stored on a Polycorder Series 720.

- Ground Penetrating Radar: GSSI SIR10A ground penetrating radar system. All data were collected with a GSSI $300 \mathrm{MHz}$ model 3105 AP. All hard copies were made with a GS-608P Plotter.

- Elevation Survey: Nikon AE-5C Automatic Level

Data format (tape/disk/hardcopy): All raw data saved as ASCII files on zip drive.

Data Collection Parameters:

\section{Data Collection Parameters:}

- A 1 x 1-meter grid was sprayed painted over the survey area. 
- The grid was directly tied to stakes that are located at key locations along the grid perimeter. The stakes were located by PNNL using Global Positioning System location survey technology.

- The magnetic and TDEM data were collected along profiles, spaced 1 meter apart with data points along individual profiles spaced 1 meter apart.

- The TDEM, EM-61 data were collected along E-W profiles. The EM-61 coils were 0.5 x 1.0 meter, carried by hand to prevent contact with the ground with the 1-meter coil dimension perpendicular to the direction of the profile.

- TDEM time gates recorded were: Bottom coil- 216, 366, and 660 microseconds. Top coil- 660 microseconds.

- The magnetic data were collected along north-south profiles.

- The magnetic data were collected in the vertical gradient mode with the lower magnetometer roughly 1 meter above the ground and the upper magnetometer roughly 2 meters above the ground (i.e. the boom was carried on the shoulder)

- No corrections were made for diurnal effects in the magnetic data.

- GPR data were collected along parallel profiles spaced 1 meter apart. Data were collected in the continuous mode with 50 scans per second and a recording window of 108 nanoseconds. A static stacking of 2 scans were used.

- GPR gains (time variable) and filters were set in the field to match soil conditions at the site.

\section{Data Processing Parameters:}

- The TDEM data were downloaded from the polycorder to a desktop computer via Geonics' software, DAT61, v1.70.

- The magnetic data were downloaded from the field magnetometer to a desktop computer using Geometrics' Geomag 2000 software.

- TDEM differential: top coil minus corresponding bottom coil (660 microseconds)

- Data were edited for mislabeled lines, viewed in raw form along each profile, and converted to XYZ.dat files.

- The TDEM and magnetic data processed and subsequently contoured using Golden Software's SURFER 7.0.

- No post processing of the GPR data were performed.

- The topographic survey data was based on the geophysical grid only and was not tied directly to the Washington State Plane Coordinate System. Likewise, the elevation data was not tied to true MSL elevations. The elevations are relative elevations tied to grid point N100/E100.

\section{Summary of Results:}

An interpretation summary map is provided that represents the integrated interpretation of the magnetics, TDEM, elevation, and GPR data. One area was identified that has the anticipated character of a stack of buried drums. All of the raw data were provided to PNNL for further analysis.

List of Attachments:

- Geophysical Investigation Results Summary

- Surfer Plot Summary Maps

- EM-61 Plots

- Magnetic Plots

- GPR and Elevation Plots 


\section{Data Filter Report}

Source Data File Name:

Isopachslisopach.xls

$X$ Column:

Y Column:

Z Column:
G:IGeophysicslerc and hanford $300 A R E A|618-4|$ topo

A

B

G - Topographic Relief

\section{Data Counts}

Number of Active Data: $\quad 125$

Number of Original Data: $\quad 125$

Number of Excluded Data: $\quad 0$

Number of Deleted Duplicates: 0

Number of Retained Duplicates: $\quad 0$

Number of Artificial Data: $\quad 0$

\section{Filter Rules}

Duplicate Points to Keep:

$X$ Duplicate Tolerance:

Y Duplicate Tolerance:

Exclusion Filter String:
First

0

0

Not In Use

\section{Data Statistics Report}

\section{Data Counts}

Number of Active Data:

Number of Original Data:

Number of Excluded Data:

Number of Deleted Duplicates:

Number of Retained Duplicates:

Number of Artificial Data:

0

0

0

0 


\section{Variable Statistics}

$X$ Range:

$X$ Midrange:

$X$ Minimum:

100

$X$ 25\%-tile:

119

$X$ Median:

134

X 75\%-tile:

146

$X$ Maximum:

150

$X$ Average:

130.32

$X$ Standard Deviation:

15.9261

$X$ Variance:

253.642

\section{Y Variable Statistics}

Y Range:

$Y$ Midrange:

$Y$ Minimum:

Y 25\%-tile:

Y Median:

Y 75\%-tile:

Y Maximum:

Y Average:

Y Standard Deviation:

$Y$ Variance:

\section{Z Variable Statistics}

$\begin{array}{ll}\text { Z Range: } & 2.4 \\ \text { Z Midrange: } & -1.2 \\ & \\ \text { Z Minimum: } & -2.4 \\ \text { Z 25\%-tile: } & -1.45 \\ \text { Z Median: } & -0.98 \\ \text { Z 75\%-tile: } & -0.58 \\ \text { Z Maximum: } & 0 \\ & \\ \text { Z Average: } & -1.0216 \\ \text { Z Standard Deviation: } & 0.523947 \\ \text { Z Variance: } & 0.274521 \\ & \\ \text { Z Coef. of Variation: } & 0 \\ \text { Z Coef. of Skewness: } & -0.0880714\end{array}$

29

114.5

100

103

110

120

129

111.432

9.25232

85.6054
$-0.0880714$ 


\section{Inter-Variable Correlation}

\begin{tabular}{llll}
\hline & $X$ & $Y$ & $Z$ \\
\hline$X:$ & 1 & 0.370468 & -0.459271 \\
$Y:$ & & 1 & -0.80784 \\
$Z:$ & & 1 \\
\hline
\end{tabular}

\section{Inter-Variable Covariance}

\begin{tabular}{llll}
\hline & $X$ & $Y$ & $Z$ \\
\hline$X:$ & 253.642 & 54.5898 & -3.83237 \\
Y: & & 85.6054 & -3.91619 \\
$Z:$ & & 0.274521 \\
\hline
\end{tabular}

\section{Gridding Report}

\section{Search Rules}

Use All Data:

true

\section{Gridding Rules}

Gridding Method:

Kriging Type:

Kriging

Point

\section{Semi-Variogram Model}

Component Type:

Variogram Slope:

Anisotropy Angle:

Anisotropy Ratio:

Linear
1
0
1
0
no

Polynomial Drift Order: $\quad 0$

Kriging standard deviation grid: no 


\section{Grid Summary}

Grid File Name:

Isopachsltrue topography.grd

Minimum X:

Maximum $\mathrm{X}$ :

Minimum Y:

Maximum $\mathrm{Y}$ :

Minimum Z:

Maximum Z:

Number of Rows:

Number of Columns:

Number of Filled Nodes:

Number of Blanked Nodes:

Total Number of Nodes:
G:IGeophysicslerc and hanford|300AREA|618-4|topo

100

150

100

129

$-2.4$

0.00656499

30

51

1530

0

1530 


\section{Data Filter Report}

Source Data File Name:

4lem61 lc61.dat

$X$ Column:

Y Column:

Z Column:
R:IGeophysicslerc and hanfordl300AREA|618-

A

$B$

F - Depth from Base Elevation

\section{Data Counts}

Number of Active Data: $\quad 1769$

Number of Original Data: $\quad 1769$

Number of Excluded Data: $\quad 0$

Number of Deleted Duplicates: 0

Number of Retained Duplicates: 0

Number of Artificial Data: $\quad 0$

\section{Filter Rules}

Duplicate Points to Keep:

$X$ Duplicate Tolerance:

Y Duplicate Tolerance:

Exclusion Filter String:
First

0

0

Not In Use

\section{Data Statistics Report}

\section{Data Counts}

Number of Active Data:

Number of Original Data:

Number of Excluded Data:

Number of Deleted Duplicates:

Number of Retained Duplicates:

Number of Artificial Data:

0

0

0

0 


\section{Variable Statistics}

$X$ Range:

50

$X$ Midrange:

$X$ Minimum:

100

$X$ 25\%-tile:

120

$X$ Median:

132

X 75\%-tile:

141

$X$ Maximum:

150

$X$ Average:

129.983

$X$ Standard Deviation:

13.7685

$X$ Variance:

189.572

\section{Y Variable Statistics}

Y Range:

$Y$ Midrange:

$Y$ Minimum:

Y 25\%-tile:

Y Median:

Y 75\%-tile:

$Y$ Maximum:

Y Average:

Y Standard Deviation:

$Y$ Variance:

\section{Z Variable Statistics}

$\begin{array}{ll}\text { Z Range: } & 2870.11 \\ \text { Z Midrange: } & 1215.98 \\ & \\ \text { Z Minimum: } & -219.07 \\ \text { Z 25\%-tile: } & 6.31 \\ \text { Z Median: } & 51.73 \\ \text { Z 75\%-tile: } & 246.96 \\ \text { Z Maximum: } & 2651.04 \\ & \\ \text { Z Average: } & 192.922 \\ \text { Z Standard Deviation: } & 319.748 \\ \text { Z Variance: } & 102239 \\ & \\ \text { Z Coef. of Variation: } & 1.65739 \\ \text { Z Coef. of Skewness: } & 2.97463\end{array}$

48

119

95

104

112

124

143

114.508

13.3418

178.002
2.97463 


\section{Inter-Variable Correlation}

\begin{tabular}{llll}
\hline & $X$ & $Y$ & $Z$ \\
\hline$X:$ & 1 & 0.383905 & -0.3518 \\
$Y:$ & & 1 & -0.0598314 \\
$Z:$ & & 1 \\
\hline
\end{tabular}

\section{Inter-Variable Covariance}

\begin{tabular}{llll}
\hline & $X$ & $Y$ & $Z$ \\
\hline$X:$ & 189.572 & 70.5219 & -1548.78 \\
Y: & & 178.002 & -255.24 \\
$Z:$ & & 102239 \\
\hline
\end{tabular}

\section{Gridding Report}

\section{Search Rules}

Number of Sectors:

Maximum Data Per Sector:

Minimum Number of Data:

Maximum Number of Empty Sectors: 0

Search Ellipse Radius \#1:

Search Ellipse Radius \#2:

Search Ellipse Angle:

\section{Gridding Rules}

Gridding Method:

Nearest Neighbor

\section{Grid Summary}

Grid File Name:

R:IGeophysicslerc and hanford $\ 300 A R E A \mid 618-$

4lem61|C61topa.grd

Minimum X:

Maximum X: 
Minimum $Y$ :

Maximum $Y$ :

Minimum Z:

Maximum Z:

Number of Rows:

Number of Columns:

Number of Filled Nodes:

Number of Blanked Nodes:

Total Number of Nodes:
95

143

$-219.07$

2651.04

49

51

1996

503

2499

D.11 


\section{Data Filter Report}

Source Data File Name:

Isopachslisopach.xls

$X$ Column:

Y Column:

Z Column:
G:IGeophysicslerc and hanford $300 A R E A|618-4|$ topo

A

B

D - Thickness of Overlying Fill

\section{Data Counts}

Number of Active Data: $\quad 580$

Number of Original Data: $\quad 580$

Number of Excluded Data: $\quad 0$

Number of Deleted Duplicates: 0

Number of Retained Duplicates: $\quad 0$

Number of Artificial Data: $\quad 0$

\section{Filter Rules}

Duplicate Points to Keep:

$X$ Duplicate Tolerance:

Y Duplicate Tolerance:

Exclusion Filter String:
First

0

0

Not In Use

\section{Data Statistics Report}

\section{Data Counts}

Number of Active Data:

Number of Original Data:

Number of Excluded Data:

0

Number of Deleted Duplicates: $\quad 0$

Number of Retained Duplicates: 0

Number of Artificial Data:

0 


\section{Variable Statistics}

$X$ Range:

$X$ Midrange:

$X$ Minimum:

100

$X$ 25\%-tile:

124

$X$ Median:

136

X 75\%-tile:

144

$X$ Maximum:

150

$X$ Average:

132.417

$X$ Standard Deviation:

13.6906

$X$ Variance:

187.433

\section{Y Variable Statistics}

Y Range:

$Y$ Midrange:

$Y$ Minimum:

Y 25\%-tile:

Y Median:

Y 75\%-tile:

Y Maximum:

Y Average:

Y Standard Deviation:

$Y$ Variance:

\section{Z Variable Statistics}

$\begin{array}{ll}\text { Z Range: } & 2.2 \\ \text { Z Midrange: } & 1.1 \\ & \\ \text { Z Minimum: } & 0 \\ \text { Z 25\%-tile: } & 0 \\ \text { Z Median: } & 0.5 \\ \text { Z 75\%-tile: } & 1 \\ \text { Z Maximum: } & 2.2 \\ & \\ \text { Z Average: } & 0.581034 \\ \text { Z Standard Deviation: } & 0.518205 \\ \text { Z Variance: } & 0.268537 \\ & \\ \text { Z Coef. of Variation: } & 0.891867 \\ \text { Z Coef. of Skewness: } & 0.618671\end{array}$

29

114.5

100

105

112

121

129

113.15

9.04871

81.8792 


\section{Inter-Variable Correlation}

\begin{tabular}{llll}
\hline & $X$ & $Y$ & $Z$ \\
\hline$X:$ & 1 & 0.4286 & 0.239497 \\
$Y:$ & & 1 & 0.206955 \\
$Z:$ & & 1 \\
\hline
\end{tabular}

\section{Inter-Variable Covariance}

\begin{tabular}{llll}
\hline & $X$ & $Y$ & $Z$ \\
\hline$X:$ & 187.433 & 53.096 & 1.69912 \\
Y: & & 81.8792 & 0.970431 \\
$Z:$ & & 0.268537 \\
\hline
\end{tabular}

\section{Gridding Report}

\section{Search Rules}

Number of Sectors: $\quad 4$

Maximum Data Per Sector: $\quad 6$

Minimum Number of Data: $\quad 5$

Maximum Number of Empty Sectors: 4

Search Ellipse Radius \#1: $\quad 28.9$

Search Ellipse Radius \#2: $\quad 28.9$

Search Ellipse Angle: 0

\section{Gridding Rules}

Gridding Method: Kriging

Kriging Type: Point

\section{Semi-Variogram Model}

Component Type:

Variogram Slope:

Anisotropy Angle:

Anisotropy Ratio:

Linear
1
0
1
0
no

Polynomial Drift Order: $\quad 0$

Kriging standard deviation grid: $\quad$ no 


\section{Grid Summary}

Grid File Name:

Isopachs ITHICK.grd

Minimum X:

Maximum $\mathrm{X}$ :

Minimum Y:

Maximum $\mathrm{Y}$ :

Minimum Z:

Maximum Z:

Number of Rows:

Number of Columns:

Number of Filled Nodes:

Number of Blanked Nodes:

Total Number of Nodes:
G:IGeophysicslerc and hanford $\backslash 300 A R E A|618-4|$ topo

100

150

100

129

$-0.179998$

2.2

30

51

1530

0

1530 


\section{Data Filter Report}

Source Data File Name:

4lem61 lc61.dat

$X$ Column:

Y Column:

Z Column:
R:IGeophysicslerc and hanfordl300AREA|618-

A

$B$

E - Bottom coil - $3^{\text {rd }}$ time gate $(660 \mu \mathrm{sec})$

\section{Data Counts}

Number of Active Data: $\quad 1769$

Number of Original Data: $\quad 1769$

Number of Excluded Data: $\quad 0$

Number of Deleted Duplicates: 0

Number of Retained Duplicates: 0

Number of Artificial Data:

0
0
0

\section{Filter Rules}

Duplicate Points to Keep:

$X$ Duplicate Tolerance:

Y Duplicate Tolerance:

First

0

0

Exclusion Filter String: Not In Use

\section{Data Statistics Report}

\section{Data Counts}

Number of Active Data:

Number of Original Data:

Number of Excluded Data:

Number of Deleted Duplicates:

Number of Retained Duplicates:

Number of Artificial Data:

0

0

0

0 


\section{Variable Statistics}

$X$ Range:

50

$X$ Midrange:

$X$ Minimum:

100

$X$ 25\%-tile:

120

$X$ Median:

132

X 75\%-tile:

141

$X$ Maximum:

150

$X$ Average:

129.983

$X$ Standard Deviation:

13.7685

$X$ Variance:

189.572

\section{Y Variable Statistics}

Y Range:

$Y$ Midrange:

$Y$ Minimum:

Y 25\%-tile:

Y Median:

Y 75\%-tile:

$Y$ Maximum:

Y Average:

Y Standard Deviation:

$Y$ Variance:

\section{Z Variable Statistics}

$\begin{array}{ll}\text { Z Range: } & 2193.82 \\ \text { Z Midrange: } & 1097.56 \\ & \\ \text { Z Minimum: } & 0.65 \\ \text { Z 25\%-tile: } & 1.36 \\ \text { Z Median: } & 26.35 \\ \text { Z 75\%-tile: } & 140.52 \\ \text { Z Maximum: } & 2194.47 \\ & \\ \text { Z Average: } & 123.437 \\ \text { Z Standard Deviation: } & 231.676 \\ \text { Z Variance: } & 53673.6 \\ & \\ \text { Z Coef. of Variation: } & 1.87687 \\ \text { Z Coef. of Skewness: } & 3.59333\end{array}$

48

119

95

104

112

124

143

114.508

13.3418

178.002
.59333 


\section{Inter-Variable Correlation}

\begin{tabular}{llll}
\hline & $X$ & $Y$ & $Z$ \\
\hline$X:$ & 1 & 0.383905 & -0.336446 \\
$Y:$ & & 1 & -0.0435445 \\
$Z:$ & & 1 \\
\hline
\end{tabular}

\section{Inter-Variable Covariance}

\begin{tabular}{llll}
\hline & $X$ & $Y$ & $Z$ \\
\hline$X:$ & 189.572 & 70.5219 & -1073.21 \\
Y: & & 178.002 & -134.594 \\
$Z:$ & & 53673.6 \\
\hline
\end{tabular}

\section{Gridding Report}

\section{Search Rules}

Number of Sectors:

Maximum Data Per Sector:

Minimum Number of Data:

Maximum Number of Empty Sectors: 0

Search Ellipse Radius \#1:

Search Ellipse Radius \#2:

Search Ellipse Angle:

\section{Gridding Rules}

Gridding Method:

Nearest Neighbor

\section{Grid Summary}

Grid File Name:

R:IGeophysicslerc and hanford $\ 300 A R E A \mid 618-$

4lem61lC61d3a.grd

Minimum X:

Maximum X: 
Minimum $Y$ :

Maximum $Y$ :

Minimum Z:

Maximum Z:

Number of Rows:

Number of Columns:

Number of Filled Nodes:

Number of Blanked Nodes:

Total Number of Nodes:
95

143

0.65

2194.47

49

51

1996

503

2499 


\section{Data Filter Report}

Source Data File Name:

4lem61 lc61.dat

$X$ Column:

Y Column:

Z Column:
R:IGeophysicslerc and hanfordl300AREA|618-

A

B

F - Top coil - $660 \mu s e c$ time gate

\section{Data Counts}

Number of Active Data: $\quad 1769$

Number of Original Data: $\quad 1769$

Number of Excluded Data: $\quad 0$

Number of Deleted Duplicates: 0

Number of Retained Duplicates: 0

Number of Artificial Data: $\quad 0$

\section{Filter Rules}

Duplicate Points to Keep:

$X$ Duplicate Tolerance:

Y Duplicate Tolerance:

Exclusion Filter String:
First

0

0

Not In Use

\section{Data Statistics Report}

\section{Data Counts}

Number of Active Data:

Number of Original Data:

Number of Excluded Data:

Number of Deleted Duplicates:

Number of Retained Duplicates:

Number of Artificial Data:

0

0

0

0 


\section{Variable Statistics}

$X$ Range:

50

$X$ Midrange:

$X$ Minimum:

100

$X$ 25\%-tile:

120

$X$ Median:

132

X 75\%-tile:

141

$X$ Maximum:

150

$X$ Average:

129.983

$X$ Standard Deviation:

13.7685

$X$ Variance:

189.572

\section{Y Variable Statistics}

Y Range:

$Y$ Midrange:

$Y$ Minimum:

Y 25\%-tile:

Y Median:

Y 75\%-tile:

$Y$ Maximum:

Y Average:

Y Standard Deviation:

$Y$ Variance:

\section{Z Variable Statistics}

$\begin{array}{ll}\text { Z Range: } & 2870.11 \\ \text { Z Midrange: } & 1215.98 \\ & \\ \text { Z Minimum: } & -219.07 \\ \text { Z 25\%-tile: } & 6.31 \\ \text { Z Median: } & 51.73 \\ \text { Z 75\%-tile: } & 246.96 \\ \text { Z Maximum: } & 2651.04 \\ & \\ \text { Z Average: } & 192.922 \\ \text { Z Standard Deviation: } & 319.748 \\ \text { Z Variance: } & 102239 \\ & \\ \text { Z Coef. of Variation: } & 1.65739 \\ \text { Z Coef. of Skewness: } & 2.97463\end{array}$

48

119

95

104

112

124

143

114.508

13.3418

178.002
2.97463 


\section{Inter-Variable Correlation}

\begin{tabular}{llll}
\hline & $X$ & $Y$ & $Z$ \\
\hline$X:$ & 1 & 0.383905 & -0.3518 \\
$Y:$ & & 1 & -0.0598314 \\
$Z:$ & & 1 \\
\hline
\end{tabular}

\section{Inter-Variable Covariance}

\begin{tabular}{llll}
\hline & $X$ & $Y$ & $Z$ \\
\hline$X:$ & 189.572 & 70.5219 & -1548.78 \\
Y: & & 178.002 & -255.24 \\
$Z:$ & & 102239 \\
\hline
\end{tabular}

\section{Gridding Report}

\section{Search Rules}

Number of Sectors:

Maximum Data Per Sector:

Minimum Number of Data:

Maximum Number of Empty Sectors: 0

Search Ellipse Radius \#1:

Search Ellipse Radius \#2:

Search Ellipse Angle:

\section{Gridding Rules}

Gridding Method:

Nearest Neighbor

\section{Grid Summary}

Grid File Name:

R:IGeophysicslerc and hanford $\ 300 A R E A \mid 618-$

4lem61|C61topa.grd

Minimum X:

Maximum X: 
Minimum $Y$ :

Maximum $Y$ :

Minimum Z:

Maximum Z:

Number of Rows:

Number of Columns:

Number of Filled Nodes:

Number of Blanked Nodes:

Total Number of Nodes:
95

143

$-219.07$

2651.04

49

51

1996

503

2499 


\section{Data Filter Report}

Source Data File Name:

4lem61 lc61.dat

$X$ Column:

Y Column:

Z Column:
R:IGeophysicslerc and hanfordl300AREA|618-

A

B

$\mathrm{H}$ - Calculated differential value (Top - Bott)

\section{Data Counts}

Number of Active Data: $\quad 1769$

Number of Original Data: $\quad 1769$

Number of Excluded Data: $\quad 0$

Number of Deleted Duplicates: 0

Number of Retained Duplicates: 0

Number of Artificial Data: $\quad 0$

\section{Filter Rules}

Duplicate Points to Keep:

$X$ Duplicate Tolerance:

Y Duplicate Tolerance:

Exclusion Filter String:
First

0

0

Not In Use

\section{Data Statistics Report}

\section{Data Counts}

Number of Active Data:

Number of Original Data:

Number of Excluded Data:

Number of Deleted Duplicates:

Number of Retained Duplicates:

Number of Artificial Data:

0

0

0

0 


\section{Variable Statistics}

$X$ Range:

50

$X$ Midrange:

$X$ Minimum:

100

$X$ 25\%-tile:

120

$X$ Median:

132

X 75\%-tile:

141

$X$ Maximum:

150

$X$ Average:

129.983

$X$ Standard Deviation:

13.7685

$X$ Variance:

189.572

\section{Y Variable Statistics}

Y Range:

$Y$ Midrange:

$Y$ Minimum:

Y 25\%-tile:

Y Median:

Y 75\%-tile:

$Y$ Maximum:

Y Average:

Y Standard Deviation:

$Y$ Variance:

\section{Z Variable Statistics}

$\begin{array}{ll}\text { Z Range: } & 1411.33 \\ \text { Z Midrange: } & -86.155 \\ & -791.82 \\ \text { Z Minimum: } & 4.93 \\ \text { Z 25\%-tile: } & 24.7 \\ \text { Z Median: } & 104.09 \\ \text { Z 75\%-tile: } & 619.51 \\ \text { Z Maximum: } & 69.4852 \\ & 96.8727 \\ \text { Z Average: } & 9384.32 \\ \text { Z Standard Deviation: } & \\ \text { Z Variance: } & 1.39415 \\ & 1.34975\end{array}$

48

119

95

104

112

124

143

114.508

13.3418

178.002 


\section{Inter-Variable Correlation}

\begin{tabular}{llll}
\hline & $X$ & $Y$ & $Z$ \\
\hline$X:$ & 1 & 0.383905 & -0.35656 \\
$Y:$ & & 1 & -0.0933467 \\
$Z:$ & & 1 \\
\hline
\end{tabular}

\section{Inter-Variable Covariance}

\begin{tabular}{llll}
\hline & $X$ & $Y$ & $Z$ \\
\hline$X:$ & 189.572 & 70.5219 & -475.578 \\
Y: & & 178.002 & -120.646 \\
$Z:$ & & 9384.32 \\
\hline
\end{tabular}

\section{Gridding Report}

\section{Search Rules}

Number of Sectors:

Maximum Data Per Sector:

Minimum Number of Data:

Maximum Number of Empty Sectors: 0

Search Ellipse Radius \#1:

Search Ellipse Radius \#2:

Search Ellipse Angle:

\section{Gridding Rules}

Gridding Method:

Nearest Neighbor

\section{Grid Summary}

Grid File Name:

R:IGeophysicslerc and hanford $\ 300 A R E A \mid 618-$

4lem61\C61difa.grd

Minimum X:

Maximum X: 
Minimum $Y$ :

Maximum $Y$ :

Minimum Z:

Maximum Z:

Number of Rows:

Number of Columns:

Number of Filled Nodes:

Number of Blanked Nodes:

Total Number of Nodes:
95

143

$-791.82$

619.51

49

51

1996

503

2499 
Geophysical Investigation Results Summary 618-4 Burial Grounds

March 2001

\begin{tabular}{|c|c|}
\hline 210 & Highly concentrated buried debris \\
\hline $\mathbb{Q 1 7 D}$ & $\begin{array}{l}\text { Debris that is buried relatively deep with significantly } \\
\text { less ferrous malerial within it. }\end{array}$ \\
\hline (IIID & $\begin{array}{l}\text { Area that has that anticipated character of a high } \\
\text { concentration of buried metallic drums. }\end{array}$ \\
\hline $\begin{array}{l}\text { (2) } \\
\pm \pm \pm\end{array}$ & $\begin{array}{l}\text { Notable anomaly above primary concentration of landfill debris. } \\
\text { (Depth in metric) } \\
\text { Excavation Boundary }\end{array}$ \\
\hline 田 & Average depth (meters) to the surrounding buried debris \\
\hline$=$ & Boundry within the dobris \\
\hline $\begin{array}{l}\text { - } \\
\text { Questions: }\end{array}$ & $\begin{array}{l}\text { Fence Post } \\
\text { Contact TH Mitchell / KA Bergstrom @ 372-9690 or 372-9591 }\end{array}$ \\
\hline
\end{tabular}
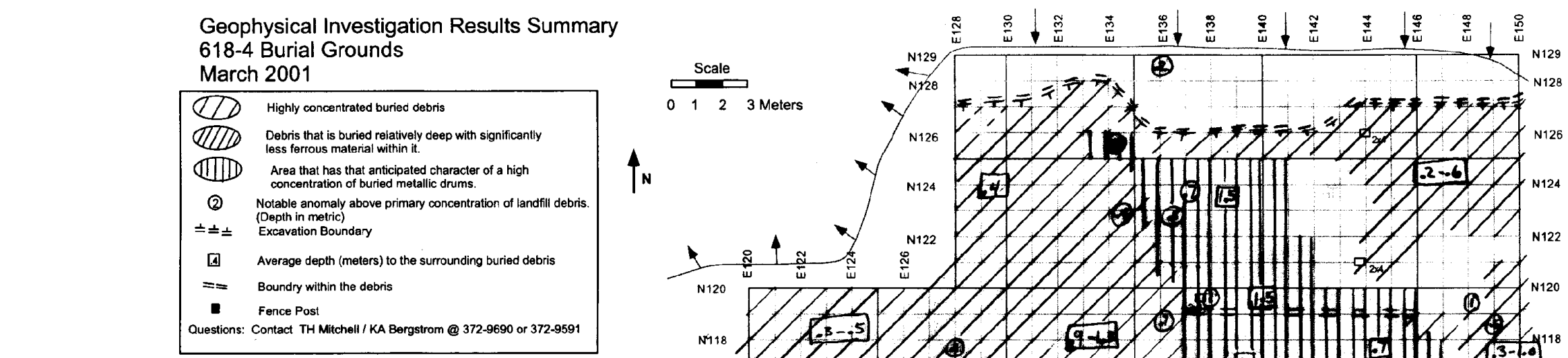

(2)

$\hat{A}_{\mathrm{N}}$

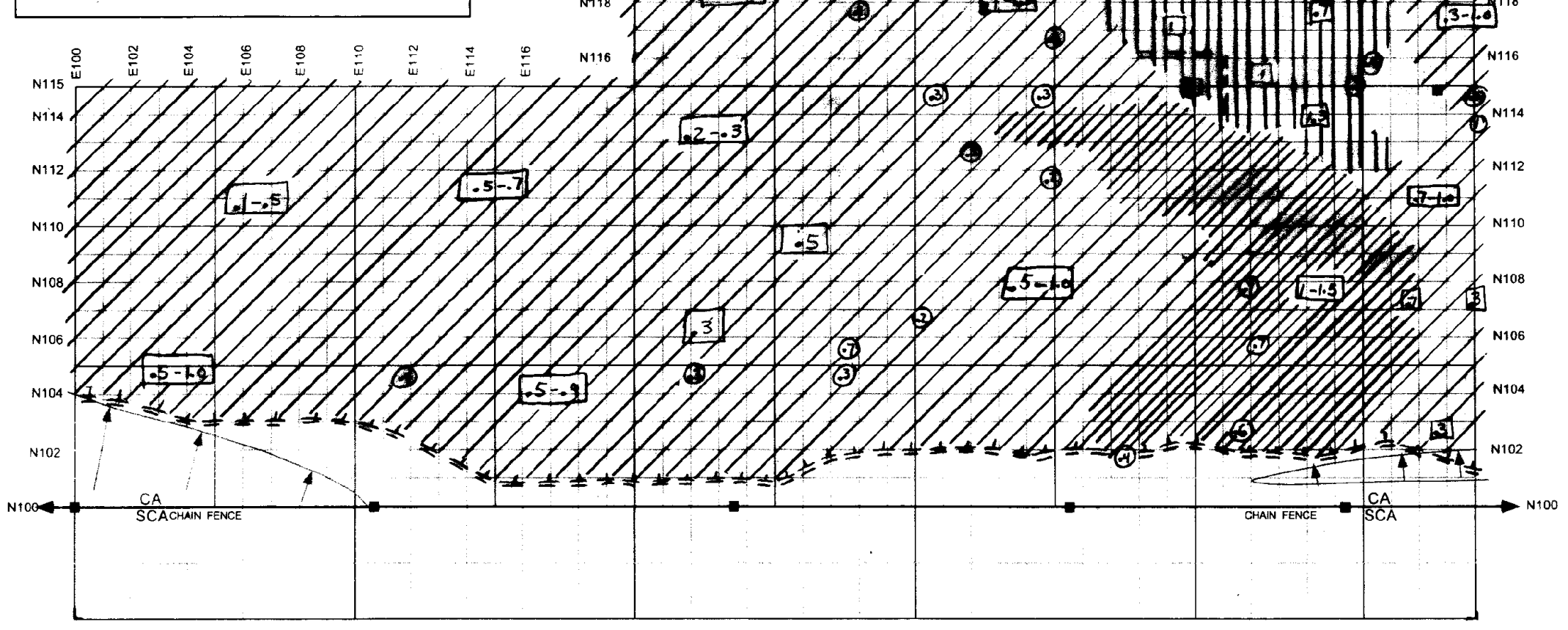

曽

Figure D.1. Geophysical Investigation Results Summary 


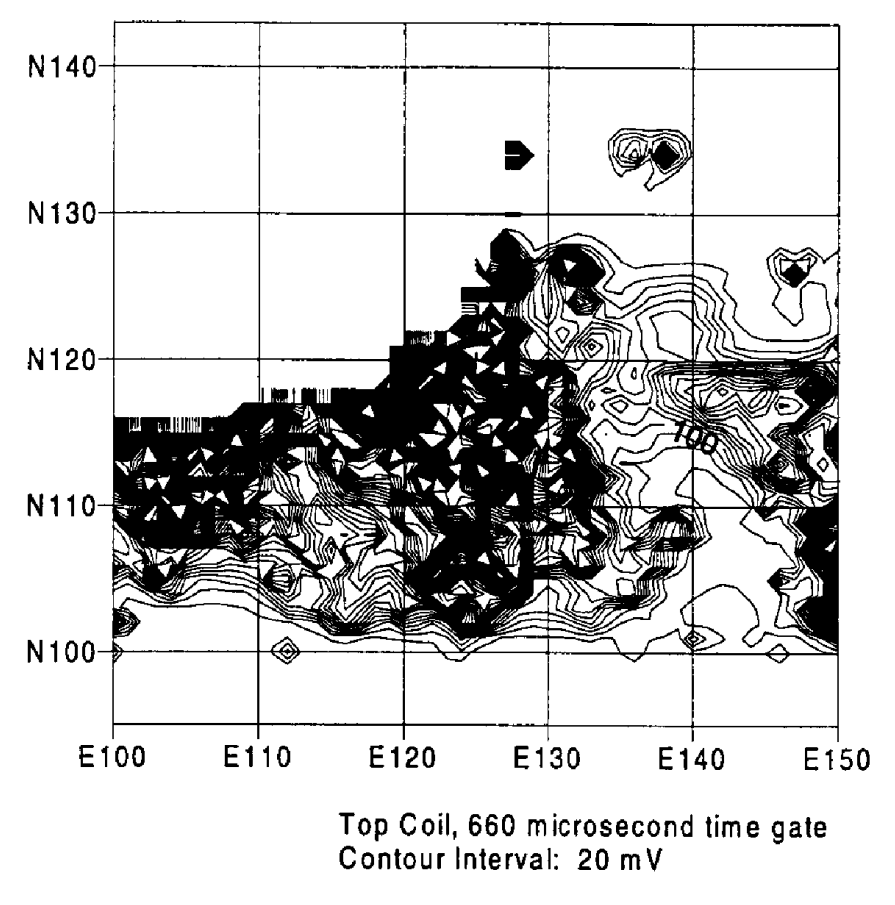

Scale in Meters
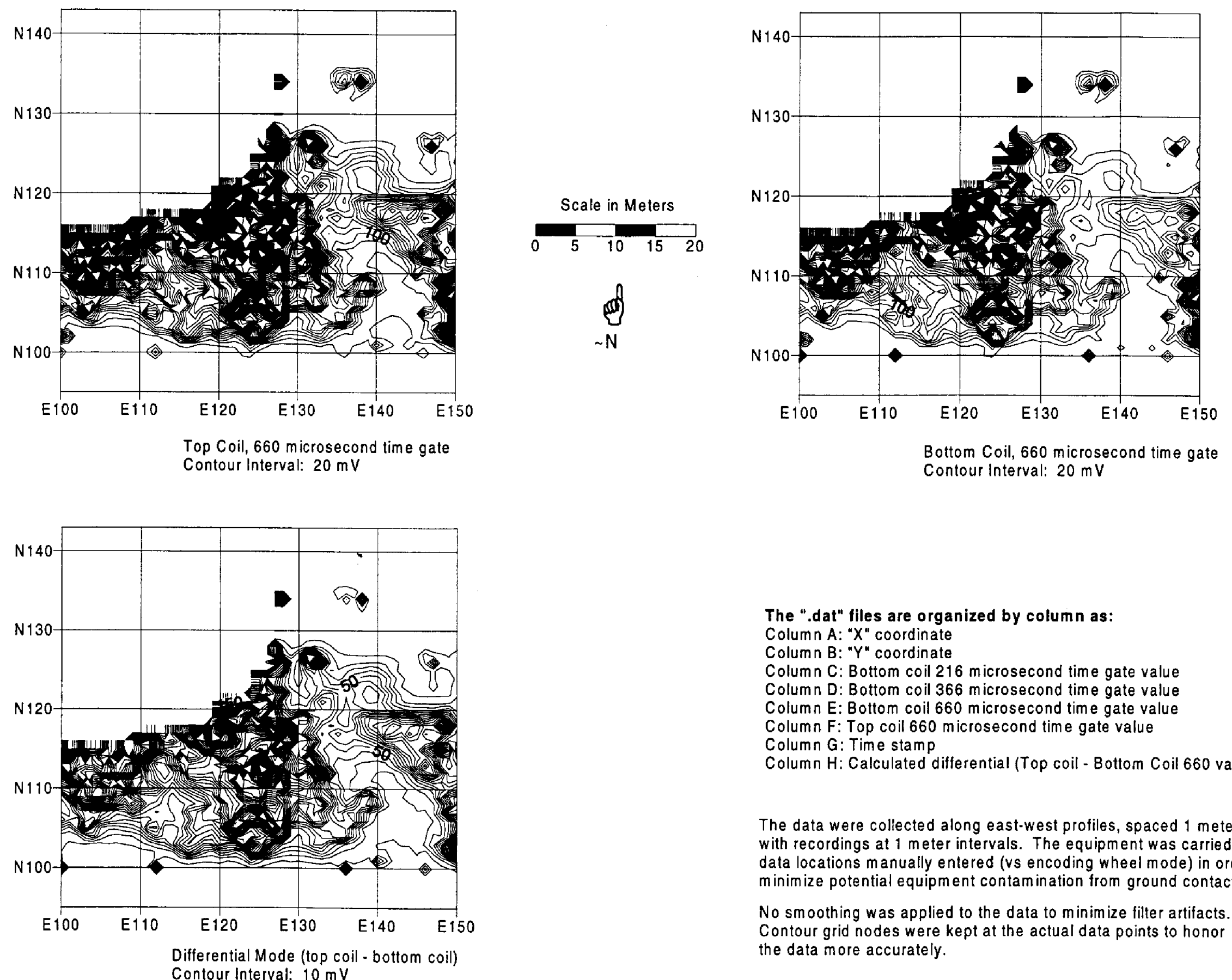

The ".dat" files are organized by column as:

Column A: "X" coordinate

Column C: Bottom coil 216 microsecond time gate value

Column D: Bottom coil 366 microsecond time gate value

Column E: Bottom coil 660 microsecond time gate value

Column Fi Top collobo microsecond ilme gale value

Column H: Calculated differential (Top coil - Bottom Coil 660 value)

The data were collected along east-west profiles, spaced 1 meter apart,
with recordings at 1 meter intervals. The equipment was carried and the

The decalngs all 1 meler int

minimize potential equipment contamination from ground contat.

No smoothing was applied to the data to minimize filter artifacts.

the data more accurately.

618-4 Burial Ground

EM61-MK2 
Elevation Survey and GPR Thickness Data

Spread Sheet Parameter Documentation:

Column A: Geophysical Grid Easting coordinate (e.g. E100, E105 etc.)

Column B: Geophysical Grid Northing coordinate (e.g. N100, N105 etc.)

Column C: Measure vertical distance from the Auto Level to the ground surface at the given location defined using columns $\mathrm{A}$ and $\mathrm{B}$.

Column D: Interpreted thickness of the fill overlying the buried debris from the GPR data.

Column E: Vertical distance from Grid point N100/E100 to the ground surface at a given location (i.e. Column $\mathrm{C}$ minus the height of the Auto Level which was 1.65 meters above the ground).

Column F: Depth from grid point N100/E100 to the top of the buried debris (Columns D plus E).

Column G: -1 multiplied by Column E. Used to create topographic map from the elevation survey data.

Column H: Created an arbitrary base elevation (i.e. 10) to which the top of the debris could be normalized using the elevation survey data and the thickness data from the GPR. 


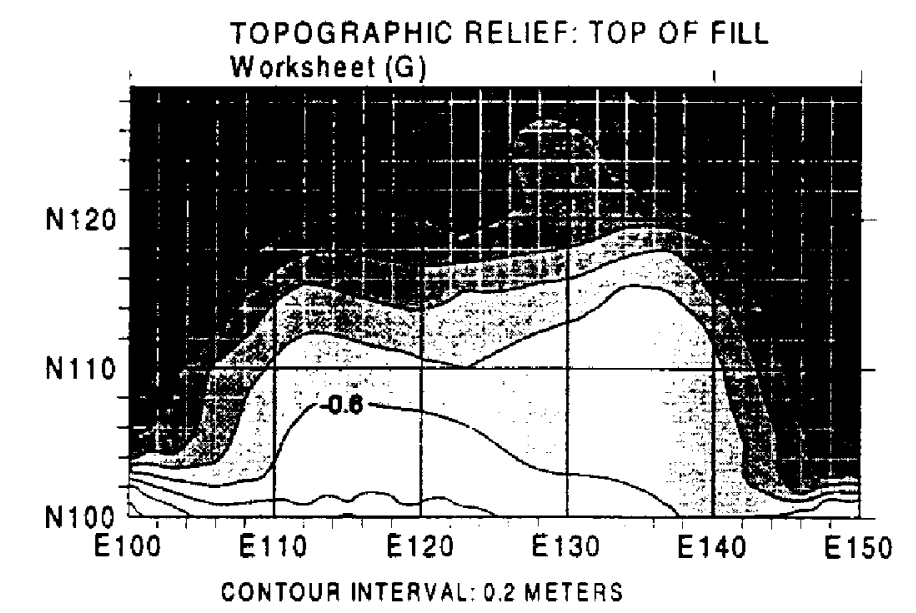

CONTOUA INTERVAL: 0.2 METERS

THICKNESS OF FILL OVERLYING BURIED DEBRIS

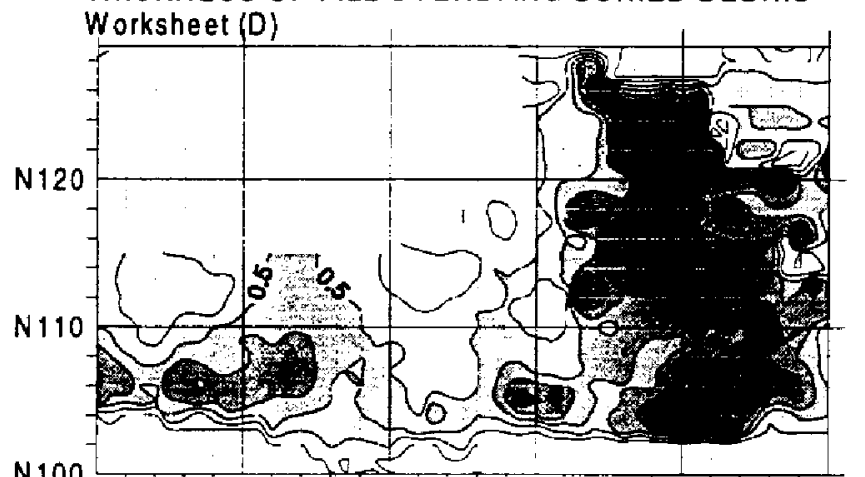

${ }_{E 100}^{N 100}{ }_{E 110}{ }_{E 120}{ }_{E 130}{ }_{E 140}{ }_{E+50}$

CONTOUR INTERVAL: 0.25 METERS

DEPTH FROM BASE ELEVATION(N100/E $100=0$ ) TO TOP OF BURIED DEBRIS

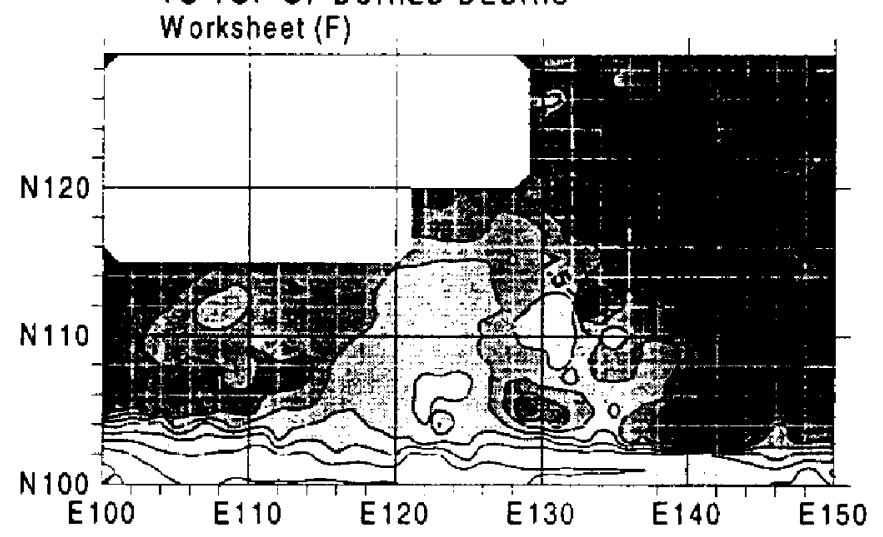

CONTOUR INTERVAL: 0.25 METEAS
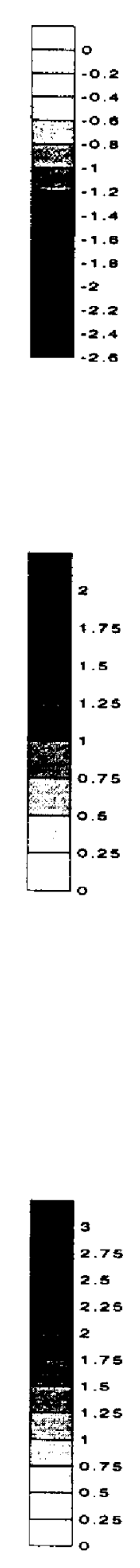

3
2.75
2.3
2.25
2
0.75
1.5
1.25
1.25
0.75
00.5
0
0.25
0

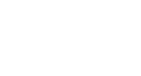
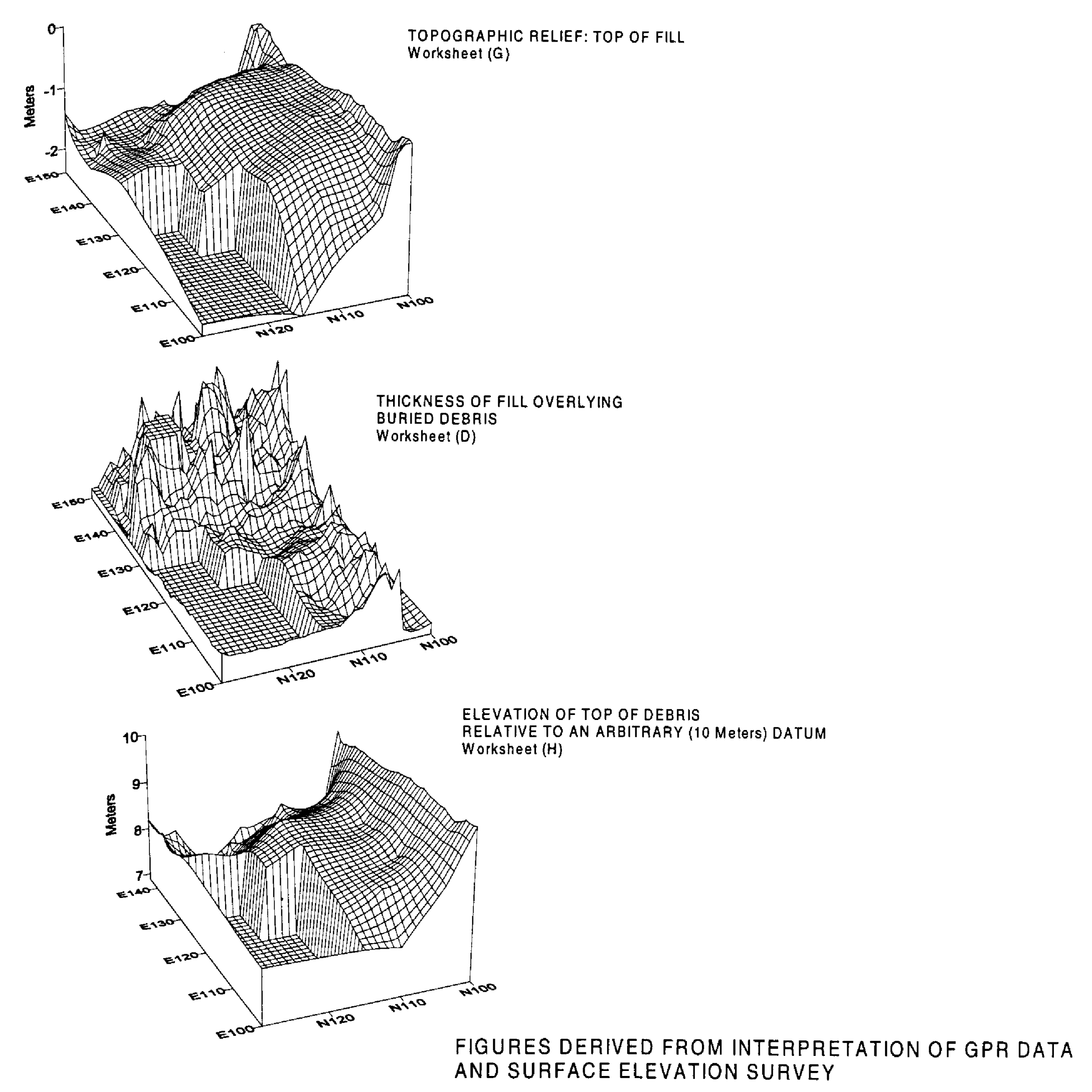


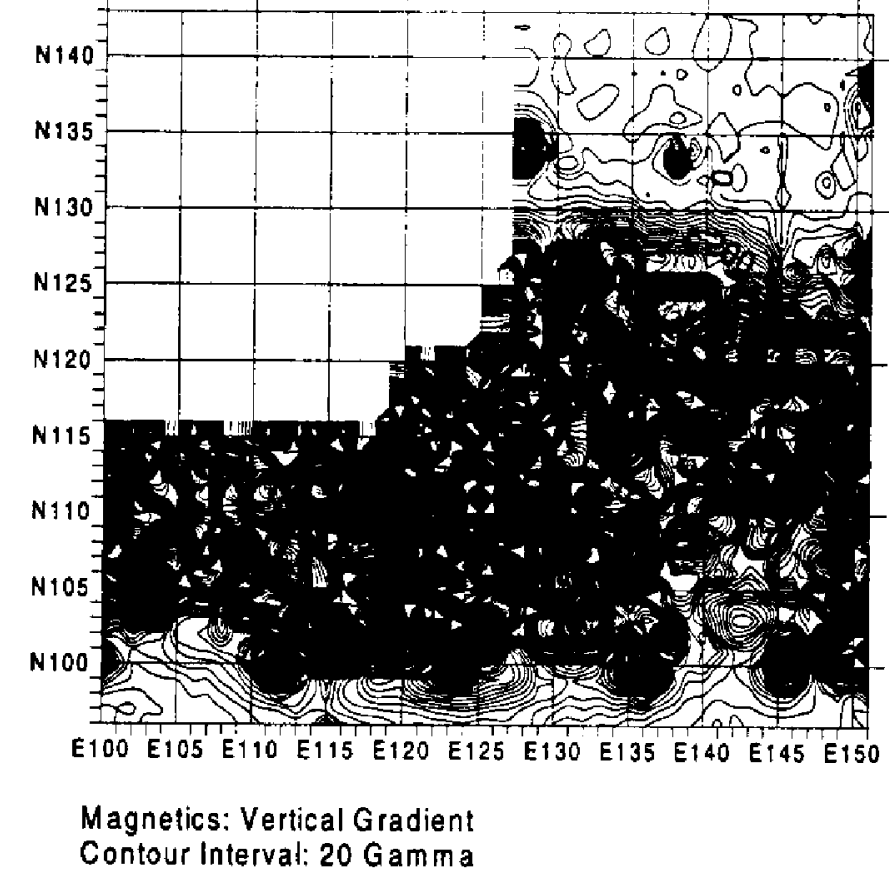

Contour Interval: 100 Gamma

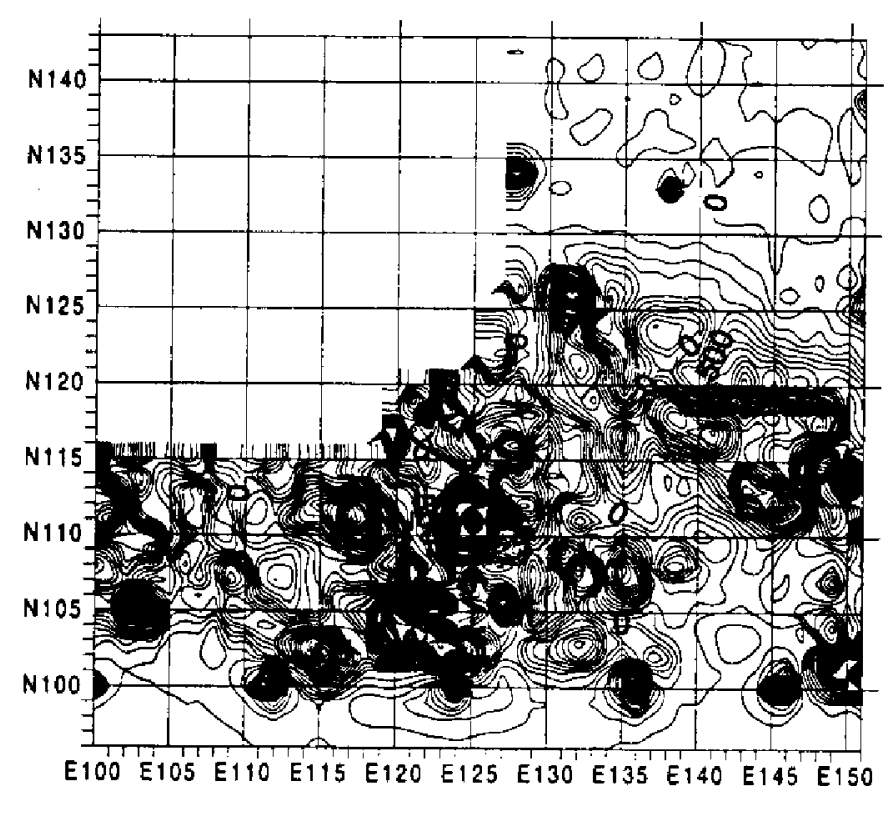

Magnetics: Vertical Gradient
Contour Interval: 100 gam ma
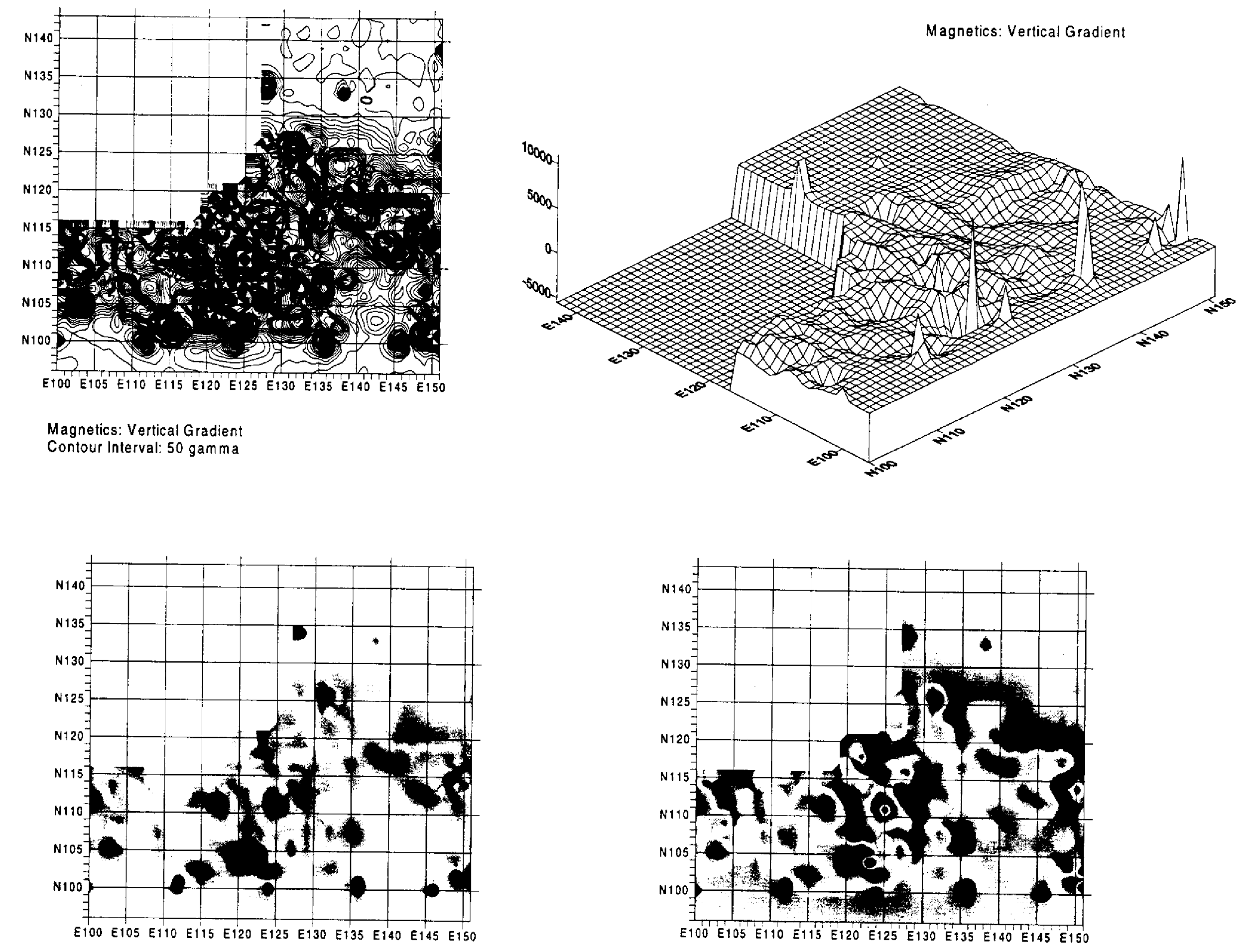
Absolute vale of Vertical Gradient
Contour Inverval: 20 Gamma

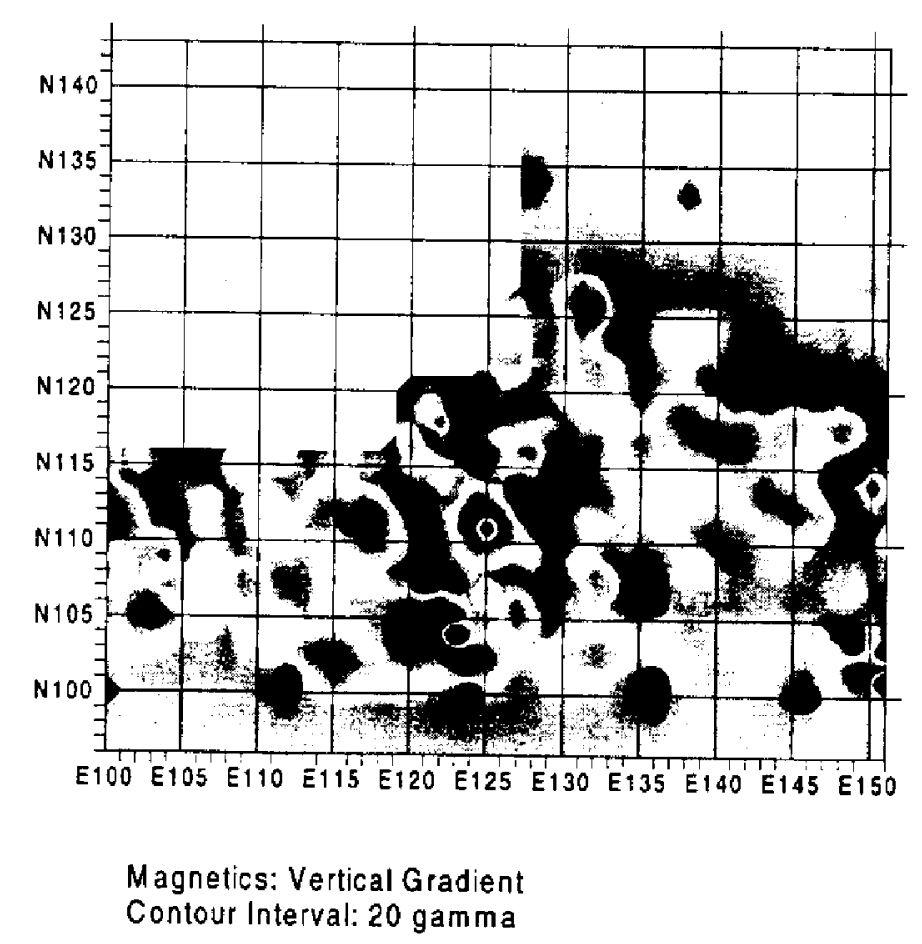

618. 4 Burial Grounds Magnetic Gradient 


\section{Distribution}

No. of

Copies

OFFSITE

R. S. Bell

ENW Services

12508 W. 6th Place

Golden, CO 80401

G. Chamberlain

U.S. Department of Energy, Headquarters

Germantown

19901 Germantown Road, EM-53

Germantown, MD 20874-1290

W. P. Clement

Boise State University/CGISS

MG206

1910 University Drive

Boise, ID 83725-1536

J. Sielinski

WMI International, Inc.

4901 Milwee Street \#109

Houston, TX 77092

J. A. Wright, Jr.

U.S. Department of Energy

Savannah River Operations

Road 1, Building 703-46A

Aiken, SC 29801

\section{ONSITE}

DOE Office of River Protection
No. of

Copies

8 DOE Richland Operations Office

B. L. Foley

$\mathrm{H} 0-12$

J. P. Hanson

R. D. Hildebrand

K8-50

A5-13

R. G. McLeod

H0-12

J. G. Morse

A5-13

J. P. Neath

K8-50

O. C. Robertson

$\mathrm{H} 0-12$

K. M. Thompson

A5-13

\section{Bechtel Hanford, Inc.}

J. G. April

L6-06

R. A. Carlson

$\mathrm{H} 0-17$

L. R. Curry

H0-19

A. G. Dada

$\mathrm{H} 0-23$

V. R. Dronen

H0-09

K. R. Fecht

$\mathrm{H} 0-02$

B. H. Ford

$\mathrm{H} 0-21$

M. J. Graham

H0-09

J. R. James

T2-05

G. B. Mitchem

$\mathrm{H} 0-19$

S. W. Petersen

$\mathrm{H} 0-23$

L. Soler

H0-19

J. D. White

H0-23

4 CH2M HILL Hanford, Inc.

K. A. Bergstrom H9-02

T. H. Mitchell H9-02

L. C. Swanson H9-02

C. D. Wittreich H9-03

R. M. Yasek

H6-60 
No. of

Copies

38 Pacific Northwest National Laboratory

B. N. Bjornstad

J. G. Bush

Y. Chien (5)

J. L. Devary

M. J. Fayer

M. D. Freshley

J. S. Fruchter

G. W. Gee

T. J Gilmore

D. G. Horton

G. V. Last (5)
No. of

Copies

W. J. Martin

K6-81

G. W. McNair

H0-21

K6-81

K6-96

K6-81

K6-96

K6-81

K5-26

K6-81

K6-81

K6-96

K6-81

P8-55 